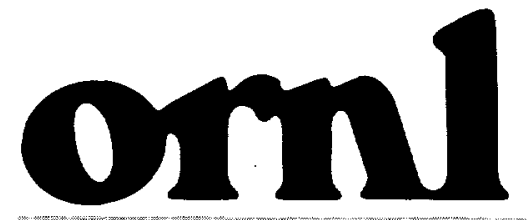

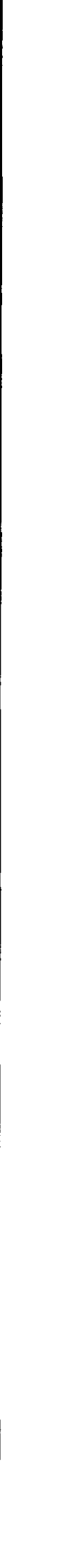

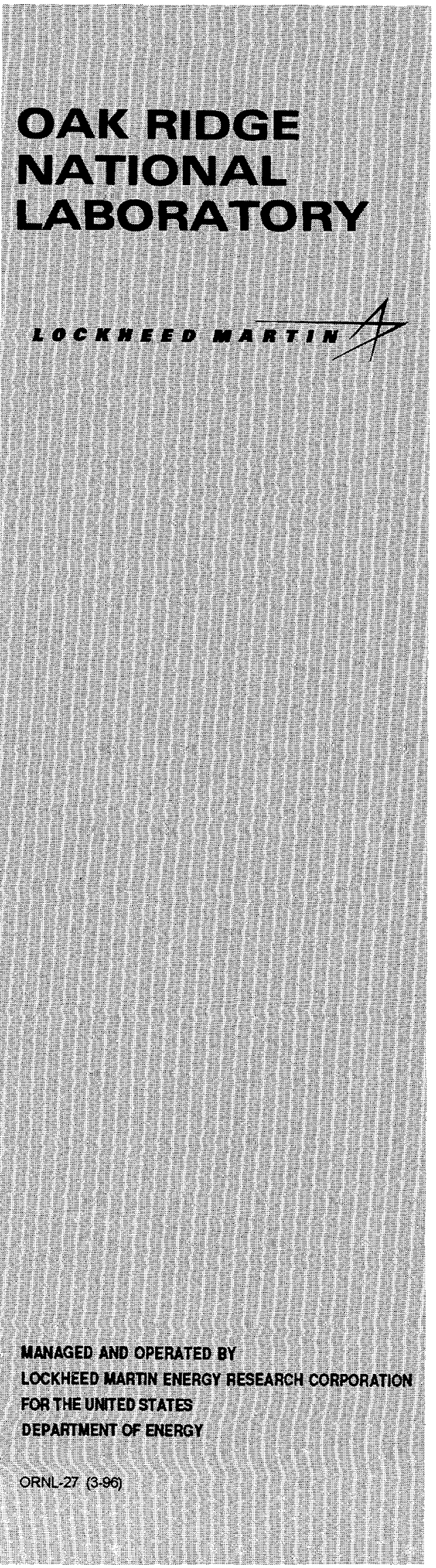

ORNL/TM-13704

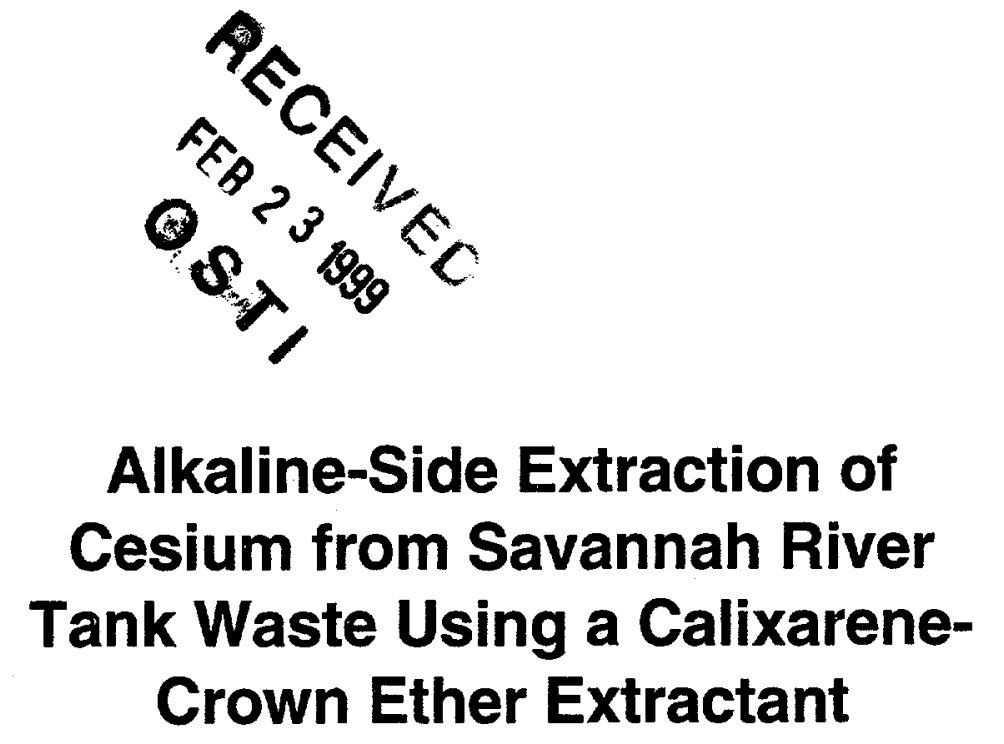

Peter V. Bonnesen

Laetitia H. Delmau

Tamara J. Haverlock

Bruce A. Moyer 


\section{DISCLAIMER}

This report was prepared as an account of work sponsored by an agency of the United States Government. Neither the United States Government nor any agency thereof, nor any of their employees, make any warranty, express or implied, or assumes any legal liability or responsibility for the accuracy, completeness, or usefulness of any information, apparatus, product, or process disclosed, or represents that its use would not infringe privately owned rights. Reference herein to any specific commercial product, process, or service by trade name, trademark, manufacturer, or otherwise does not necessarily constitute or imply its endorsement, recommendation, or favoring by the United States Government or any agency thereof. The views and opinions of authors expressed herein do not necessarily state or reflect those of the United States Government or any agency thereof. 


\section{DISCLAIMER}

Portions of this document may be illegible in electronic image products. Images are produced from the best available original document. 
Chemical and Analytical Sciences Division

\title{
ALKALINE-SIDE EXTRACTION OF CESIUM FROM SAVANNAH RIVER TANK WASTE USING A CALIXARENE-CROWN ETHER EXTRACTANT
}

\author{
Peter V. Bonnesen, Laetitia H. Delmau, Tamara J. Haverlock, and Bruce A. Moyer
}

\begin{abstract}
"The submitted manuscript has been authored by a The submitted me Government under contract No. contractor of the U. S. Accordingly, the U.S. DE-AC05-96OR22464. Accordingly, the U. S. Government retains a nonexclusive, published form of license to publish or reproduce the published fontribution, or allow others to do so, for U.S. Government purposes."
\end{abstract}

Date Published-December 1998
U. S. Department of Energy, Office of Environmental Management, Office of Science and Technology, Efficient Separations and Processing Cross-Cutting Program

\author{
Prepared by the \\ OAK RIDGE NATIONAL LABORATORY \\ Oak Ridge, Tennessee 37831-6119 \\ managed by \\ LOCKHEED MARTIN ENERGY RESEARCH CORP. \\ for the \\ U. S. DEPARTMENT OF ENERGY \\ under contract DE-AC05-96OR22464
}




\section{CONTENTS}

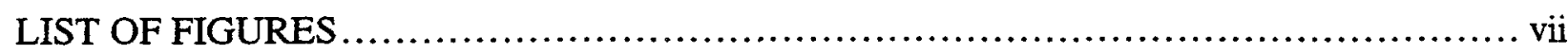

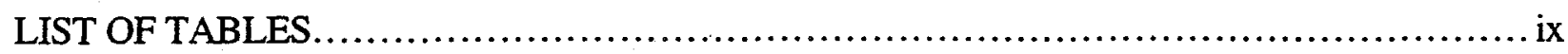

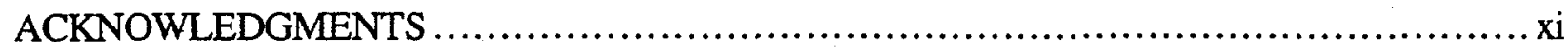

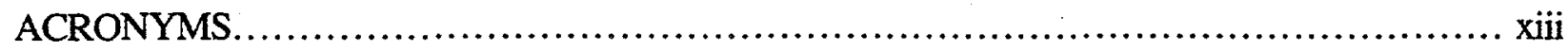

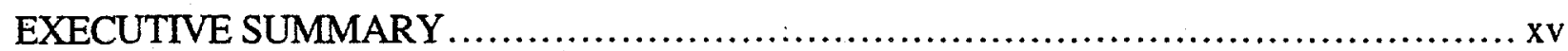

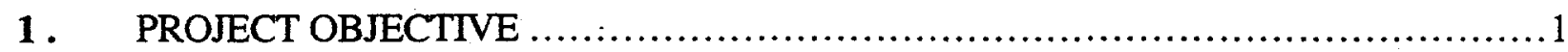

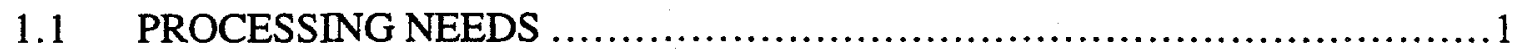

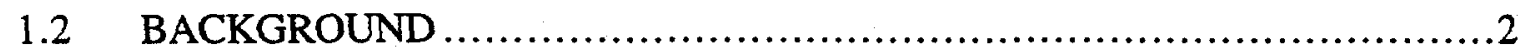

1.3 PERFORMANCE CRITERIA FOR SOLVENT EXTRACTION .................5

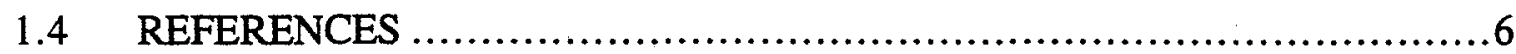

2. INITIAL SOLVENT DEVELOPMENT .......................................... 10

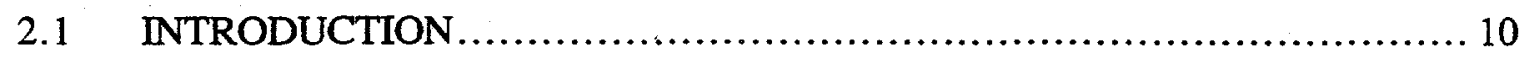

2.2 EXPERIMENTAL ........................................................... 10

2.2.1 Materials and Instrumentation ........................................ 10

2.2.2 Modifier Synthesis............................................... 11

2.2.3 Savannah River High Level Tank Waste Simulants .................... 13

2.2.4 Contacting Procedures ............................................ 13

$2.3 \quad$ RESULTS AND DISCUSSION .......................................... 15

2.3.1 Initial Screening of Modifiers .................................... 15

2.3.2 Optimization of Solvent Composition ......................................... 15

2.3.3 First Flowsheet Using Cs3 Modifier ............................... 16

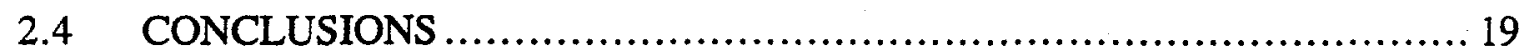

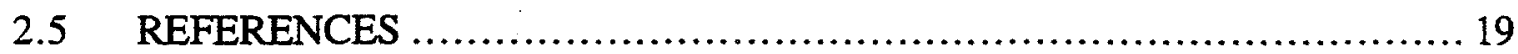


3. UNDERSTANDING AND CONTROLLING STRIPPING....................... 20

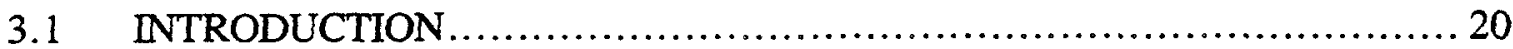

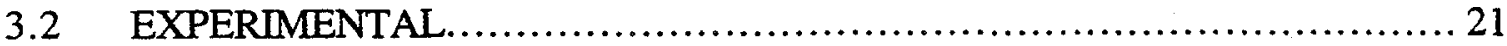

3.2.1 Materials and Instrumentation ......................................... 21

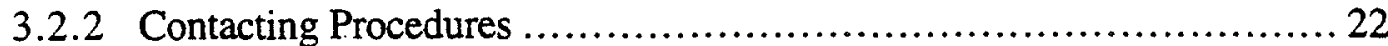

3.2.3 Preparation of SRS\#2/1' Simulant.................................... 23

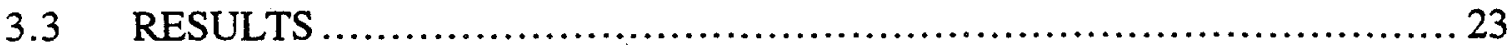

3.3.1 Relationship Between Cesium Nitrate Concentration and $D_{\mathrm{Cs}}$ as a Function of Nitric Acid Concentration ................................ 23

3.3.2 Effect of Trioctyl Amine or Tetraheptyl Ammonium Nitrate in the Solvent .................................................... 26

3.3.3 Kinetics and Effect of Temperature on Stripping Performance............ 33

$3.4 \quad$ THEORY AND DISCUSSION................................................ 34

3.4.1 Extraction and Stripping Mechanism ................................... 34

3.4.2 Theory of Ion-Pair Dissociation........................................ 39

3.4.3 Why add Cesium Nitrate to the Strip Solution? ............................ 42

3.4.4 Alkylamine Alternative Improves Stripping .............................. 43

3.4.5 Process Experience with Amine Extractants in Nitrate Systems .......... 44

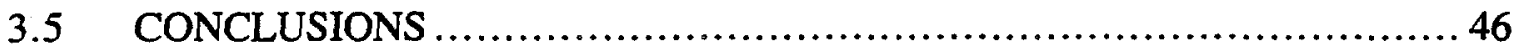

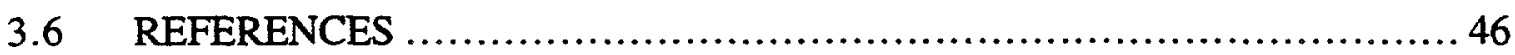

4. PARTITIONING OF SOLVENT COMPONENTS AND SELECTED POTENTIAL

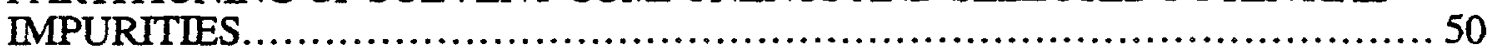

$4.1 \quad$ INTRODUCTION ............................................................. 50

4.2 EXPERIMENTAL ........................................................ 50

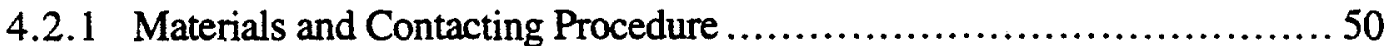

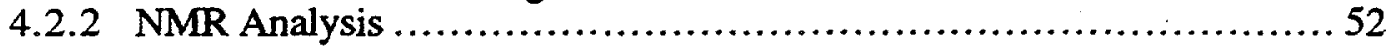

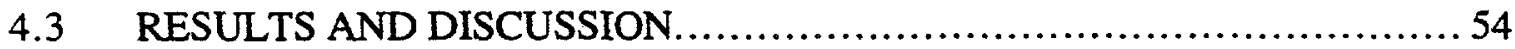

4.3.1 Partitioning Behavior of Solvent Components and

Impurities to Flowsheet Aqueous Phases.............................. 54

4.3.2 Partitioning Behavior of Solvent Components and Impurities to Candidate Wash Solutions ............................ 55

4.4 CONCLUSIONS AND RECOMMENDATIONS FOR SOLVENT CLEANUP.. 58

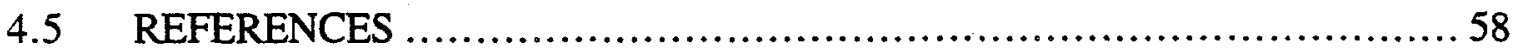


5. MINOR COMPONENTS: THEIR DISTRIBUTION, AND THEIR EFFECT ON CESIUM EXTRACTION AND STRIPPING PERFORMANCE ..................... 59

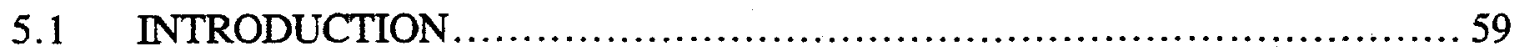

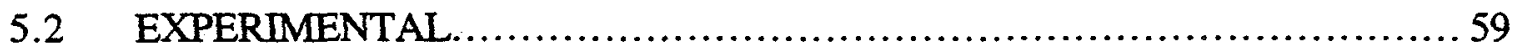

5.2 .1 Materials and Simulants........................................... 59

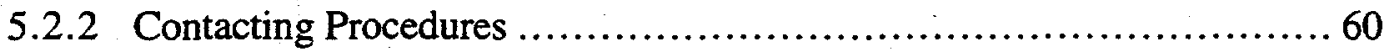

5.2.3 Elemental Analyses by Inductively Coupled Plasma (ICP) Spectroscopy . 60

5.3 RESULTS AND DISCUSSION ........................................... 62

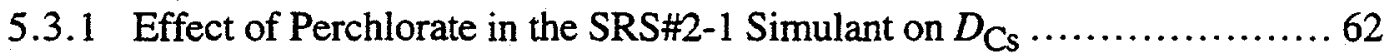

5.3.2 Effect of the Presence of Phenols in the Solvent on $D_{\mathrm{Cs}} \ldots \ldots \ldots \ldots \ldots \ldots . \ldots 4$

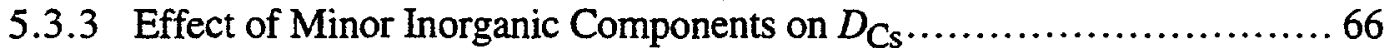

5.3.4 Distribution of Minor Inorganic Components in SRS\#3 Simulant......... 67

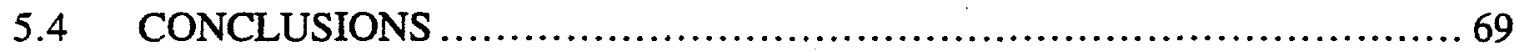

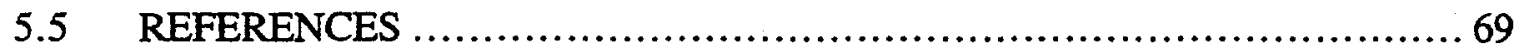

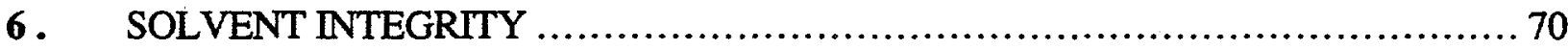

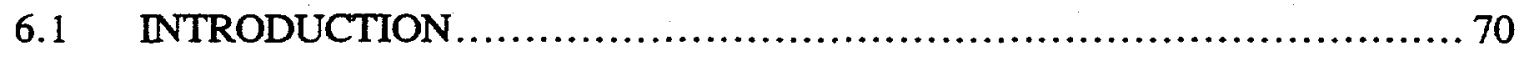

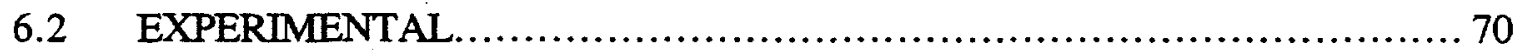

6.2.1 Materials and Contacting Procedures................................ 70

6.2.2 NMR Analyses................................................................. 70

6.2.3 Solvent Irradiations at Savannah River................................. 71

6.3 RESULTS AND DISCUSSION .......................................... 71

6.3.1 Chemical Stability .................................................... 71

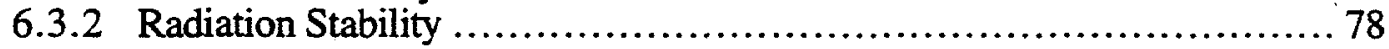

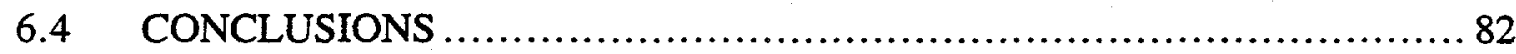

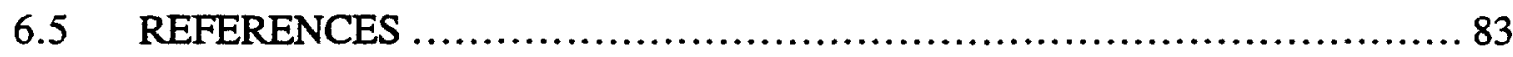


7. OTHER FACTORS AFFECTING STRIPPING PERFORMANCE $\ldots \ldots \ldots \ldots \ldots \ldots \ldots . . \ldots 4$

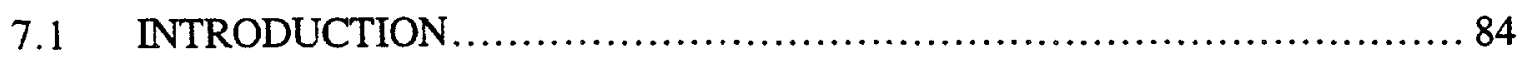

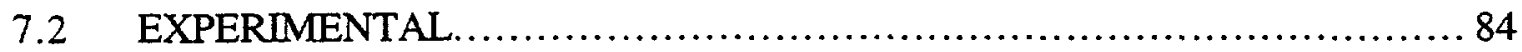

7.2.1 Materials and Contacting Procedures....................................... 84

7.2 .2 NMR Analỳses.................................................... 84

7.2.3 Simulant Preparations (ORNL) .................................... 85

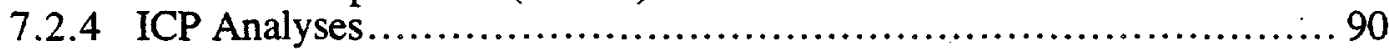

$7.3 \quad$ RESULTS AND DISCUSSION ....................................... 90

7.3.1 Analysis of Solvents Used In July 22, 1998 Centrifugal Contactor Test at Argonne National Laboratory....

7.3.2 Effect of Simulant Preparation on Stripping Performance ................ 94

7.3.3 Effect of Trialkylamines and Temperature on Stripping Performance (ANL and ORNL Experiments).

7.3.4 Investigating What Might be Different Between ANL and ORNL Simulants using ICP

7.4 CONCLUSIONS AND RECOMMENDATIONS ........................... 102

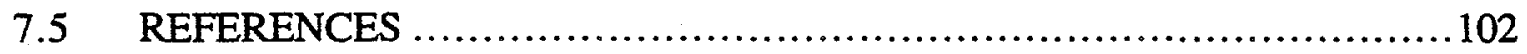




\section{LIST OF FIGURES}

1.1 Examples of 1,3-alt-calix[4]arene-crown-6 compounds ..............................

1.2 Lipophilic calixarene-crown derivative, calix[4]arene-bis-( $t$-octylbenzo-crown-6), abbreviated BoBCalixC6................................................................

$2.1 \quad$ Modifiers examined for Cs solvent extraction..................................... 15

2.2 Relationship between modifier concentration and $D_{\mathrm{Cs}}$ on extraction from SRS\#2-1 simulant .............................................................. 17

2.3 Extraction, scrubbing, and stripping performance for solvent $\mathrm{Cs} 3 \mathrm{~B} / 150 \mathrm{~L}$

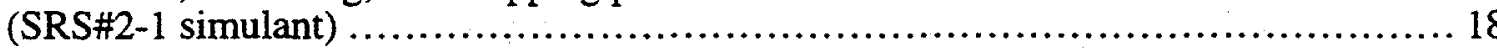

3.1 Extraction, scrubbing, and successive stripping of cesium at $25^{\circ} \mathrm{C} \ldots \ldots \ldots \ldots \ldots \ldots \ldots .25$

3.2 Distribution behavior of cesium nitrate as a function of cesium nitrate concentration at various dilute nitric acid concentrations at $25^{\circ} \mathrm{C}$.

3.3 Distribution behavior of cesium as a function of cesium nitrate concentration at $0.5 \mathrm{mM}$ nitric acid at $25^{\circ} \mathrm{C}$

3.4 Cesium nitrate concentration in the organic phase as a function of cesium nitrate concentration in a $0.5 \mathrm{mM}$ nitric acid aqueous phase for extraction by $\mathrm{Cs} 3 \mathrm{C} / 120 \mathrm{~L}-2$ solvent alone, or containing trioctyl amine at $0.1 \mathrm{mM}$, or tetraheptyl ammonium nitrate at various concentrations, at $25^{\circ} \mathrm{C}$

3.5 Distribution behavior of cesium nitrate as a function of cesium nitrate concentration in the aqueous phase at $25^{\circ} \mathrm{C}$

3.6 Distribution behavior of cesium nitrate as a function of HDDNS concentration in the solvent, with and without trioctyl amine added at $0.1 \mathrm{mM}$, at $25^{\circ} \mathrm{C}$

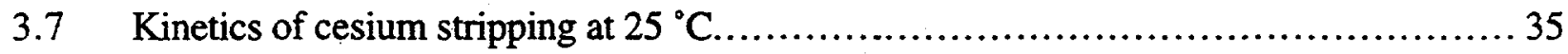

3.8 Kinetics of Cs stripping from solvent $\mathrm{Cs} 3 \mathrm{C} / 120 \mathrm{~L}-2$ at various temperatures ............. 36

3.9 Distribution behavior of cesium nitrate as a function of initial cesium nitrate concentration at various dilute nitric acid concentrations.

3.10 Extraction with Cs3C/120L-2 solvent containing tetraheptyl ammonium nitrate at various concentrations.

5.1 Dependence of cesium distribution on perchlorate concentration n SRS\#2-1 simulant (Cs3C/120L-2 solvent).

5.2 Dependence of cesium distribution on the presence of 4-t-octylphenol $(0.02 \mathrm{M})$

or 2-nitro-4-t-octylphenol $(0.01 \mathrm{M})$ in the Cs3C/120L-2 solvent

6.1 Solvent performance following thermal treatment .................................. 73

6.2 Solvent performance following reconstitution of the thermally degraded solvent .........77 
6.3 Performance of solvent Cs3B/150L following irradiation

7.1 Comparison of solvents from ANL Multistage Test (both pristine and "post-contactor") with ORNL pristine solvent: post-contactor solvent is different 


\section{LIST OF TABLES}

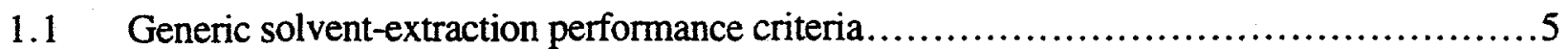

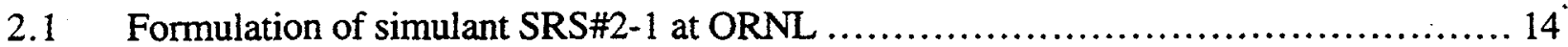

3.1 Batch flowsheet tests with SRS\#2-1 simulant...................................... 24

3.2 Batch tests of extraction, scrubbing, and stripping contacts at $25^{\circ} \mathrm{C}$ with cesium, after adding trioctylamine to the solvent............................................... 33

3.3 Dissociation constants calculated by the Fuoss treatment ............................ 40

4.1 Chemical shifts of peaks used to determine concentrations of solvent components ....... 53

4.2 Partition ratio $P$ of solvent components to aqueous flowsheet solutions.................. 54

4.3 Partition ratio $P$ of solvent components and 4-t-octylphenol to aqueous flowsheet solutions.

4.4 Partition ratio $P$ of 4-t-octylphenol and/or Cs3C modifier to various alkaline candidate wash solutions.

4.5 Partition ratio $P$ of solvent components and 4-t-octylphenol or 2-nitro-

4-t-octylphenol to various alkaline candidate wash solutions...........................5 57

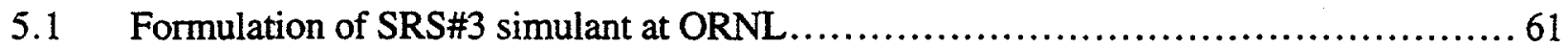

5.2 Cesium distribution ratios for Cs3C/120L-2 solvent, with and without

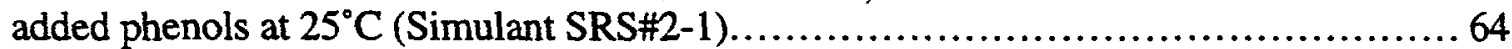

5.3 Cesium distribution ratios for Cs3D/120L-2 solvent with simulants SRS \#2-1 and SRS \#3 at $25^{\circ} \mathrm{C}$ 66

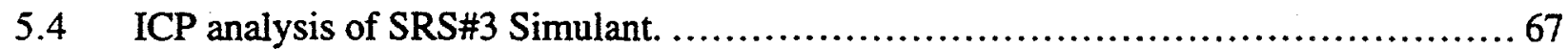

5.5 ICP analysis of aqueous phases from extraction, scrubbing, and stripping contacts...... 68

6.1 Comparison between decrease in $D_{\mathrm{Cs}}$ and decrease in [Cs3] for solvents contacted with SRS\#2-1 simulant containing Cs- 137 tracer at $53{ }^{\circ} \mathrm{C}$

6.2 Comparison between decrease in $D_{\mathrm{Cs}}$ and decrease in [Cs3] for solvents contacted with SRS\#2-1 simulant containing Cs- 137 tracer at $25^{\circ} \mathrm{C}$

6.3 Appearance of CS3B/150L solvent samples following Co-60 irradiation at SRS 79

6.4 Modifier concentration and appearance of BoBCalixC6 in selected irradiated solvent samples.

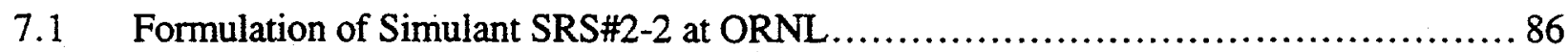

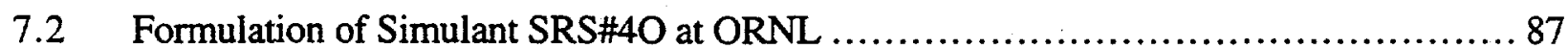




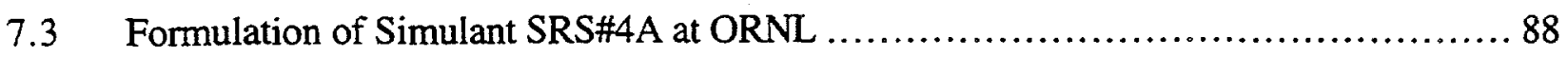

7.4 Formulation of Simulant SRS\#4A-G at ORNL ................................... 89

7.5 Cesium distribution ratios for two stripping contacts from ANL "post-contactor solvent" subjected to various treatments, and from pristine controls .

7.6 Cesium distribution ratios for Cs3D/120L-2 solvent with various ORNL simulants, and Cs3C/120L-2 with ANL SRS\#2 simulant.

7.7 Cesium distribution ratios for Cs3D/120L-2 solvent with various ANL simulants: effect of one vs. two extraction contacts, and scrubbing with $2 \mathrm{M} \mathrm{NaOH}$.

7.8 Cesium distribution ratios for $\mathrm{Cs} 3 \mathrm{D} / 120 \mathrm{~L}-2$ solvent with and without trioctyl amine (TOA) at $0.1 \mathrm{mM}$ with ORNL \#4 simulants at $25^{\circ} \mathrm{C}$ (ORNL results)

7.9 Cesium distribution ratios for Cs3D/120L-2 solvent with tri-isooctyl amine (TiOA) at $1.0 \mathrm{mM}$ and $0.1 \mathrm{mM}$ with ANL \#4 simulant at $25^{\circ} \mathrm{C}$ (ANL results).

7.10 ICP and ICP/MS results from solvent analysis 


\section{ACKNOWLEDGMENTS}

The authors would like to acknowledge funding from the following sources. The invention, development, and initial investigations of the alkaline-side CSEX process occurred in FY 1997 and 1998 and were sponsored by the Efficient Separations and Processing (ESP) Crosscutting Program, Office of Science and Technology, Office of Environmental Management, U. S. Department of Energy, under contract number DE-AC05-96OR22464 with Oak Ridge National Laboratory, managed by Lockheed Martin Energy Research Corp. Work reported herein that was specifically sponsored by ESP includes Chapter 2, Chapter 3 (all results except data in Fig. 3.5 using ANL solvent or simulant and except data in Fig. 3.6 pertaining to effect of didodecylnaphthalene sulfonate anion), and Chap. 7 (ANL centrifugal-contactor test in July, 1998).

The remainder of the results reported herein were obtained in the period August September, 1998, under a Memorandum Purchase Order from Westinghouse Savannah River Corporation to Oak Ridge National Laboratory, managed by Lockheed Martin Energy Research Corp. This funding also supported the writing of an initial draft of this report, submitted to Westinghouse Savannah River Corporation in early October, 1998.

It is also appropriate to acknowledge the fundamental understanding of the extraction mechanism and the NMR procedure for partitioning experiments, developed through research sponsored by the Environmental Management Science Program, Offices of Energy Research and Environmental Management, U. S. Department of Energy, under Contract DE-AC05-96OR22464 with Oak Ridge National Laboratory, managed by Lockheed Martin Energy Research Corporation. Without the knowledge obtained under this program, the rapid progress made since May, 1998, on developing the alkaline-side CSEX process would not have been possible.

Finally, the authors wish to thank Richard A. Sachleben in the Chemical Separations Group of the ORNL Chemical and Analytical Sciences Division for many helpful discussions and for proof-reading the manuscript, and Charles F. Coleman (retired from ORNL) for thoroughly reviewing the manuscript. The authors would additionally like to thank our colleagues at Argonne National Laboratory (Clifford Connor, Ralph A. Leonard, Jacob Sedlet, and George F. Vandegrift) for their role in designing the process flowsheet and for many helpful discussions, and our colleagues at Savannah River (C.L. Crawford, F.F. Fondeur, R.A. Peterson and T.L. White) for performing radiation stability experiments, supplying irradiated solvents, and providing information on the process needs at the Savannah River Site. 


\section{ACRONYMS AND ABBREVIATIONS}

ANL

BoBCalixC6

CF

$\mathrm{Ci}$

Cs3

CSEX

$\mathrm{DF}$

DOE

$D_{\text {Cs }}$

ES\&H

ESP

Teflon ${ }^{\circledR}$ FEP

FW

HDDNS

HLW

ICP

ICP/MS

ITP

LMER

$\mathrm{M} \Omega$

NMR

O/A

ORNL

PTFE

RCRA

SRS

SRTALK

SXISQI

TBP

TCC

TCLP

TIOA

TOA
Argonne National Laboratory

calix[4]arene-bis( $t$-octylbenzo-crown- 6

concentration factor

Curie

1-(4-tert-octylphenoxy)-3-(1,1,2,2-tetrafluoroethoxy)-2-propanol

Cesium Solvent Extraction

decontamination factor

Department of Energy

distribution ratio for cesium

Environmental Safety and Health

Efficient Separations Program

flourinated ethylene propylene

formula weight.

didodecylnaphthalene sulfonic acid

High Level Waste

Inductively Coupled Plasma

Inductively Coupled Plasma/Mass Spectrometry

in-tank-precipitation

Lockheed Martin Research Corporation

mega Ohm

Nuclear Magnetic Resonance

organic to aqueous ratio

Oak Ridge National Laboratory

polytetrafluoroethylene

Resource Conservation and Recovery Act

Savannah River Site

Strontium Technetium Alkaline-Side Solvent Extraction

Solvent Extraction Least Square Ion Modeling

tributyl phosphate

thermal closed cup

Toxic Characteristics Leaching Procedure

tri-isooctyl amine

trioctyl amine 


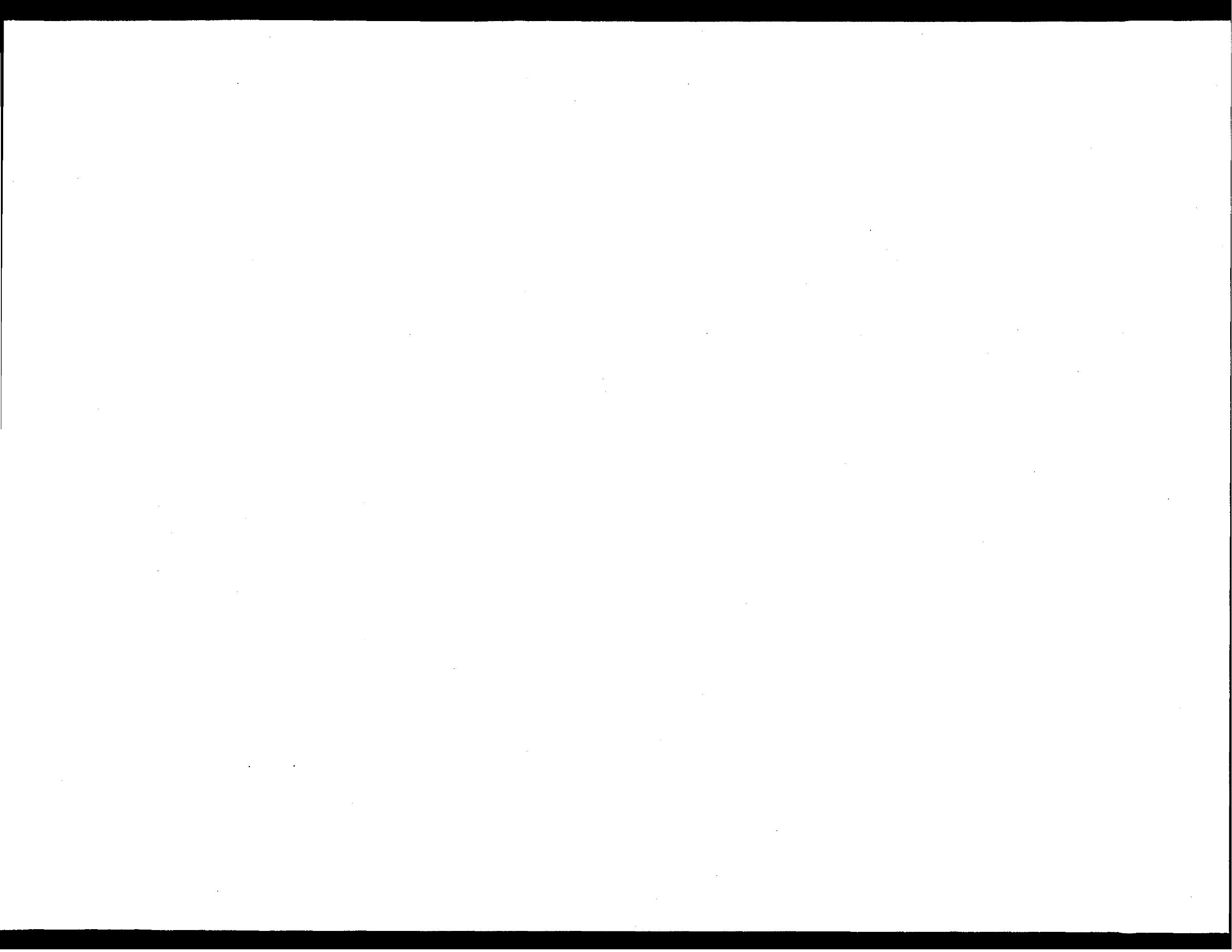




\section{EXECUTIVE SUMMARY}

Results are presented supporting the viability of the alkaline-side CSEX process as a potential replacement for the In-Tank Precipitation process for removal of cesium from aqueous high-level waste (HLW) at the Savannah River Site (SRS). Under funding from the USDOE Efficient Separations and Crosscutting Program, a flowsheet was suggested in early June of 1998, and in the following four months, this flowsheet underwent extensive testing, both in batch tests at ORNL and ANL and in two centrifugal-contactor tests at ANL. To carry out these tests, the initial ESP funding was augmented by direct funds from Westinghouse Savannah River Corporation. The flowsheet employed a solvent containing a calixarene-crown hybrid compound called BoBCalixC6 that was invented at ORNL and can now be obtained commercially for government use from IBC Advanced Technologies. This special extractant is so powerful and selective that it can be used at only $0.01 \mathrm{M}$, compensating for its expense, but a modifier is required for use in an aliphatic diluent, primarily to increase the cesium distribution ratio $D_{\mathrm{Cs}}$ in extraction. The modifier selected is a relatively economical fluorinated alcohol called Cs3, invented at ORNL and so far available only from ORNL. For the flowsheet, the modifier is used at $0.2 \mathrm{M}$ in the branched aliphatic kerosene Isopar ${ }^{\circledR}$ L. Testing at ORNL and ANL involved simulants of the SRS HLW. After extraction of the Cs from the waste simulant, the solvent is scrubbed with $0.05 \mathrm{M} \mathrm{HNO}_{3}$ and stripped with a solution comprised of $0.0005 \mathrm{M} \mathrm{HNO}_{3}$ and $0.0001 \mathrm{M} \mathrm{CsNO}_{3}$. The selection of these conditions is justified in this report, both on the basis of experimental data and underlying theory.

Using simulants made at ORNL, excellent performance was obtained in selected batch tests. Sequential extraction, scrubbing, and stripping gave $D_{\mathrm{Cs}}$ values that potentially imply the attainment of good concentration and decontamination factors. At $25{ }^{\circ} \mathrm{C}$, two successive $1: 1$ contacts of solvent with fresh simulant gives $D_{C s}$ values of $11.1-12.2$ and $9.7-10.8$, respectively. Values of $D_{C s}$ on scrubbing lie in the range $0.6-0.8$; ICP analyses showed that almost all of the $\mathrm{Na}, \mathrm{K}$, and traces of $\mathrm{Al}$ that are extracted are scrubbed out in two scrub contacts. On stripping, $D_{C s}$ values drop typically to $0.03-0.05$ and remain stable for up to 8 contacts. Stripping kinetics in vortexing experiments were fast in the range $25-43{ }^{\circ} \mathrm{C}$, giving $D_{\mathrm{Cs}}$ values below 0.1 in 10 seconds. On raising the temperature over the same range, the stripping $D_{\mathrm{Cs}}$ value drops by a factor of 1.7. Minor components $\mathrm{Na}_{2} \mathrm{SiO}_{3}, \mathrm{Hg}(\mathrm{II}), \mathrm{Pb}(\mathrm{II}), \mathrm{Fe}(\mathrm{II})$, and $\mathrm{NaClO}_{4}$ added to the simulant gave negligible or only minor changes in $D_{\mathrm{Cs}}$ values in extraction, scrubbing, and stripping. By ICP analysis, only traces of $\mathrm{Si}, \mathrm{Hg}, \mathrm{Pb}$, and $\mathrm{Fe}$ appear in the first scrub and strip solutions. Chemical stability tests showed that the solvent exhibits detectable signs of a slow degradation at $25^{\circ} \mathrm{C}$, which hastens at $53^{\circ} \mathrm{C}$. After 375 hours at $53^{\circ} \mathrm{C}$, the solvent has lost about half of its extraction strength, and stripping worsens, though not seriously. The degradation 
appears to be due to the modifier and not BoBCalixC6. If the modifier concentration is replenished, extraction strength is restored. Partition studies using NMR spectrometry showed that the BoBCalixC6 and Cs-3 modifier partition negligibly to the aqueous simulant or to the scrub and strip solutions. Alkylphenol impurities partition slightly ( $3-5 \%)$ from the solvent to $0.1-0.5$ $\mathrm{MLiOH}$ or $\mathrm{NaOH}$ solutions on $1: 1$ contacts at $25^{\circ} \mathrm{C}$.

Despite the good performance obtained in batch tests at ORNL, similarly good results were not duplicated at ANL. In particular, $D_{\mathrm{Cs}}$ values on stripping were an order of magnitude higher (i.e., ca. 0.3) than values obtained at ORNL. The differences were finally traced on September 16,1998 , to dissimilarity in the ANL and ORNL simulants. Experimental protocol, analytical procedures, or solvent compositions were ruled out. The simulant difference was apparently the cause of the unexpectedly high $D_{\mathrm{Cs}}$ values obtained in the July centrifugal-contactor tests at ANL; contamination of the solvent during the test with residue in the contactors (sufficient to give 0.015 M TBP in the solvent) was probably not responsible. Unfortunately, there was an insufficient supply of ANL simulant at ORNL and insufficient time before the ANL centrifugal-contactor test on September 25,1998 , to identify the exact chemical difference between the simulants. Work is continuing in FY99 to address this question.

Marked flowsheet improvements that mitigate or even nullify the effect of the simulant differences are recommended: 1) Add trioctylamine (TOA) extractant at $10^{-4}-10^{-3} \mathrm{M}$ to the solvent. This was shown in our laboratory to offer several benefits, perhaps the most important of which is to nullify the effect of anionic impurities. (It also obviates the use of $\mathrm{CsNO}_{3}$ in the strip solution.) This was demonstrated with didodecylnaphthalene sulfonate as a model anion. Further, $D_{\mathrm{Cs}}$ on stripping the solvent from the ANL July test went from 0.3 to 0.02 on addition of $10^{-4} \mathrm{M}$ TOA to the used solvent. ANL obtained a similar result with the same simulant and solvent later used in their Sept. 25 contactor test. Over 40 years of experience with trialkylamine extractants in the radiochemical process industry exists to support such a change in the solvent. 2) As suggested by ANL data, lower the temperature of the extraction section $\left(D_{\mathrm{Cs}}=26\right.$ at $\left.9{ }^{\circ} \mathrm{C}\right)$ and raise the temperature of the stripping section $\left(D_{\mathrm{Cs}}=0.02\right.$ at $\left.50^{\circ} \mathrm{C}\right)$.

In summary, we believe that the data overall show that the alkaline-side CSEX process has much promise as a cesium separation technology applicable to the HLW at SRS and other USDOE sites. Batch data point to a pathway leading to substantial improvements in performance over the flowsheet formulated in June 1998. Engineering tests at ANL did not include these improvements and thus could not demonstrate the performance that can now be realized. Rather, the tests served as indicators of potential problems and have already forced advancement in the technology. As a result, alkaline-side CSEX is now more robust and a step closer to maturity. Work in FY99. will address such questions as dealing with the inevitable anionic impurities, solvent degradation, and solvent cleanup. 


\section{PROJECT OBJECTIVE}

\subsection{PROCESSING NEEDS}

The purpose of this undertaking was to develop a solvent-extraction process for the removal of cesium from Savannah River's High Level Waste tanks, as a possible replacement for the in-tank-precipitation (ITP) process [1,2] that had been employed at the Savannah River Site (SRS) until recently. Difficulties with decomposition of the tetraphenylborate precipitant [2] led to an intensive search at the SRS for alternative technologies able to meet the challenging decontamination factor (DF), concentration factor (CF), and flow requirements formerly met by the ITP process. Based on published data [2] and information provided by personnel at the SRS $[3,4]$, we prepared an initial set of target performance requirements expected to bracket or approximate more precise requirements to be defined at a later date:

- Handle HLW feed flow of $10-20 \mathrm{gal} / \mathrm{min}$ at ca. $7 \mathrm{M} \mathrm{Na}$ and avg. $4 \mathrm{Ci} / \mathrm{gal}{ }^{137} \mathrm{Cs}$

- $\quad{ }^{137} \mathrm{Cs}$ in raffinate $<45 \mathrm{nCi} / \mathrm{g}(20 \mathrm{nCi} / \mathrm{g}$ offers margin)

- $\mathrm{DF}=500-400,000(10,000-40,000$ average $)$

- $\quad{ }^{137} \mathrm{Cs}$ in strip effluent $<44 \mathrm{Ci} / \mathrm{gal}(30 \mathrm{Ci} / \mathrm{gal}$ optimal)

- $\quad$ Average $\mathrm{CF}=7.7$

- $\quad \mathrm{Na}$ in strip effluent $<0.02 \mathrm{M}$

- Organics in saltstone to pass TCLP test

In September, 1998, more specific targets were set as follows [5]: feed flow = $19 \mathrm{gal} / \mathrm{min} @ 6.4$ $\mathrm{M} \mathrm{Na}$ and average $4 \mathrm{Ci} / \mathrm{gal}{ }^{137} \mathrm{Cs}$; strip effluent flow $=1.5 \mathrm{gal} / \mathrm{min}$ (i.e., $\mathrm{CF}=12.6$ ); and ${ }^{137} \mathrm{Cs}$ activity in raffinate $=20 \mathrm{nCi} / \mathrm{g}$ (i.e., $\mathrm{DF}=40,000$ ). Meeting the feed flow requirement was set as a rigid engineering goal that would meet the plant schedule. High value was also placed on the strip effluent flow of $1.5 \mathrm{gal} / \mathrm{min}$, because this avoids installation of an evaporator prior to downstream vitrification. The DF and CF requirements would then be met by appropriate flowsheet design, especially the phase ratios and number of stages. Use of centrifugal contactors having a rotor diameter of 25 -cm was also strongly recommended.

In view of the fact that other technologies (e.g., crystalline silicotitanate ion exchange) were also considered viable candidates for cesium removal from SRS HLW [6], we expected that the competitive position of alkaline-side Cs solvent extraction (CSEX) would be improved by minimizing capital and operating costs. Although it was not required by explicit statement by SRS personnel, we assumed that a significant advantage would be obtained if the alkaline-side CSEX flowsheet could be designed for 18 stages to allow for the possibility of using existing installed 
equipment at the SRS. This would obviate construction of new facilities and purchase of new contacting equipment, significantly minimizing capital investment. In addition, we assumed that maximum cost savings would be obtained by achieving a "plug-in" of alkaline-side CSEX where the ITP previously existed in the overall plant flowsheet. That is, it is most desirable to avoid adjustments to, or upstream operations on, the HLW feed and to minimize changes to the two end waste products, low-level grout (saltstone) and high-level glass, and the processes that produce them. Hence, the decontaminated raffinate ideally differs from the HLW feed stream only in the lack of ${ }^{137} \mathrm{Cs}$ activity in the former. At the same time, the strip effluent containing the concentrated ${ }^{137} \mathrm{Cs}$ activity should contain a minimum concentration of dissolved salts or acid, so as to minimize impacts to downstream processing, especially the burden upon expensive vitrification and $\mathrm{HLW}$ glass storage.

In addition to the problem with excess benzene emissions, some disadvantages of the ITP process suggest the possibility that a potential replacement process might offer even better performance. Disadvantages of the ITP process include: 1) excess reagent in the filtrate; 2) coseparation from the HLW feed of essentially all of the potassium, which together with the Cs and some residual $\mathrm{Na}$ reports to the vitrification process; 3) special downstream processing to separate the Cs from reagent prior to vitrification; 4) production of a toxic and flammable compound, benzene, as a product of stripping; and 5) consumption of a specialty reagent, sodium tetraphenylborate.

\subsection{BACKGROUND}

New cesium-selective extractants from the calix[4]arene-crown- 6 family have recently been introduced by collaborating European investigators [7-21], making it possible to suggest a solventextraction process as a candidate for cesium separation from SRS HLW under the constraints

A

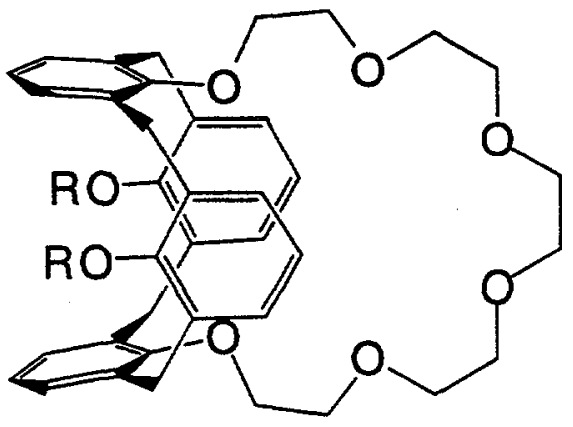

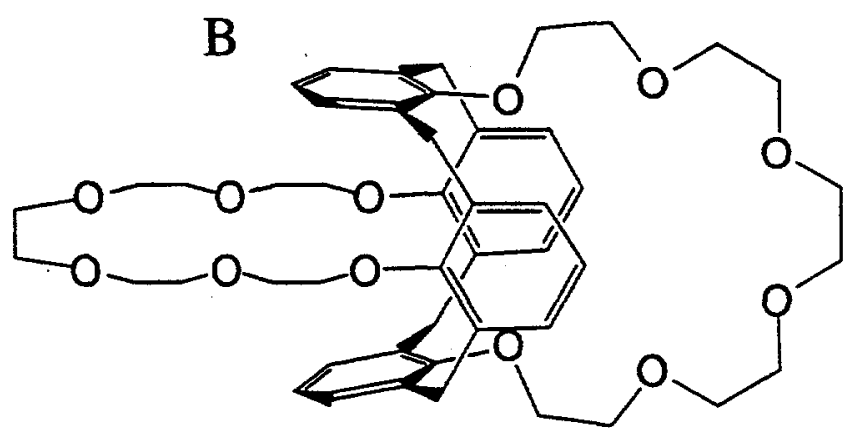

Figure 1.1. Examples of 1,3-alt-calix[4]arene-crown-6 compounds. A: monocrown calix[4]arene bearing two alkoxy substituents. B: calix[4]arene-bis(crown-6). 
described above. As shown in Figure 1.1, these compounds represent a hybrid of the calix[4]arene and crown ether families, in which one or two crown- 6 fragments bridge the phenolic positions of the calix[4]arene in the 1,3-alternate conformation. The facing pairs of aromatic rings. of the calixarene in this conformation form two cavities that are each preorganized for partial insertion of a $\mathrm{Cs}^{+}$ion. Crystal structures of model complexes with cesium salts [7,16-19] have demonstrated a significant pi-interaction between these facing aromatic rings and the guest $\mathrm{Cs}^{+}$ion, which is also coordinated by the six ether oxygen atoms of the polyether chain. This unique structure leads to strongly enhanced selectivity and strength in the extraction of cesium $[7,13,16$ $21,22]$. By comparison to the most selective crown ethers, which give $\mathrm{Cs} / \mathrm{Na}$ separation factors of "only" several hundred, the calix[4]arene-crown-6 family of compounds give Cs/ $\mathrm{Na}$ separation factors exceeding $10^{4}$. Since the mole ratio of Cs to $\mathrm{Na}$ in the SRS HLW feed stream is also approximately $10^{4}$ [2], it may be expected that the new compounds could potentially be used efficiently without competition from $\mathrm{Na}$ extraction. As we will show later in this report, this is indeed the case.

Despite these highly favorable properties, members of the calix[4]arene-crown-6 family reported so far had hitherto not been adapted to solvent-extraction process applications suitable for US DOE use. In particular, needs for the practical application of cesium removal from nuclear waste were identified as improved stripping, improved selectivity over potassium, and higher solubility of the extractants in alkane diluents [22]. Good stripping is critical and is a dominant theme in major sections of this report, including all of Chapter 3. Selectivity for Cs vs. K has not proven to be an especially important issue for the SRS problem; however, because the concentration of $\mathrm{K}$ in the SRS HLW is only $0.02 \mathrm{M}$ on average [2]. By contrast, competition due to $K$ extraction from Hanford double-shell slurry feed, where $K$ is approximately. $1 \mathrm{M}$, represents an important limiting factor. The need for solubility in alkane diluents arises in connection with hydrometallurgical applications, especially applications in the nuclear industry where such issues as radiation degradation, production of mixed wastes, and safety have unique significance. As reported ëlsewhere from the perspective of our initial efforts to develop an alkaline-side CSEX process for Hanford tank waste [23], the alkyl-substituted compound calix[4]arene-bis $(t-$ octylbenzo-crown-6) (BoBCalixC6) was found to have adequate solubility in aliphatic diluents. The structure of BoBCalixC6 is shown in Figure 1.2.

Although the substitution of the $t$-octyl groups on the benzo groups confers improved solubility (e.g., at $25^{\circ} \mathrm{C}$, BoBCalixC6 dissolves to a maximum of $0.010 \mathrm{M}$ in Isopar ${ }^{\circledR} \mathrm{L}$ [23]), use of alkane diluents causes a problem, namely low Cs distribution ratios $D_{\mathrm{Cs}}$ on extraction from simulants. This is an expected consequence of the poor solvating ability of alkanes, especially toward the extracted co-anion [22-24]. Gaining practical values of $D_{C s}$ at reasonably low extractant concentrations therefore requires selection of an appropriate diluent modifier. A range of 
modifiers was surveyed $[23,24]$ and narrowed down to a family of alkylphenyl ether alcohols that will be presented in Chapter 2. The use of alcohols in particular follows from their good solvating power toward anions [25]. Since the value of $D_{\mathrm{Cs}}$ depends markedly on the structure of the alcohol, process economics depends on an optimal choice, since a weak modifier must be compensated by a high extractant concentration.

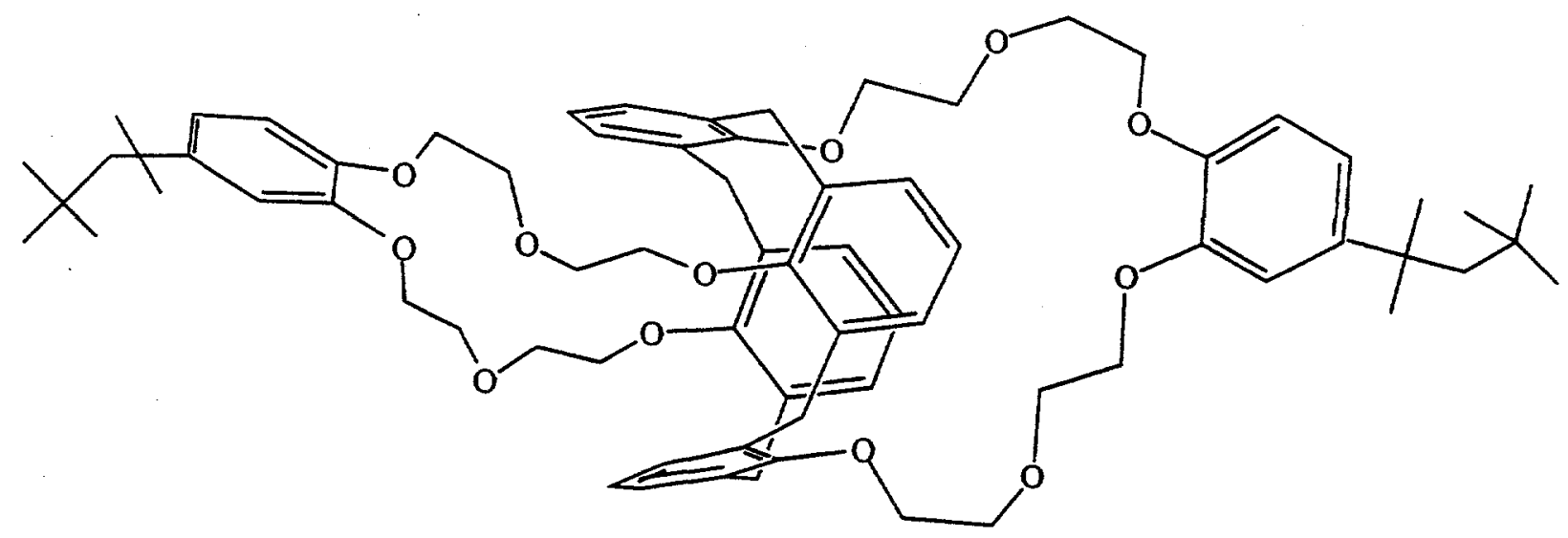

Figure 1.2. Lipophilic calixarene-crown derivative, calix[4]arene-bis- $(t$ octylbenzo-crown-6), abbreviated BoBCalixC6.

The extractant is currently expensive and is now commercially available for government use from IBC Advanced Technologies, American Fork, UT. The cost for a 40-gram lot has recently been $\$ 500 / \mathrm{g}$, though this price can be expected to drop to as low as $\$ 100 / \mathrm{g}$ as scaleup synthetic procedures are optimized. However, its low concentration, coupled with the use of phase modifiers developed at ORNL which can dramatically increase extraction strength, and the use of high-throughput centrifugal contactors, permits its use without undue investment in reagent inventory. A provisional patent application covering the extractant, modifiers, and process was submitted in September 1997 to the U.S. Patent Office by Lockheed Martin Energy Research Corporation, followed by a full patent application in September 1998 [26]. 


\subsection{PERFORMANCE CRITERIA FOR SOLVENT EXTRACTION}

Solvent extraction as a generic separation technique for separation of metal ions from aqueous solution has enjoyed a long history of successes in the nuclear industry [27-29]. Key advantages include high selectivity, flexibility, high throughput, and adaptability to remote operation. A listing of performance criteria is given in Table 1.1. The listed items constitute the normal criteria that in total determine the viability of a solvent-extraction process in a particular application.

Table 1.1. Generic solvent-extraction performance criteria

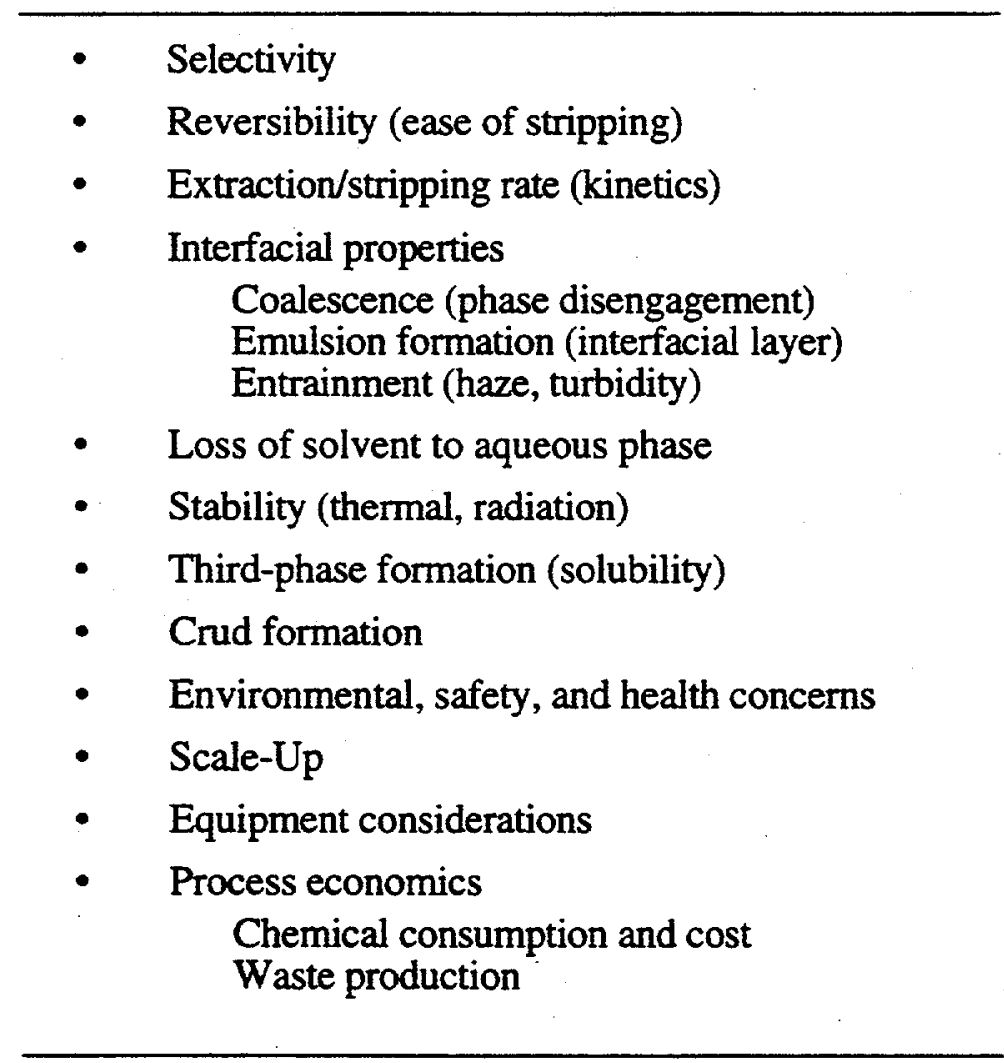

Accordingly, this report deals with many of the listed criteria in Table 1.1. Selectivity toward $\mathrm{Cs}$ vs. bulk metals such as $\mathrm{Na}, \mathrm{K}$, and $\mathrm{Al}$ has been examined together with the distribution of minor species such as $\mathrm{Fe}, \mathrm{Si}, \mathrm{Pb}$, and $\mathrm{Hg}$ (Chapter 5). As mentioned earlier, stripping is covered extensively in Chapter 3. Kinetics are briefly examined in Chapter 3 to show that stripping rate is sufficiently fast for centrifugal contactors, and accordingly, stage efficiency tests at ANL have shown that kinetics do not appear to be a problem [30]. Interfacial effects have been 
examined extensively in the present work to the extent that break times and turbidity were generally recorded in most batch tests and shown generally to be acceptable; hydraulics were found to be excellent in studies at ANL [31]. Loss of solvent by any number of mechanisms in total determines the largest part of the operating cost of the process, namely the replacement rate of the calixarene and modifier. Information related to solvent losses supplied in this report include partitioning of solvent components to the aqueous phase (Chapter 4) and stability, both radiation and chemical (Chapter 6).

Environmental, safety, and health (ES\&H) concerns were taken into account in our solvent development (Chapter 2) [23]. Although nitroaromatic or halocarbon solvents have been most studied for use with calixarene extractants, the alkaline-side CSEX process recommended here was in fact predicated on the desirability of aliphatic diluents based on ES\&H considerations. The diluent Isopar ${ }^{\circledR}$ L was chosen to have the highest flashpoint possible without undue sacrifice of hydraulic performance, and the RCRA ignitability characteristic does not apply, such that spent solvent will not be considered RCRA waste.

Scale-up and equipment considerations are dealt with in the ANL reports [30,31]. Likewise, overall process economics depends on engineering flowsheet design and goes beyond the scope of this report. We point out, however, that the solvent-loss mechanisms that have been examined here show that the expensive extractant used is likely to stand up to many cycles. Assuming that recovery of solvent lost due to entrainment is installed, operating costs are likely to be favorable. The use of centrifugal contactors minimizes solvent inventory and thus minimizes capital costs due to purchase of the calixarene. We showed earlier [32] how solvent inventory in the SRTALK process can be set as low as a few thousand liters for technetium removal from Hanford tank waste at a flow rate of $100 \mathrm{~L} / \mathrm{min}$, and similar usage is expected here. The question as to the number of stages that would be required has been dealt with elsewhere [31] and hinges on how high and low the value of $D_{\mathrm{Cs}}$ can be made on extraction and stripping, respectively. The

present report deals at length with factors that influence $D_{\mathrm{Cs}}$ values and how they may be controlled, ultimately providing the means to minimize the number of stages.

\subsection{REFERENCES}

1. Hobbs, D. T.; Walker, D. D. Chemical Pretreatment of Svannah River Site Nuclear Waste Disposal. In Chemical Pretreatment of Nuclear Waste for Disposal; Schulz, W. W., Horwitz, E. P., Eds.; Plenum, New York, 1995; pp 17-24. 
2. Walker, D. D.; Barnes, M. J.; Crawford, C. L.; Peterson, R. A.; Swingle, R. F.; Fink, S. D. In-Tank Precipitation with Tetraphenylborate: Recent Process and Research Results. In Science and Technology for Disposal of Radioactive Tank Wastes; Schulz, W. W., Lombardo, N. J., Eds.; Plenum, New York, 1998; pp 219-230.

3. Morin, J. Savannah River FY $99 \mathrm{HLW}$ ESP Technology Needs. Presented at the Efficient Separations and Processing Crosscutting Program Annual Meeting, Augusta, GA, Mar. $17,1998$.

4. Peterson, R. A.; Tamosaitis, W. Westinghouse Savannah River, Aiken, SC. Private communications, May-Aug., 1998.

5. Piccolo, S.; Carter, J.. Presented at Argonne National Laboratory, Sept. 10, 1998.

6. Thompson, M. C. Presented at the Proceedings of the Efficient Separations and Processing Crosscutting Program 1997 Technical Exchange Meeting, Gaithersburg, MD, Jan. 28-30, 1997; Report PNNL-SA-28461; Pacific Northwest National Laboratory: Richland, WA, 1997, pp 3.27-3.30.

7. Ungaro, R.; Casnati, A.; Úgozzoli, F.; Pochini, A.; Dozol, J.-F.; Hill, C.; Rouquette, H. Angew. Chem. Int. Ed. Engl., 1994, 33, 1506.

8. Asfari, Z.;Wenger, S.;Vicens, J. J. Inclusion Phenom., 1994, 19, 137.

9. Hill, C.; Dozol, J.-F.; Lamare, V.; Rouquette, H.; Eymard, S.; Tournois, B.; Vicens, J.; Asfari, Z.; Bressot, C.; Ungaro, R.; Casnati A. J. Inclusion Phenom. Mol. Recognit. Chem., 1994, 19, 399.

10. Hill, C., Ph. D. Thesis, Universite Louis Pasteur de Strasbourg, 1994.

11. Casnati, A.; Pochini, A.; Ungaro, R.; Ugozzoli, F.; Arnaud, F.; Fanni, S.; Schwing, M.J.; Egberink, R. J. M.; de Jong, F.; Reinhoudt, D. N. J. Am. Chem. Soc., 1995, 117, 2767.

12. Asfari, Z.; Bressot, C.; Vicens, J.; Hill, C.; Dozol, J.-F.; Rouquette, H.; Eymard, S.; Lamare, V.; Tournois, B. Anal. Chem., 1995, 67, 3133. 
13. Arnaud-Neu, F.; Asfari, Z.; Souley, B.; Vicens J. New J. Chem., 1996, $20,453$.

14. Asfari, Z.; Nierlich, M.; Thuery, P.; Lamare, V.; Dozol, J.-F.; Leroy, M.; Vicens J. Anales de Quimica Int. Ed., 1996, 92, 260.

15. Lauterbach, M.; Wipff, G. In Physical Supramolecular Chemistry, Echegoyen, L., Kaifer, A. E., Eds.; Kluwer Academic Publishers: Netherlands, 1996; pp 65-102.

16. Thuery, P.; Nierlich, M.; Bressot, C.; Lamare, V.; Dozol, J.-F.; Asfari, Z.; Vicens, J. J. Inclusion Phenom. Mol. Recognit. Chem., 1996, 23, 305.

17. Thuery, P.; Nierlich, M.; Asfari, Z.; Vicens, J. J. Inclusion Phenom. Mol. Recognit. Chem., 1997, 27, 169.

18. Asfari, Z.; Naumann, C.; Vicens, J.; Nierlich, M.; Thuery, P.; Bressot, C.; Lamare, V.; Dozol, J.-F. New J.Chem., 1996, 20, 1183.

19. Thuery, P.; Nierlich, M.; Bryan, J. C.; Lamare, V.; Dozol, J. -F.; Asfari, Z.; Vicens, J. J. Chem Soc., Dalton Trans., 1997, 22, 4191.

20. Dozol, J.-F.; Bohmer, V.; McKervey, A.; Lopez Calahorra, F.; Reinhoudt, D.; Schwing, M.-J.; Ungaro, R.; Wipff, G. New Macrocyclic Extractants for Radioactive Waste Treatment: Ionizable Crown Ethers and Functionalized Calixarenes; Report EUR-17615; European Communities: Luxembourg, 1997.

21. Dozol, J.-F.; Simon, N.; Lamare, V.; Rouquette, H.; Eymard, S.; Tournois, B.; De Marc, D.; Macias, R. M. Sep. Sci. Technol. (In press).

22. Haverlock, T. J.; Bonnesen, P. V.; Sachleben, R. A.; Moyer, B.A. Radiochim. Acta., 1997, 76, 103.

23. Bonnesen, P.V.; Presley, D.J.; Haverlock, T.J.; Sachleben, R.A.; Lumetta, G.J.; Moyer B.A. (Manuscript in preparation). 
24. Moyer, B.A. Complexation and Transport. In Molecular Recognition: Receptors for Cationic Guests, Gokel, G. W., Ed.; Comprehensive Supramolecular Chemistry, Atwood, J. L., Davies, J. E. D., MacNicol, D. D., Vögtle, F., Lehn, J.-M., Eds.; Pergamon, Elsevier: Oxford, 1996, pp 377-416.

25. Moyer, B. A.; Bonnesen, P. V. Physical Factors in Anion Separations. In Supramolecular Chemistry of Anions; Bianchi, A., Bowman-James, K., Garcia-España, E., Eds.; VCH: New York, 1977, Chap. 1.

26. Moyer, B. A.; Bonnesen, P. V.; Sachleben, R. A.; Presley, D. J. Solvent and Process for Extracting Cesium from Alkaline Waste Solutions. Patent application submitted to the U.S. Patent Office, Sept. 3, 1998. Provisional application under same title filed Sept. 5, 1997.

27. Musikas, C.; Schulz, W. W. Solvent Extraction in Nuclear Science and Technology. In Principles and Practices of Solvent Extraction; Rydberg, J., Musikas, C., Choppin, G. R., Eds.; Marcel Dekker: New York, 1992, Chap. 11.

28. Ritcey, G. M.; Ashbrook, A. W. Solvent Extraction, Principles and Applications to Process Metallurgy; Elsevier: New York, 1984; Part I.

29. Schulz, W. W.; Horwitz, E. P., Eds. Chemical Pretreatment of Nuclear Waste for Disposal; Plenum Press: New York, 1994.

30. Leonard, R. A. Centrifugal Contactors; Letter Report submitted to Westinghouse Savannah River Co., Oct., 1998.

31. Leonard, R. A.; Conner, C.; Liberatore, M. W.; Aase, S. B.; Vandegrift, G. F. Evaluation of an Alkaline-Side Solvent Extraction Process for Cesium Removal from SRS Tank Waste using Laboratory-Scale Centrifugal Contactors; Letter Report submitted to Westinghouse Savannah River Co., Oct., 1998.

32. Leonard, R. A.; Conner, C.; Liberatore, M. W.; Bonnesen, P. V.; Presley, D. J.; Moyer, B. A.; Lumetta, G. J., Sep. Sci. Technol. (In press). 


\section{INITIAL SOLVENT DEVELOPMENT}

\subsection{INTRODUCTION}

In this section, we briefly describe the composition of the solvent. This solvent consists of three components: the extractant (calix[4]arene-bis(t-octylbenzo-crown-6) or "BoBCalixC6"), the "modifier" (selected from a specific class of alkylphenoxy alcohols), which serves to both enhance the extraction power of the BoBCalixC6 and prevent third phase formation, and the diluent (here Isopar ${ }^{\circledR} \mathrm{L}$, a blend of $\mathrm{C} 10$ to $\mathrm{C} 12$ branched alkanes available from Exxon Chemical Company). We have found that one of the most significant variables effecting the efficiency of cesium extraction is the structure and concentration of the modifier. Due to the high cost of the extractant, it is desirable to keep the extractant concentration as low as is practical (e.g., $0.01 \mathrm{M}$ ), and to "tune" the solvent performance by the addition of carefully selected solvating materials (modifiers).

\subsection{EXPERIMENTAL}

\subsubsection{Materials and Instrumentation}

Reagents. All salts and solvents were reagent grade and were used as received. Distilled, deionized water was obtained from a Bamstead Nanopure filtering system (resistivity $18 \mathrm{M} \Omega$ ), and was used to prepare all aqueous solutions, including the simulants. Nitric acid was Ultrex II grade (J.T. Baker). Dilute nitric acid solutions were prepared by volumetric dilution, and the $\mathrm{pH}$ checked using an Orion ${ }^{\circledR}$ Model $230 \mathrm{~A}$ pH meter with an Orion ${ }^{\circledR}$ Ross $8103 \mathrm{pH}$ electrode. The meter was always calibrated (two-point) prior to use. Glycidyl 1,1,2,2-tetrafluoroethyl ether (98\%) and 4-tert-octylphenol (97\%) were obtained from Aldrich Chemical Company, and were used as received. Isopar ${ }^{\circledR} \mathrm{L}$ isoparaffinic diluent (lot\# 0306 10967) was obtained from Exxon Chemical Company, Houston, Texas. The BoBCalixC6 employed in initial solvent development was prepared at ORNL by Dr. Richard Sachleben (used in Cs3B/120L solvents). Subsequent solvent development work used two batches of BoBCalixC6 obtained from IBC Advanced Technologies (American Fork, UT): IBC 980508KC4-114-17 (used for Cs3C/120L-1 solvents), and IBC $980731 \mathrm{KC}-428$ (used for Cs3C/120L-2 and Cs3D/120L-2 solvents). Note: these latter two solvent formulations were employed at Argonne for the September 25, 1998 centrifugal contactor tests, as well as solvent using an additional batch of BoBCalixC 6 obtained from IBC by SRS. No differences in performance have been observed between Cs3B/120L, Cs3C/120L-1, Cs3C/120L-2, or Cs3D/120L-2 solvents at ORNL. The July 22,1998 contactor test at ANL 
employed a different batch of BoBCalixC6: IBC 980508KC4-11-17. The solvent prepared with this batch used modifier Cs3 lot $\mathrm{B}$, and is designated as Cs3B/120L-ANL.

Nuclear Magnetic Resonance Spectrometry. Proton NMR spectra were obtained on a Bruker MSL 400 NMR spectrometer operating at $400.13 \mathrm{MHz}$ for proton.

Cesium-137 Radiotracers. The ${ }^{137} \mathrm{Cs}$ radiotracer used for spiking the waste simulants was obtained as ${ }^{137} \mathrm{CsCl}$ in $1 \mathrm{M} \mathrm{HCl}$ from Amersham (Arlington Heights, $\mathbb{I L}$ ) and was used as received. For experiments where it was necessary to have an acid-free source of ${ }^{137} \mathrm{CsNO}_{3}$, (as for example experiments aimed at examining the stripping mechanism) a portion of the ${ }^{137} \mathrm{CsCl}$ in $1 \mathrm{M} \mathrm{HCl}$ was converted to ${ }^{137} \mathrm{CsNO}_{3}$ in water by passage through a small column containing Amberlite ${ }^{\circledR}$ IRA-900 anion exchange resin (obtained from Aldrich Chemical Company) which had been converted to the nitrate form [1]. The cleanliness of the resin prior to loading the radiotracer was examined by checking the eluant from aqueous washings of the resin for metals by inductively coupled plasma optical emission spectroscopy (ICP-OES). Conversion of the ${ }^{137} \mathrm{CsCl}$ tracer to the nitrate form was determined by washing the resin after conversion and quantifying the eluate by titration using the Mohr method for $\mathrm{Cl}^{-}$determination. The liquid from the ${ }^{137} \mathrm{CsNO}_{3}$ eluate was evaporated in a Teflon beaker using a heat lamp, and the residue re-dissolved in Barnstead Nanopure water, and the $\mathrm{pH}$ checked. The cycle was repeated until the $\mathrm{pH}$ of the solution matched that of the dilution water (about $\mathrm{pH} \mathrm{6).} \mathrm{The} \mathrm{final} \mathrm{residue} \mathrm{was} \mathrm{diluted} \mathrm{to} \mathrm{a} \mathrm{volume} \mathrm{of} 1.0 \mathrm{~mL}$.

Gamma Counting of Cesium. The cesium activity in the samples was determined by standard gamma( $(\gamma)$-counting techniques using a Packard ${ }^{\circledR}$ Cobra Quantum Model 5003 gamma counter equipped with a 3" $\mathrm{NaI}(\mathrm{Tl})$ crystal through-hole type detector. A counting window of 580 to $750 \mathrm{keV}$ was employed for the $662 \mathrm{keV}$ emmision from $137 \mathrm{mBa}$. Count times varied with the activity of the sample, but were generally long enough to ensure that a total of 1000 total counts had been collected. A decay time (following separation of the aqueous and organic phases) of at least $1 \mathrm{hr}$ was employed to ensure that secular equilibrium had been achieved between the extracted

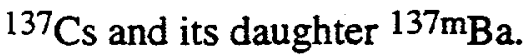

\subsubsection{Modifier Synthesis}

Typical Synthesis of 1-(4-tert-octylphenoxy)-3-(1,1,2,2-tetrafluoroethoxy)-2-propanol (Modifier "Cs3", lot D). A 2 liter 3-neck flask equipped with an overhead paddle-stirrer at the center neck was charged with $208 \mathrm{~g}$ (1.01 mole) of 4-tert-octylphenol, a catalytic amount of dry, ground potassium carbonate (14.18 g, 0.103 mole), and $95 \%$ ethanol $(700 \mathrm{~mL})$ under argon. A condenser with an argon inlet was attached to one side arm and a $250 \mathrm{~mL}$ pressure-equalizing addition funnel was attached to the other side arm. (Teflon sleeves were used between all ground glass joints.) The solution was warmed using an oil bath to about $50^{\circ} \mathrm{C}$ under argon, whereupon the addition funnel was charged with $186.7 \mathrm{~g}$ (1.07 mole) of glycidyl 1,1,2,2-tetrafluoroethyl 
ether. The epoxide was added dropwise to the stirred solution under Ar positive pressure over the course of 20 minutes, during which time the bath temperature was raised to $76^{\circ} \mathrm{C}$. The addition funnel was rinsed with $20 \mathrm{~mL}$ of $95 \%$ ethanol, the rinsings were added to the reaction mixture, and the funnel was replaced with a ground glass stopper. The Ar inlet was removed and the oil bath temperature raised to $95-100{ }^{\circ} \mathrm{C}$ to allow a moderate rate of reflux. The solution was refluxed with stirring for 24 hours, after which a one $\mathrm{mL}$ aliquot was pulled from the colorless solution, the solvent was evaporated, and a proton NMR was obtained on the clear oil residue in deuterochloroform. The NMR showed that conversion was $>99 \%$ with $<1 \%$ unreacted phenol remaining. The reaction mixture was allowed to cool to about $40^{\circ} \mathrm{C}$, then transferred to a large round bottom flask, and the ethanol removed on a rotary evaporator at $50{ }^{\circ} \mathrm{C}$ and $140-160 \mathrm{mbar}$ pressure. The clear oil containing residual potassium carbonate was dissolved in $800 \mathrm{~mL}$ hexanes, transferred to a $4 \mathrm{~L}$ separatory funnel, and washed with one liter portions of deionized water (1X), $0.5 \mathrm{M} \mathrm{NaOH}(4 \mathrm{X})$, and once again with deionized water. The hexanes layer was dried over anhydrous magnesium sulfate, filtered, and the hexanes removed under vacuum to give $372 \mathrm{~g}$ (97\%) of crude product. To methylate the residual 4-tert-octylphenol, the flask containing the modifier was charged with a large stirbar, potassium carbonate $(2.764 \mathrm{~g}, 0.02$ mole $), 50 \mathrm{~mL}$ of acetone (to lower the viscosity), and $3.56 \mathrm{~g}$ (0.025 mole) of iodomethane (Caution: iodomethane is a carcinogen; use only in a well-functioning fume hood).. The flask was sealed, and immersed half-way in an oil bath, and the solution stirred at $58{ }^{\circ} \mathrm{C}$ for 24 hours. The sealing cap was removed and the volatiles removed under vacuum at $58{ }^{\circ} \mathrm{C}$. The reaction mixture was allowed to cool, dissolved again in $800 \mathrm{~mL}$ hexanes, and washed with deionized water ( $2 \times 500 \mathrm{~mL})$, saturated sodium chloride $(1 \times 300 \mathrm{~mL}$ ), and once again with $500 \mathrm{~mL}$ water. After drying over anhydrous magnesium sulfate, the hexanes were removed by rotary evaporation to give $364 \mathrm{~g}$ of product with very low phenol content. The product $(\mathrm{FW}=380.43 \mathrm{~g} / \mathrm{mol}$ ) was purified by fractional distillation under high (oil-pump) vacuum, and the fraction $(307.4 \mathrm{~g}, 80 \%)$ which distilled between $170-180^{\circ} \mathrm{C}$ at 0.04-0.06 mm Hg was collected. Residual 4-t-octylphenol was present at a level barely detectable by proton NMR ( $\leq 0.5 \mathrm{~mol} \%$ on the modifier). Analysis by gas chromatography (GC) is a more sensitive and accurate determination method; the analysis for this sample was not available as of this writing. The cost to synthesize the modifier (based on material and labor costs at ORNL) is approximately $\$ 1500 \pm \$ 500$ per kilogram (about $\$ 120 \pm \$ 40$ per liter of solvent, for a $0.20 \mathrm{M}$ solution).

Initial solvent development employed Lots A-C of this modifier. All lots were distilled before use, however only lots $B$ and $D$ were treated as described above with iodomethane to methylate the excess 4-t-octylphenol (to produce 4-t-octylanisole, which is essentially "inert" in the extraction, and is mostly removed in the distillation forerun). The residual 4-t-octylphenol content of each of these lots of modifiers was measured by GC to be, respectively for lots $\mathrm{A}, \mathrm{B}$, and $\mathrm{C}$ : 
$0.047 \mathrm{~mol} \%, 0.077 \mathrm{~mol} \%$, and $0.268 \mathrm{~mol} \%$ (on the Cs3 modifier). It was independently determined (see also Chapter 5) that trace 4-t-octylphenol does not adversely effect the performance of the solvent until the concentration reaches above 20 millimolar (here $10 \mathrm{~mol} \%$ of the modifier at $0.20 \mathrm{M}$ ), and even then the effect is mainly to increase the $D_{\mathrm{Cs}}$ during extraction from the simulant.

\subsubsection{Savannah River High Level Tank Waste Simulants}

Preparation of SRS\#2-1 Simulant. The simulant was prepared on the basis of analytical data obtained from SRS for selected High Level Waste Tanks. The simulant was prepared directly in a $2 \mathrm{~L}$ Nalgene Teflon ${ }^{\circledR}$ FEP bottle using distilled, deionized water (Barnstead still) and reagent grade salts, following the order indicated in Table 2.1 .

\subsubsection{Contacting Procedures}

Cesium-137 Tracer Experiments. The early flowsheet development studies described here were performed using deionized water-rinsed borosilicate vials as extraction vessels, however all subsequent work, especially extraction studies examining the stripping contacts, were performed in polypropylene or Teflon ${ }^{\circledR}$ FEP tubes. Contacting at $25^{\circ} \mathrm{C}$ was performed in a "homemade" plexiglass airbox at $\mathrm{ORNL}$, where the temperature inside the box was controlled by both heating and cooling elements, and the temperature variation was $\pm 0.2{ }^{\circ} \mathrm{C}$. Generally, equal volumes of aqueous and organic phases were contacted first by vortexing (VWR Scientific Vortex Genie ${ }^{\mathrm{TM}}$. 2) for 30 seconds outside the airbox at the ambient laboratory temperature of $20-25^{\circ} \mathrm{C}$, followed by gentle end-over-end rotation for 30 minutes at a constant temperature of $25^{\circ} \mathrm{C}$ using a Glass-Col ${ }^{\circledR}$ laboratory rotator placed inside the airbox. After vortexing, but before the samples were placed on the rotator, the phase coalescence behavior and time-to-break (essentially when all the small droplets at the interface between the two phases have disappeared) was recorded. A contact time of 30 minutes was used on the rotator to ensure attainment of equilibrium, even though equilibrium is reached within five minutes (see Chapter 3). All samples were centrifuged for three to five minutes at $2869 \times g$ in a refrigerated centrifuge maintained at $25 \pm 1{ }^{\circ} \mathrm{C}$ (Sanyo MSE Mistral $2000 \mathrm{R}$ ) to ensure complete phase separation. Aliquots of each phase were removed for analysis (Cs-137 counting). $D_{C s}$ was determined as the ratio of the Cs-137 activity in the organic phase to the activity in the aqueous phase at equilibrium. 
Table 2.1. Formulation of simulant SRS\#2-1 at ORNL.

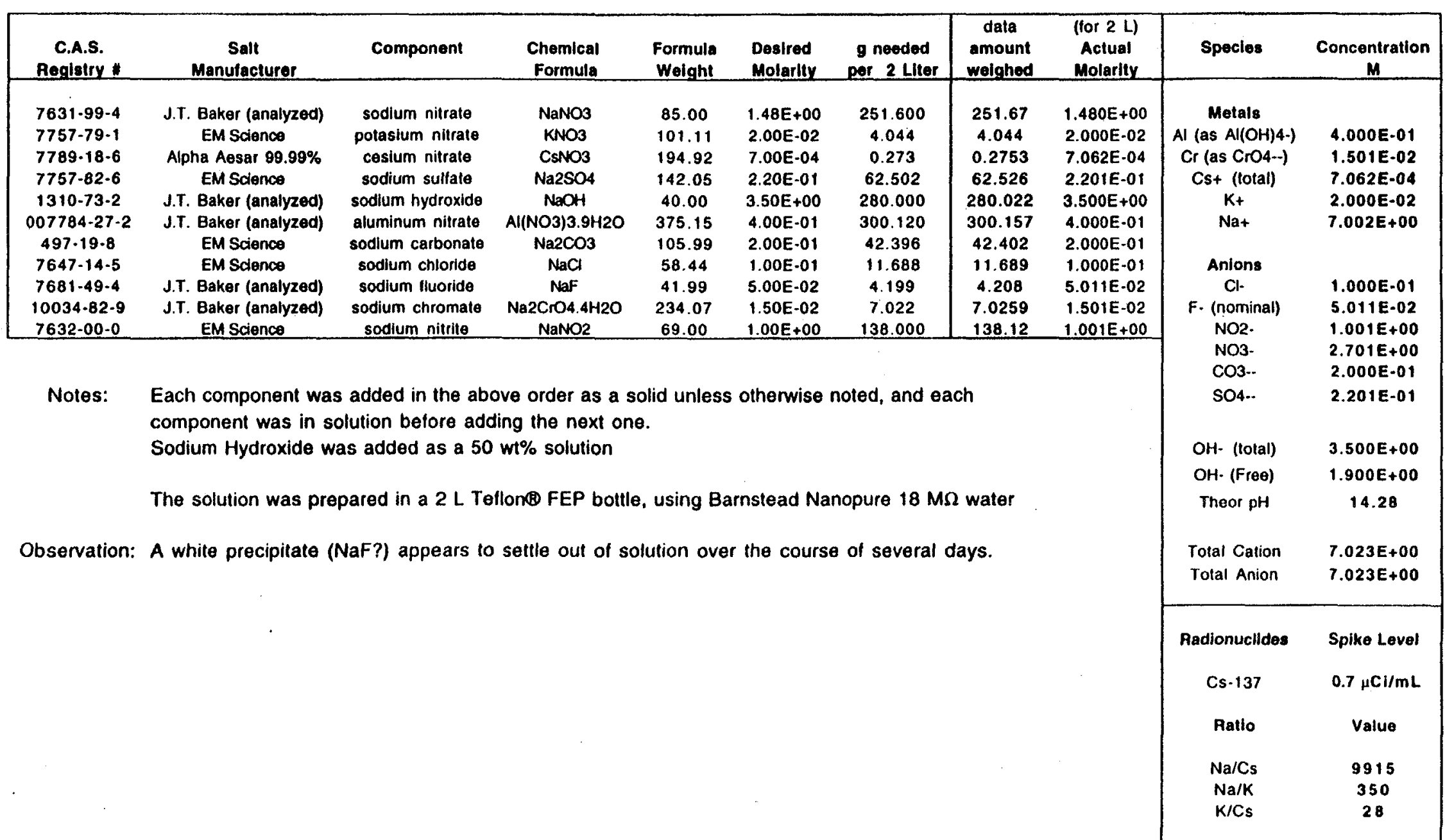




\subsection{RESULTS AND DISCUSSION}

\subsubsection{Initial Screening of Modifiers.}

Three modifiers were initially examined to determine which would be most suitable for the process. Criteria included modifier potency, ease and cost of synthesis, and phase behavior. The modifiers are shown below in Figure 2.1. The modifier with the best balance of potency, ease and cost of synthesis, and phase behavior, was found to be 1-(4-tert-octylphenoxy)-3-(1,1,2,2tetrafluoroethoxy)-2-propanol (designated modifier "Cs3").

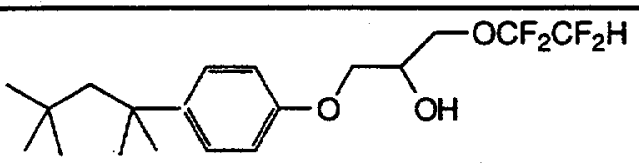

1-(1,1,2,2-tetrafluoroethoxy), -3-[4-(t-octyl)phenoxy]-2-propanol, "Cs3"<smiles>CC(C)(C)CC(C)(C)C1CCC(OCCCO)CC1</smiles>

3-[4-(t-octyl)phenoxy]-1-propanol, "Cs4"<smiles>CC(CO)CO[C@H]1CC[C@H](C(C)(C)CC(C)(C)C)CC1</smiles>

3-[4-(t-octyl)phenoxy]-2-methyl-1-propanol, "Cs-5"

Figure 2.1. Modifiers examined for Cs solvent extraction.

\subsubsection{Optimization of Solvent Composition.}

The diluent Isopar ${ }^{\circledR} \mathrm{L}$ was selected based on our previous experience employing this diluent in the SRTALK process $[2,3]$. Isopar ${ }^{\circledR} \mathrm{L}$ is a blend of branched alkanes with a distillation range of $191-205^{\circ} \mathrm{C}$ possessing a viscosity of 1.6 centipoise at $25^{\circ} \mathrm{C}$, a specific gravity of 0.767 $\mathrm{g} / \mathrm{mL}$ at $60^{\circ} \mathrm{F}\left(15.5^{\circ} \mathrm{C}\right)$, and a TCC flashpoint of $144{ }^{\circ} \mathrm{F}\left(62{ }^{\circ} \mathrm{C}\right.$ ) (data courtesy of Exxon Chemical Company). Since the extractant calix [4]arene-bis(t-octylbenzo-crown-6) (BoBCalixC6) can be synthesized commercially in moderately large (e.g., 40 gram) quantities, and since it has good solubility properties, it was selected as the Cs extractant. As the BoBCalixC6 is many times more expensive than the $\mathrm{Cs} 3$ modifier, the performance of the solvent was optimized by keeping 
the BoBCalixC6 concentration as low as possible. The effect of modifier concentration on the strength of extraction of Cs from the SRS\#2-1 simulant by the BoBCalixC6 at $0.01 \mathrm{M}$ was studied for both the Cs3 and Cs4 modifiers; the results are plotted in Figure 2.2. It can be seen that modifier Cs 3 is much more potent than $C s 4$, and that $D_{C s}$ is very sensitive to the $\operatorname{Cs} 3$ concentration up to about $1 \mathrm{M}$ concentration.

\subsubsection{First Flowsheet Using Cs3 Modifier.}

Following the extraction contacts, it is necessary to scrub and strip the solvent. Since the BoBCalixC6 can be nitrated to a measurable extent by nitric acid concentrations greater than $1 \mathrm{M}$ (nearly $50 \%$ nitrated after $210 \mathrm{hr}$ of continuous contact of BoBCalixC6 at $0.02 \mathrm{M}$ in deuterochloroform with $4 \mathrm{M}$ nitric acid [4]), only dilute nitric acid solutions should be used for the scrub and strip. The purpose of the scrub solution is to remove co-extracted metals (e.g., potassium) without removing an extensive amount of $\mathrm{Cs}$, such that there will not be a lot of co-extracted metals appearing in the strip phase along with the Cs. The first solvent formulation that was examined, and comprised the first flowsheet using Cs3, was solvent "Cs3B/150L", where the Cs3 modifier (Lot "B") was at $0.50 \mathrm{M}$, and the BoBCalixC6 was at $0.01 \mathrm{M}$, in Isopar ${ }^{\circledR} \mathrm{L}$. The concentration of $0.50 \mathrm{M}$ for the $\mathrm{Cs} 3$ modifier was selected since at that concentration, $D_{\mathrm{Cs}}$ for a contact between pristine solvent and the SRS\#2-1 simulant was about 80+\% of maximum; the curve of $D_{\mathrm{Cs}}$ vs. [Cs3] starts to flatten out above $0.5 \mathrm{M}$, and there is not much to be gained by using higher concentrations of modifier. In fact, phase coalescence behavior and stripping efficiency begin to suffer when the modifier concentration is too high. Useful distribution ratios $\left(D_{\mathrm{Cs}} \geq 10\right)$ can be obtained even at lower Cs3 concentrations (e.g., $\left.0.20 \mathrm{M}\right)$. For the first extraction, scrub, and strip test, the solvent was contacted with an equal volume of cold SRS\#2-1 simulant (comprising a "pre-equilibration" or first extraction contact), followed by a second extraction contact with simulant containing ${ }^{137} \mathrm{Cs}$ tracer, followed by two scrubs using $50 \mathrm{mM}$ nitric acid, and three strips using $1 \mathrm{mM}$ nitric acid. The results are shown graphically in Figure 2.3 .

Phase coalescence on all contacts was satisfactory. While it can be seen that $D_{\mathrm{Cs}}$ values are stable for both scrubbing contacts, the $D_{\mathrm{Cs}}$ on stripping increases on subsequent contacts, especially for the last contact where the total [Cs] is on the order of 6-7 micromolar. The fact that $D_{\mathrm{Cs}}$ on stripping appears to increase as the [Cs] decreases was a cause for some concern (since this will limit the extent to which the solvent can be decontaminated, and the overall decontamination factor), and will be the subject of Chapter 3, "Understanding and Controlling Stripping". 


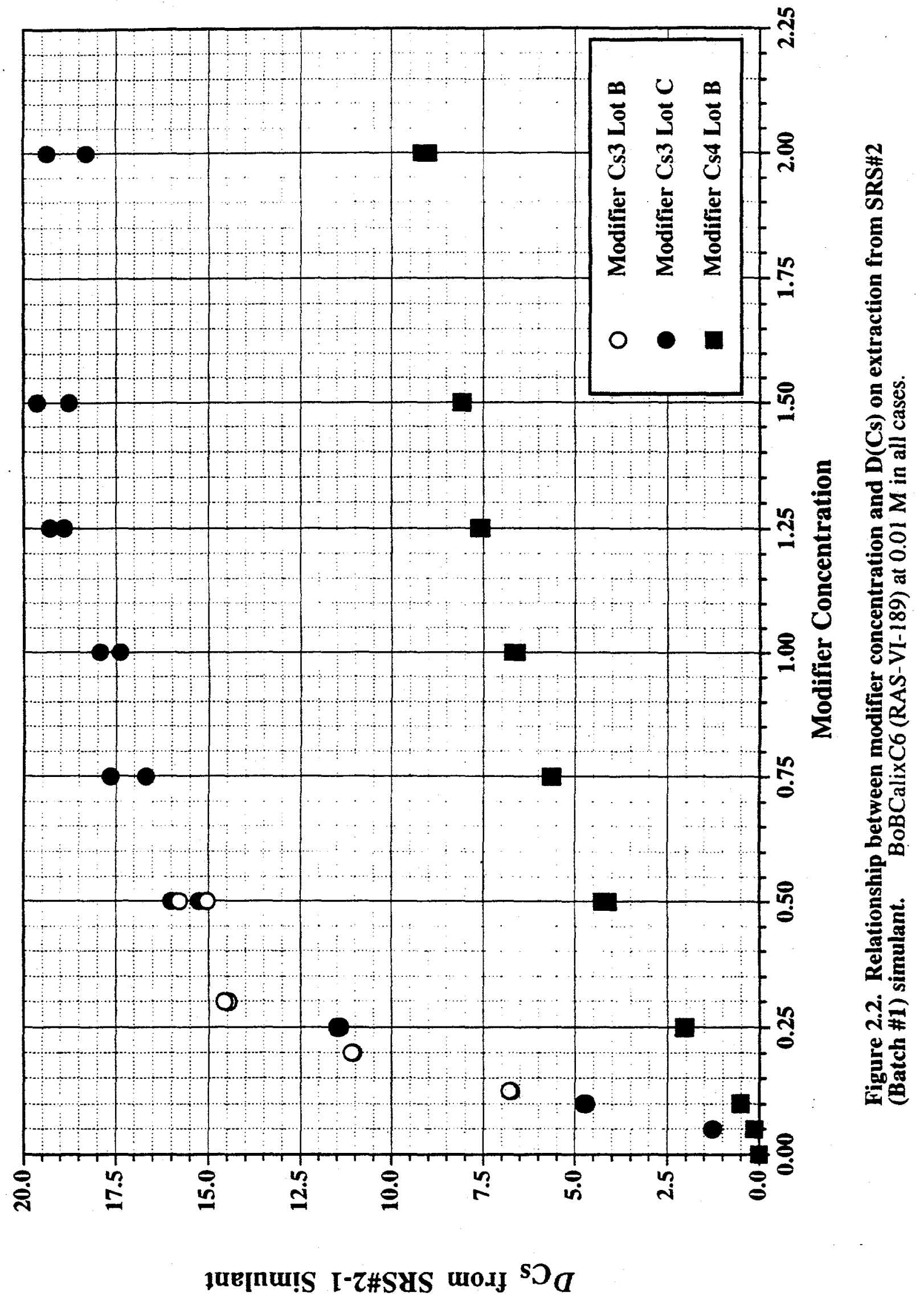




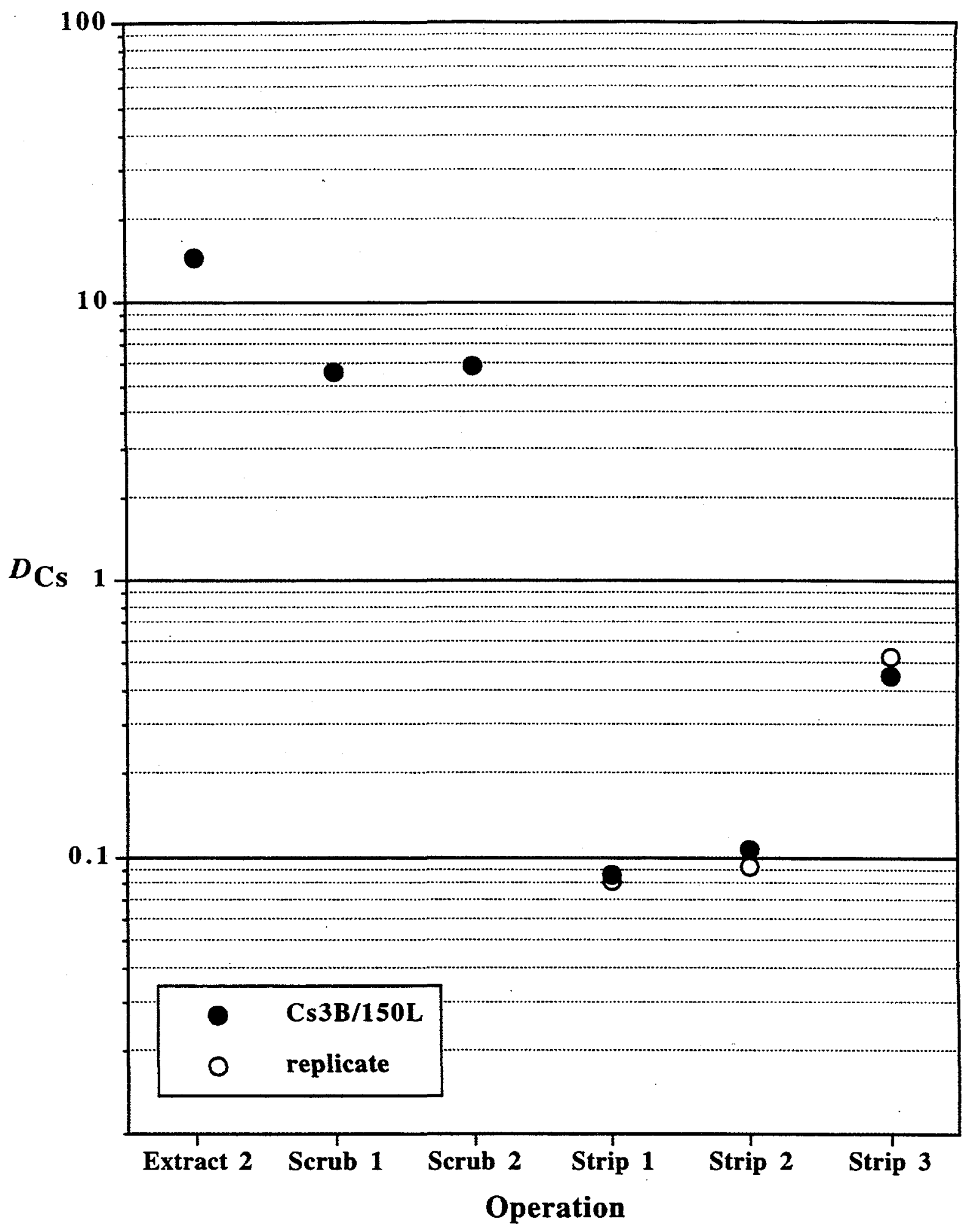

Figure 2.3. Extraction, scrubbing, and stripping performance for solvent Cs3B/150L (SRS\#2-1 simulant). All distribution measurements were conducted with $\mathrm{O} / \mathrm{A}=1$ at $25^{\circ} \mathrm{C}$. Scrub aqueous phase was $50 \mathrm{mM}$ nitric acid; strip aqueous phase was $1 \mathrm{mM}$ nitric acid. 


\subsection{CONCLUSIONS}

A suitable candidate solvent for removing Cs from a SRS alkaline waste simulant was formulated as consisting of the BoBCalixC6 extractant at $0.01 \mathrm{M}$, and the Cs3 modifier at $0.50 \mathrm{M}$ (initially) in Isopar ${ }^{\circledR}$ L diluent. The solvent shows good performance during the scrub stages, but the $D_{\mathrm{Cs}}$ on stripping creeps up with increasing contacts (decreasing [Cs]), forcing closer examination of the strip cycle and the factors that control stripping (Chapter 3 ).

\subsection{REFERENCES}

1. Haverlock, T.J.; Bonnesen, P.V.; Sachleben, R.A.; Moyer, B.A. J. Inclusion Phenom. Mol. Recognit. Chem. (Submitted).

2. Bonnesen, P.V.; Moyer, B.A.; Presley, D.J.; Armstrong, V.S.; Haverlock, T.J.; Counce, R.M.; and Sachleben, R.A. Alkaline-Side Extraction of Technetium from Tank Waste Using Crown Ethers and Other Extractants; Report ORNLTM-13241, Oak Ridge National Laboratory: Oak Ridge, TN, June, 1996.

3. Leonard, R.A.; Conner, C.; Liberatore, M.W.; Bonnesen, P.V.; Presley, D.J.; Moyer, B.A.; and Lumetta, G.J. Sep. Sci. Technol. (In press).

4. Bonnesen, P.V., Oak Ridge National Laboratory, Oak Ridge, TN. Unpublished results, 1997. 


\section{UNDERSTANDING AND CONTROLLING STRIPPING}

\subsection{INTRODUCTION}

As the development of the alkaline-side CSEX process advanced in our laboratory over the past six months, the focus shifted to stripping, since it was found that good phase disengagement and efficient removal of cesium from the solvent were not always achieved with candidate stripping solutions. In early trials it was observed that the stripping agent preferred on thermodynamic and economic grounds, namely water, gave poor phase disengagement and cloudy phases upon settling. Since it is generally known that phase disengagement requires the presence of salt or acid to maintain at least a minimal ionic strength, subsequent trials were carried out with alkaline, neutral-salt, and acid solutions. Nitric acid solutions $\left(10^{-4}\right.$ to $\left.10^{-2} \mathrm{M}\right)$ were found to be superior, as was discovered previously for the SRTALK process [1]. In general, adequate break times of under two minutes were obtained upon shaking vials containing equal volumes of the aqueous and organic phases, and dispersion-number tests at ANL were subsequently good. Although this was accepted as an empirical fact, it was surmised that the acidity was important in preventing hydrolytic precipitation of traces of metals such as aluminum that might be carried into the stripping stages or possibly in neutralizing interface-active anionic impurities such as phenols known to be present in trace amounts in the solvent. As a further case against the use of other possible stripping solutions, it was generally deemed undesirable to add salt to the strip effluent, since it would partially defeat the purpose of employing such a selective extractant as BoBCalixC6, and burden downstream evaporation (if used) and vitrification. Of the possible acids that could have been employed, nitric acid was chosen as the most suitable acid for the present purpose. Nitrate is already an expected waste component and as such is compatible with downstream processes, and $\mathrm{HNO}_{3}$ is volatile, potentially allowing its removal from the strip solution on evaporation (if used) and recycle. Of the alternative mineral acids, hydrochloric acid is highly corrosive, and sulfuric acid as a source of sulfate has limited compatibility with vitrification.

Although nitric acid at concentrations down to $0.001 \mathrm{M}$ gave good phase disengagement, it was found that successive stripping of loaded solvent with fresh $0.001 \mathrm{M}$ nitric acid solutions gave decreasingly efficient stripping performance. After several such stripping contacts, the distribution ratio exceeded unity, effectively ending any further stripping at concentrating O/A ratios (i.e., those greater then unity). Experimental results will be detailed below. This observation led to a careful consideration of the underlying equilibria of extraction and stripping. Two hypotheses for the decreasing stripping performance on successive stripping contacts were advanced. Based on extensive literature on calixarenes [2-13], crown ethers [14], and the solvent extraction of alkali 
metals generally [15], we proposed that the extraction mechanism itself changed when the organicphase cesium nitrate concentration fell below approximately $10^{-5} \mathrm{M}$. In the sections that follow, we will develop this argument in detail and show how it quantitatively fits the data. Based on this understanding, a range of possible approaches to efficient stripping was envisaged, and two successful approaches to obtaining good stripping performance were actually tested. One entailed adding non-radioactive $\mathrm{CsNO}_{3}$ to the strip solution at $10^{-4} \mathrm{M}$, and the other entailed adding any of a number of extractants to the solvent at $10^{-4} \mathrm{M}$. Data presented below show that either or both of these changes lower distribution ratios in the stripping stages to a value of 0.03 or lower, without affecting performance in the extraction and scrub stages.

On the other hand, any anionic impurity that persists in the solvent could inhibit stripping, and probably will eventually do so under process conditions, as suggested by the ANL group. Impurities could be introduced by degradation of the solvent or from the waste itself, or possibly they could be present to begin with in pristine solvent. We will also show below how either the nonradioactive $\mathrm{CsNO}_{3}$ or the alkylamine extractant could effectively neutralize the effect of anionic impurities, enabling good stripping even in their presence. Especially in the case of the alkylamine, the result is a more robust solvent that has inherently good stripping characteristics and tolerates anionic impurities that inevitably will find their way into the solvent under process conditions.

In summary, a good understanding of the extraction/stripping mechanism has been obtained. This understanding has led to efficient stripping even in the presence of impurities and even when the concentration of $\mathrm{CsNO}_{3}$ in the solvent decreases below $10^{-5} \mathrm{M}$. Although adding an adjunct extractant such as an alkylamine in a small concentration to the solvent could not be accommodated in the engineering tests at ANL in July and September, the batch data obtained at ORNL and ANL indicate that this change in the solvent would markedly improve stripping performance. Below we will present data, modeling, and theory to support our understanding of stripping and proposed approaches toward a more robust solvent. We also briefly discuss some process experience that supports our contention that addition of an alkylamine extractant to the solvent may be considered in the realm of ordinary processing practice.

\subsection{EXPERIMENTAL}

\subsubsection{Materials and Instrumentation}

Reagents. See section 2.2.1. Trioctyl amine was distilled, and tetraheptyl ammonium nitrate was recrystallized, prior to use. A solution of HDDNS (didodecylnaphthalene sulfonic acid) in toluene was evaporated several times to make sure all water was removed, and a solution 
of the acid in the CS3C/120L-2 solvent prepared by weighing the acid into a volumetric flask, and diluting with the solvent.

Cesium-137 Radiotracers and Gamma Counting of Cesium. See section 2.2.1.

\subsubsection{Contacting Procedures}

Cesium-137 Tracer Experiments. For all experiments involving a succession of preequilibration, extraction, scrub, and strip contacts, the experimental conditions are the same as those described in the section 2.2.4. Experiments on cesium "forward" stripping were performed at $25^{\circ} \mathrm{C}$ with an $\mathrm{O} / \mathrm{A}$ phase ratio of unity, using polypropylene vials. Organic and aqueous phase volumes of $0.75 \mathrm{~mL}$ were contacted for one hour using a Glass-Col ${ }^{\circledR}$ rotator at $50 \mathrm{RPM}$. The aqueous phase contained nitric acid and cesium nitrate at different concentrations plus a spike of ${ }^{137} \mathrm{Cs}$, unless otherwise stated. The organic phase was pristine solvent. Following contacting, the vials or tubes were centrifuged for typically $3 \mathrm{~min}$ at $2869 \times \mathrm{g}$, and $0.5 \mathrm{~mL}$ of each phase was removed for analysis $\left({ }^{137} \mathrm{Cs}\right.$ counting).

Kinetic Measurements. Contacting at $25 \pm 0.2{ }^{\circ} \mathrm{C}$ was performed inside the temperaturecontrolled airbox described in section 2.2.4. Contacting at temperatures above $25^{\circ} \mathrm{C}$ was accomplished using a Lab-line ${ }^{\circledR}$ incubator, where the temperature variation is nominally $\pm 1{ }^{\circ} \mathrm{C}$. However, owing to frequent entries into the incubator chamber, the temperature fluctuation during the kinetics experiments was probably closer to $\pm 5{ }^{\circ} \mathrm{C}$. In a typical experiment, the aqueous phases $(0.75 \mathrm{~mL})$ containing ${ }^{137} \mathrm{Cs}$ tracer were pipetted into $2.0 \mathrm{~mL}$ Eppendorf microcentrifuge tubes at ambient lab temperature. The organic phases $(0.75 \mathrm{~mL})$ were placed into a separate set of tubes. All the tubes were set inside a rack in the airbox or incubator for at least one hour, along with the mixing and centrifuging equipment, to ensure that the solutions would be at the desired temperature (either 25,34 , or $43^{\circ} \mathrm{C}$ ) before the start of the experiment. At the beginning of each equilibration, the organic phase was carefully pipetted into the tube containing the aqueous phase using a polyethylene transfer pipet, taking care not to mix the two solutions prematurely. The tube was then vortexed inside the airbox or incubator for the desired time (VWR Scientific Vortex Genie 2 , set for speed 6 ), then immediately centrifuged for 1 minute at 5000 RPM using a microcentrifuge (VWR Scientific Model V) placed beside the vortexer. Sub-samples of $0.5 \mathrm{~mL}$ of each phase were then $\gamma$-counted.

Equilibrium Experiments at Elevated Temperatures. The contacting was performed in the same manner as above except that mixing was performed using a Glass-Col ${ }^{\circledR}$ rotator (placed inside the airbox or incubator) in place of the vortex mixer. Microcentrifuge tubes containing $0.75 \mathrm{~mL}$ each of the organic and aqueous phases were rotated at 40 RPM for 30 minutes or one hour, then centrifuged and subsampled as above. The temperature variation for these experiments was $\pm 2{ }^{\circ} \mathrm{C}$. 


\subsubsection{Preparation of SRS\#2/1' Simulant}

One set of experiments was performed using SRS\#2-1 simulant to which additional materials (sodium silicate, ferric nitrate, lead chloride, and mercuric chloride) were nominally added. (This simulant was a precursor of the simulant SR\#3 described in Chapter 5). Specifically, simulant SRS \#2-1' was prepared by adding a solution containing $0.1652 \mathrm{~g}$ of 99.999\% $\mathrm{SiO}_{2}$ (Aldrich) plus $0.45 \mathrm{~g} 50 \% \mathrm{NaOH}$ (Baker) to $250 \mathrm{~mL}$ of SRS\#2-1 simulant: The silicate (nominally $0.11 \mathrm{M}$ ) appeared to dissolve. To this simulant solution was also added 0.250 $\mathrm{mL}$ of a solution containing ferric nitrate $\left(1 \times 10^{-2} \mathrm{M}\right), \mathrm{PbCl}_{2}\left(1 \times 10^{-1} \mathrm{M}\right)$, and $\mathrm{HgCl}_{2}\left(1 \times 10^{-1}\right.$ $\mathrm{M}$ ) in $0.5 \mathrm{M}$ nitric acid, affording $\mathrm{Fe}, \mathrm{Hg}$, and $\mathrm{Pb}$ concentrations nominally of $1 \times 10^{-5} \mathrm{M}, 1 \times 10^{-4}$ $\mathrm{M}$, and $1 \times 10^{-4} \mathrm{M}$, respectively. Precipitation of especially the Fe was noted when the $0.250 \mathrm{~mL}$ solution was added to the simulant. The simulant was shaken, and allowed to stand for at least 24 hours before being used in the experiments.

\subsection{RESULTS}

\subsubsection{Relationship Between Cesium Nitrate Concentration and $D_{C s}$ as a Function of Nitric Acid Concentration}

Section 3.3 presents the results obtained in Cs stripping experiments. Detailed discussion will follow in section 3.4.

Results of cross-current batch tests of extraction, scrubbing, and stripping at $25{ }^{\circ} \mathrm{C}$ are shown in Table 3.1. It may be seen that on extraction, $D_{\mathrm{Cs}}$ values of 10.3 and 9.5 are obtained in two successive contacts of the same solvent with fresh simulant, with scrubbing sufficient to retain $\mathrm{Cs}$ in the organic phase at an $\mathrm{O} / \mathrm{A}$ ratio of 5 . (Note: the tabulated values of $D_{\mathrm{Cs}}$ equal to 1.40 and 1.47 shown in scrubbing were obtained with an initial solution of nitric acid that by $\mathrm{pH}$ determination was found to be on the order of $63 \mathrm{mM}$ in concentration. Use of a solution of nitric acid on the order of $50 \mathrm{mM}$ in concentration in all future scrubbing operations afforded the consistent attainment of scrubbing $D_{\mathrm{Cs}}$ values in the range 0.6-0.8.) With $0.0005 \mathrm{M} \mathrm{HNO}_{3}$ as the stripping solution, values of $D_{\mathrm{Cs}}$ start at a good value of 0.034 but rise in successive contacts with fresh strip solution, exceeding 5 by the fifth contact. If an O/A ratio of 3 were used in the process, stripping would thus become quickly inefficient. For reasons detailed in section $3.4, \mathrm{CsNO}_{3}$ was added to the strip solution at a concentration of $0.0001 \mathrm{M}$, giving essentially the same value of 0.035 on the first contact, and a stable value of 0.056 on the next two contacts. A recurring pattern that we have noticed in subsequent tests is the increase of $D_{C s}$ by $0.01-0.02$ on the second contact; the reason that will become more obvious below relates to the decreased concentration of $\mathrm{CsNO}_{3}$ in the aqueous strip solution on the second contact. 
Table 3.1. Batch flowsheet tests with SRS\#2-1 simulant. ${ }^{a}$

\begin{tabular}{|c|c|c|c|c|c|c|}
\hline Stage & $\begin{array}{c}\text { Aqueous } \\
\text { phase }\end{array}$ & $D_{\mathrm{Cs}}$ & $\begin{array}{c}{[\mathrm{Cs}]_{\text {org }}} \\
\mathrm{mol} / \mathrm{L}\end{array}$ & $\begin{array}{c}\text { Aqueous } \\
\text { phase }\end{array}$ & $D_{\mathrm{Cs}}$ & $\begin{array}{l}{[\mathrm{Cs}] \text { org }} \\
\mathrm{mol} / \mathrm{L}\end{array}$ \\
\hline Extract 1 & $\begin{array}{c}\text { SRS } \\
\text { simulant }\end{array}$ & 10.24 & $1.23 \times 10^{-3}$ & $\begin{array}{c}\text { SRS } \\
\text { simulant }\end{array}$ & 10.37 & $1.24 \times 10^{-3}$ \\
\hline Extract 2 & $\begin{array}{c}\text { SRS } \\
\text { simulant }\end{array}$ & 9.50 & $1.75 \times 10^{-3}$ & $\begin{array}{c}\text { SRS } \\
\text { simulant }\end{array}$ & 9.52 & $1.76 \times 10^{-3}$ \\
\hline Scrub 1 & $\begin{array}{c}0.063 \mathrm{M} \\
\mathrm{HNO}_{3}\end{array}$ & 1.40 & $1.02 \times 10^{-3}$ & $\begin{array}{l}0.05 \mathrm{M} \\
\mathrm{HNO}_{3}\end{array}$ & 0.739 & $7.46 \times 10^{-4}$ \\
\hline Scrub 2 & $\begin{array}{c}0.063 \mathrm{M} \\
\mathrm{HNO}_{3}\end{array}$ & 1.47 & $6.09 \times 10^{-4}$ & $\begin{array}{l}0.05 \mathrm{M} \\
\mathrm{HNO}_{3}\end{array}$ & 0.779 & $3.27 \times 10^{-4}$ \\
\hline Strip 1 & $\begin{array}{c}0.0005 \mathrm{M} \\
\mathrm{HNO}_{3}\end{array}$ & 0.0338 & $1.99 \times 10^{-5}$ & $\begin{array}{c}+0.0001 \mathrm{M} \\
\mathrm{CsNO}_{3}{ }^{\mathrm{b}}\end{array}$ & 0.0352 & $1.45 \times 10^{-5}$ \\
\hline Strip 2 & $\begin{array}{c}0.0005 \mathrm{M} \\
\mathrm{HNO}_{3}\end{array}$ & 0.181 & $3.06 \times 10^{-6}$ & $\begin{array}{c}+0.0001 \mathrm{M} \\
\mathrm{CsNO}_{3} \mathrm{~b}\end{array}$ & 0.0560 & $6.07 \times 10^{-6}$ \\
\hline Strip 3 & $\begin{array}{c}0.0005 \mathrm{M} \\
\mathrm{HNO}_{3}\end{array}$ & 1.06 & $1.57 \times 10^{-6}$ & $\begin{array}{c}+0.0001 \mathrm{M} \\
\mathrm{CsNO}_{3} \mathrm{~b}\end{array}$ & 0.0557 & $5.60 \times 10^{-6}$ \\
\hline Strip 4 & $\begin{array}{c}0.0005 \mathrm{M} \\
\mathrm{HNO}_{3}\end{array}$ & 2.41 & $1.11 \times 10^{-6}$ & $\begin{array}{c}+0.0001 \mathrm{M} \\
\mathrm{CsNO}_{3} \mathrm{~b}\end{array}$ & $\mathrm{ND}^{\mathrm{c}}$ & NDC \\
\hline Strip 5 & $\begin{array}{c}0.0005 \mathrm{M} \\
\mathrm{HNO}_{3}\end{array}$ & 5.77 & $9.43 \times 10^{-7}$ & $\begin{array}{c}+0.0001 \mathrm{M} \\
\mathrm{CsNO}_{3} \mathrm{~b}\end{array}$ & $\mathrm{ND}$ & $\mathrm{ND}^{\mathrm{c}}$ \\
\hline
\end{tabular}

a Conditions: Equal volume contacts by vortexing for $30 \mathrm{sec}$ and then end-over-end rotation for $30 \mathrm{~min}$ at $25^{\circ} \mathrm{C}$ (see section 2.2.4.). Solvent was $0.01 \mathrm{M}$ calix[4]arene-bis(t-octylbenzo-crown-6) (BoBCalixC6) and $0.20 \mathrm{M}$ Cs3 modifier in Isopar ${ }^{\circledR} \mathrm{L}$ aliphatic kerosene. Solvent was pre-equilibrated once with equal volume of SRS\#2-1 simulant before test.

b The aqueous phase on stripping contained $0.0005 \mathrm{M} \mathrm{HNO}_{3}$ plus $0.0001 \mathrm{M} \mathrm{CsNO}_{3}$.

c Not determined because of insufficient ${ }^{137} \mathrm{Cs}$ activity remaining.

Since ${ }^{137} \mathrm{Cs}$ activity is rapidly lost from the solvent in such successive contacting, making counting statistics poor by the third or fourth contact, a similar experiment was conducted in which the strip solution itself was spiked with ${ }^{137} \mathrm{Cs}$. This experiment employed simulant SRS\#2-1', which differs slightly from SRS\#2-1 in that minor amounts of $\mathrm{Si}, \mathrm{Fe}, \mathrm{Hg}$, and $\mathrm{Pb}$ were added as described in section 3.2.3 above. Despite the slight differences between simulants SRS\#2-1' and SRS\#2-1, the stripping behavior obtained using SRS\#2-1' was similar to that observed for SRS\#2-1 (Table 3.1 above). Figure 3.1 shows the results. In this case, the first strip contact gave $D_{\mathrm{Cs}}=0.030$, and the next seven contacts had an average value of 0.043 . 


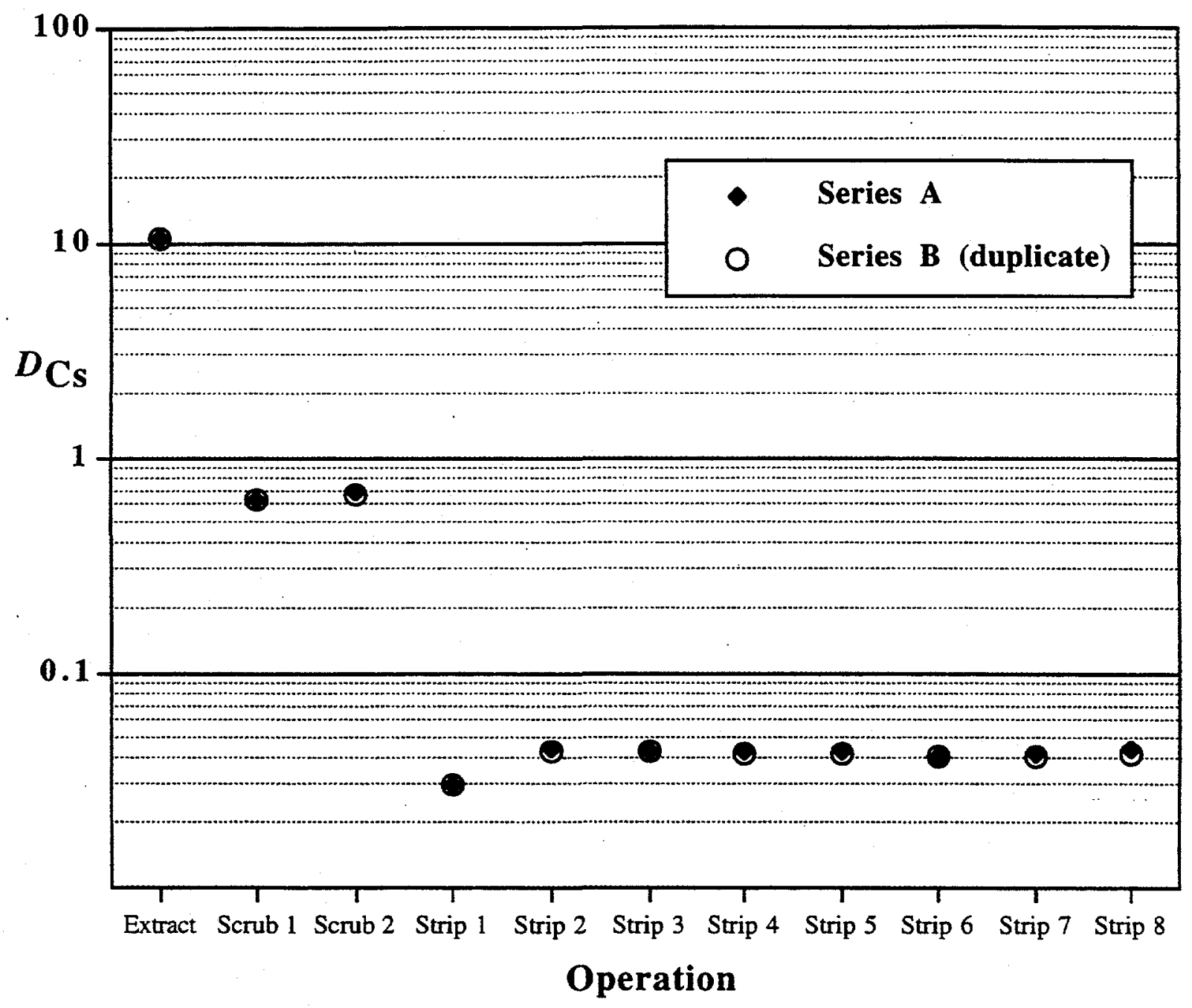

Figure 3.1 Extraction, scrubbing and successive stripping of cesium at $25^{\circ} \mathrm{C}$. Solvent Cs $3 / 120 \mathrm{~L}$ was pre-equilibrated with simulant SRS \#2-1' (see section 3.2.3) containing no ${ }^{137} \mathrm{Cs}$ tracer, then equilibrated once with simulant SRS \#2-1' containing ${ }^{137} \mathrm{Cs}$ tracer. The organic phase was then scrubbed twice with $50 \mathrm{mM} \mathrm{HNO}_{3}$, and stripped eight times with $0.5 \mathrm{mM} \mathrm{HNO}_{3}$ containing $\mathrm{CsNO}_{3}$ at $0.1 \mathrm{mM}$. 
To gain an understanding of the isotherm governing stripping at $25^{\circ} \mathrm{C}$, experiments were conducted in which pristine solvent was equilibrated at a 1:1 phase ratio with aqueous solutions containing varying concentrations of $\mathrm{CsNO}_{3}$ at fixed concentrations of $\mathrm{HNO}_{3}$. Tracer was added to the initial aqueous solution. Since such experiments reflect stripping conditions but reach equilibrium in the forward direction, they are referred to as "forward" stripping experiments in several places in this report. Figure 3.2 shows that plots of $\log D_{\mathrm{Cs}}$ vs. $\log \left[\mathrm{Cs}^{+}\right]_{\mathrm{aq}}$ have a "U" shape with a minimum occurring at an aqueous concentration of cesium roughly equal to $10^{-4} \mathrm{M}$ for almost all concentrations of nitric acid in the aqueous phase. This behavior can be rationalized as described in the theory section. Some differences appear at low concentrations of cesium. Although the discrepancies remain to be resolved, the concentrations of cesium in the organic phase are in a low range $\left(<10^{-7} \mathrm{M}\right)$ where reproducibility is often difficult to achieve. The only exception to the "U" shape is at $50 \mathrm{mM} \mathrm{HNO}$, essentially scrubbing conditions. At this aqueous $\mathrm{HNO}_{3}$ concentration, the quantity of extracted nitrate, though small, is undoubtedly sufficient to ensure that an ion-pair complex formed during the extraction of cesium (see theory section 3.4.2). The distribution ratio $D_{\mathrm{Cs}}$ is thus almost independent of the concentration of cesium. The decrease in $D_{\mathrm{Cs}}$ at high concentrations of cesium indicates the beginning of a loading effect.

We can compare the data obtained with the "forward" stripping method and the ones obtained in the multiple-contact (extraction, scrub, and strip) experiments. Figure 3.3 shows the distribution ratios of cesium obtained either with a "forward" strip, starting from a ${ }^{137} \mathrm{Cs}$-traced strip solution (0.0001 $\mathrm{M} \mathrm{CsNO}_{3}, 0.0005 \mathrm{M} \mathrm{HNO}_{3}$ ), or after a cycle of extraction, scrub, and strip, using ORNL or ANL solvents with ORNL SRS\#2-1 simulant. The minimum of $D_{\mathrm{Cs}}$ obtained in the experiments of "forward" stripping apparently is displaced somewhat to the right when the stripping is performed after extraction and scrub contacts.

\subsubsection{Effect of Trioctyl Amine or Tetraheptyl Ammonium Nitrate in the Solvent}

As discussed below in the theory section, the " $U$ " shape curve can be predicted by modeling of two extraction equilibria, assuming a dissociation of the ion-pair extraction complex takes place in the organic phase. The dissociation occurs as the extraction complex becomes highly dilute. Commonly available trialkylamine or quaternary alkylammonium extractants represent a good source of nitrate to suppress the ion-pair dissociation through a common-ion effect; the added amine extractant might thus be viewed as a sort of "nitrate buffer". By adding a fixed amount of such an extractant, a minimum quantity of nitrate (we will see $10^{-4} \mathrm{M}$ is probably sufficient) is ensured in the organic phase. Note that trialkylamines will be converted to the trialkylammonium nitrate form upon contact with dilute $\mathrm{HNO}_{3}$ solutions. If the trialkyl or quaternary ammonium extractant has 24 or more aliphatic carbon atoms, it should be highly lipophilic and should partition 


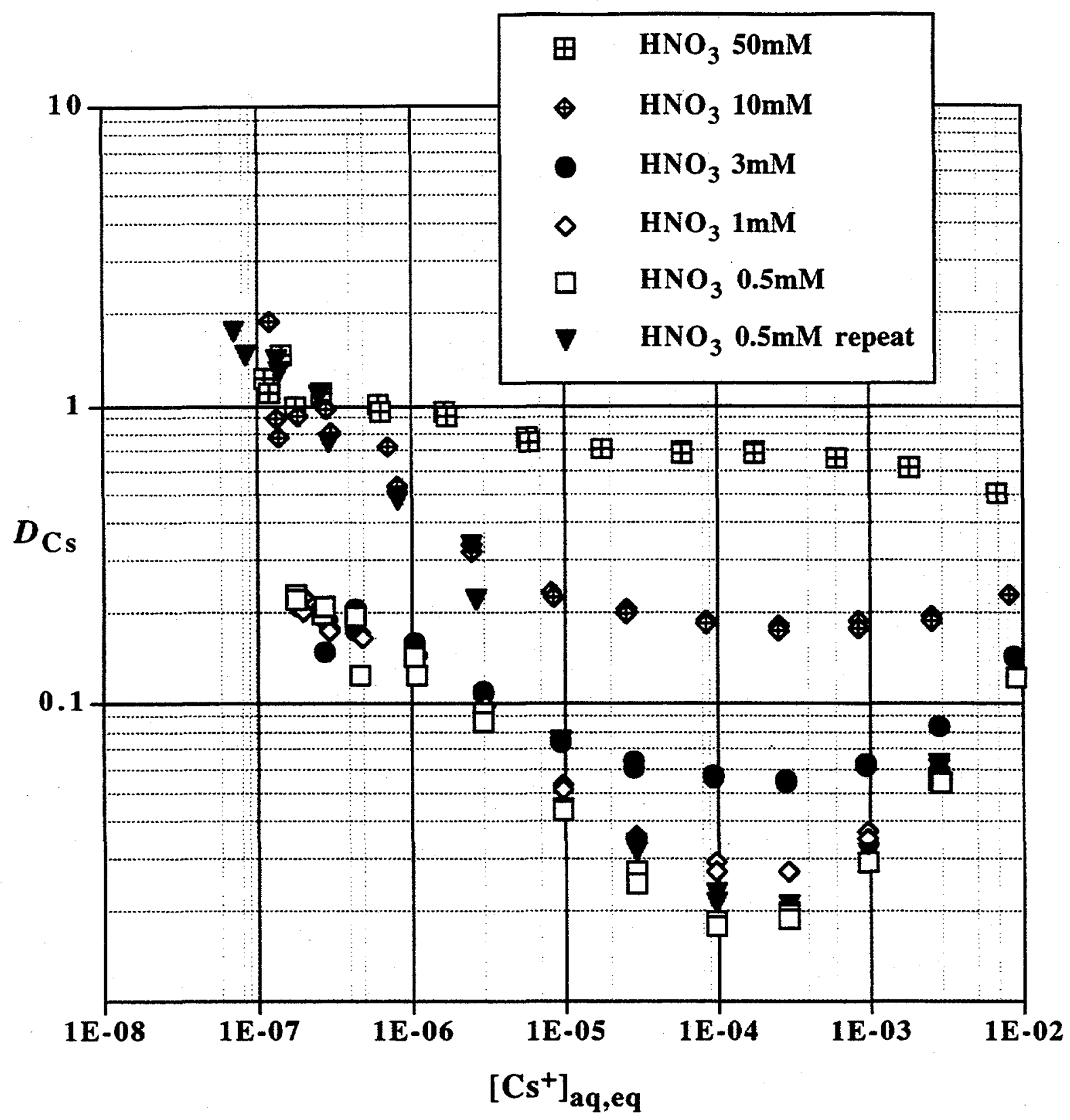

Figure 3.2 Distribution behavior of cesium nitrate as a function of cesium nitrate concentration at various dilute nitric acid concentrations at $25^{\circ} \mathrm{C}$. Organic phase: Solvent Cs3C/120L-2. Aqueous phase: $\mathrm{HNO}_{3}$ and $\mathrm{CsNO}_{3}$ at variable concentrations (see legend). Solvent for the experiments at $0.5 \mathrm{mM}, 1 \mathrm{mM}$, and $3 \mathrm{mM}$ nitric acid was preequilibrated with these acid solutions (no cesium). 


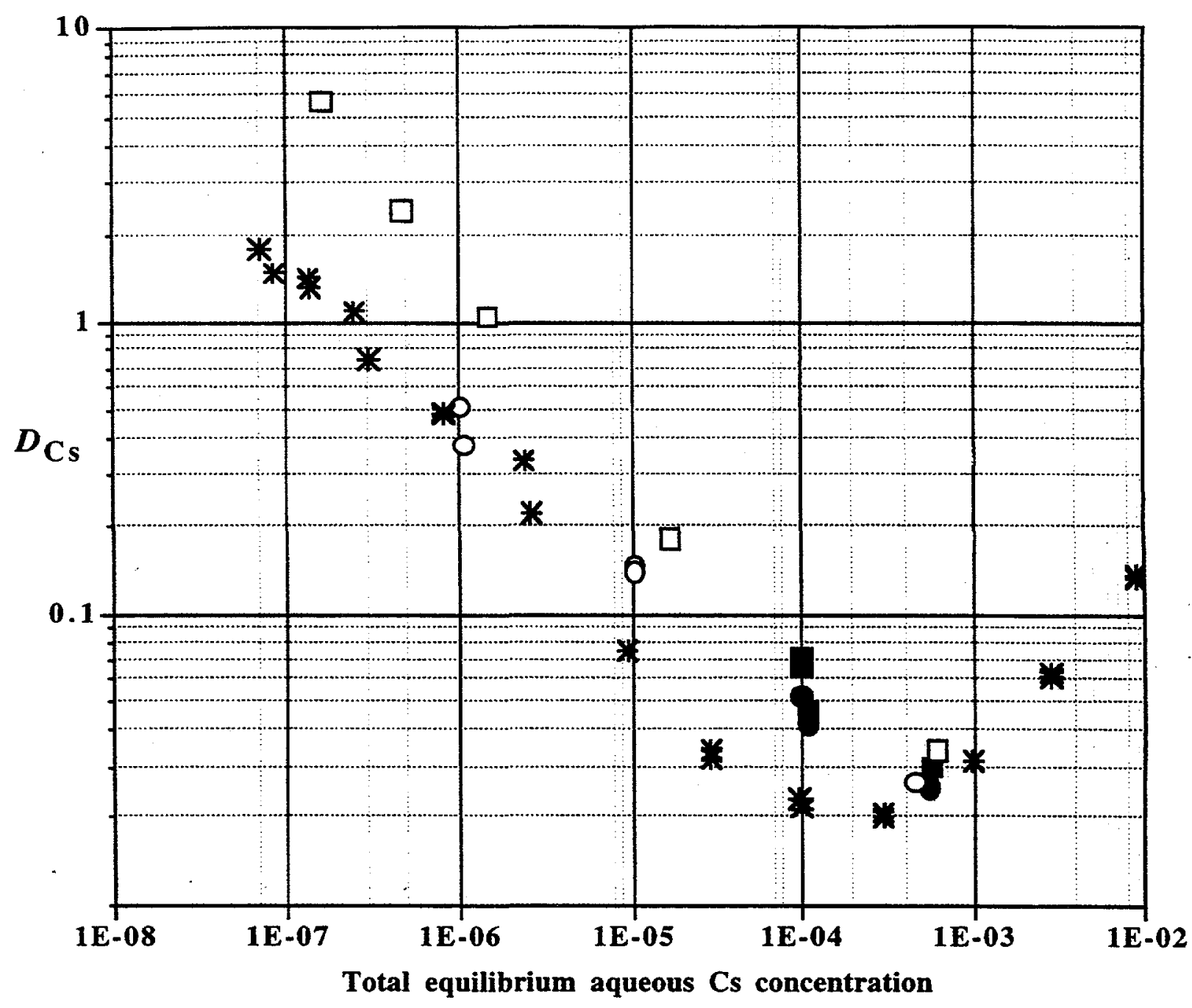

\begin{tabular}{|ll|}
\hline$*$ & ORNL Cs3C/120L-2; Forward strip \\
$\square$ & ORNL Cs3C/120L-2; SRS\#2-1 Sim; Strips w/o Cs \\
$\square$ & ORNL Cs3/120L-2; SRS\#2-1 Sim; Strips w/Cs \\
O & ANL Cs3B/120L; SRS\#2-1 Sim; Strips w/o Cs \\
$\bullet$ & ANL Cs3B/120L; SRS\#2-1 Sim; Strips w/Cs \\
\hline
\end{tabular}

Figure 3.3. Distribution behavior of cesium as a function of cesium nitrate concentration at $0.5 \mathrm{mM}$ nitric acid at $25{ }^{\circ} \mathrm{C}$. These experiments can be divided into two categories: 1) $D_{\mathrm{Cs}}$ forward strip where the cesium is originally in the aqueous phase; and 2) $D_{\mathrm{Cs}}$ values on stripping after extraction (ORNL simulant SRS \#2-1) and scrub contacts (50 mM nitric acid) using a) ORNL pristine Cs3C/120L-2 solvent or b) ANL pristine Cs3B/120L-ANL solvent, with and without cesium at 0.1 $\mathrm{mM}$ in the $0.5 \mathrm{mM}$ nitric acid strip solution. 
negligibly to the aqueous phase. Trioctyl, triisooctyl, tridecyl, triisodecyl, tridodecyl, and triisotridecyl amines are typical amines that function in approximately the same manner; Alamine ${ }^{\circledR}$ 336 is a commercial form having mixed linear $\mathrm{C}_{8}, \mathrm{C}_{10}$ chains. Tetraheptylammonium nitrate is a typical quaternary ammonium nitrate extractant; Aliquat ${ }^{\circledR} 336$ is Alamine ${ }^{\circledR} 336$ quaternized by methylation.

Figures 3.4 and 3.5 show the influence of tetraheptyl ammonium nitrate and trioctylamine (TOA) as adjuvants to the solvent. Figure 3.4 is plotted as a standard isotherm, while Fig. 3.5 shows the same data converted to a plot of $\log D_{\mathrm{Cs}}$ vs. $\log [\mathrm{Cs}]_{\mathrm{aq} \text {,eq }}$. Although their concentrations are small, both (ammonium) compounds produce dramatic and identical effects. At $1 \times 10^{-4} \mathrm{M}$, both tetraheptyl ammonium (nitrate) and trioctylammonium (nitrate) cause the data to fall into a straight line with slope $=1$ for the isotherm (Figure 3.4) and a straight horizontal line with slope = 0 for the $\log D_{\mathrm{Cs}}$ plot (Figure 3.5). In the theory section, it is shown that the lines correspond to the behavior of the ion-paired complex. It may be seen from the plots that a concentration of $10^{-6}$ $M$ of either ammonium compound is nearly sufficient to produce the effect, while straight-line behavior is reached at $10^{-5} \mathrm{M}$.

One of the major advantages of the amine adjuvants is that they can nullify the effect of anionic impurities. This was a point emphasized by the ANL group. It was therefore beneficial to demonstrate this effect with a model anion, didodecylnaphthalene sulfonate. In its acid form, this extractant (HDDNS) is a much studied anion exchanger. Mixed with a crown ether; HDDNS acts in a synergistic fashion to greatly enhance the distribution ratio of extracted metal ions, as reported extensively in the literature [16]. Figure 3.6 shows how well cesium can be extracted by addition of HDDNS to the regular solvent. It may be seen that HDDNS produces a dramatic enhancement of $D_{\mathrm{Cs}}$. Even at $10^{-4} \mathrm{M}$, this extractant raises $D_{\mathrm{Cs}}$ to a value of 9 under our usual "forward" stripping conditions. However, as expected, this effect is neatly suppressed when TOA is added to the solvent at a concentration comparable with that of HDDNS.

In view of the favorable results obtained in the "forward" strip experiments with TOA as a solvent adjuvant, a cycle of extraction, scrubbing, and stripping was performed. The cycle was intended to demonstrate more realistic O/A ratios, the avoidance of addition of $\mathrm{CsNO}_{3}$ to the strip solution, the use of a somewhat higher $\mathrm{HNO}_{3}$ concentration in stripping (which would be preferred for better process control), and overall better performance than we have obtained with the usual flowsheet. As such, the test was a prototype of an improved flowsheet employing TOA, and the results, shown in Table 3.2, were excellent. Because of the different O/A ratios, the results are not directly comparable with previous experiments using 1:1 O/A ratios. However, since the $D_{\mathrm{Cs}}$ values in the table below reflect the increased loading on extraction; the first extraction is essentially the same as obtained on the second extraction shown in Table 3.1. Scrubbing is essentially within 


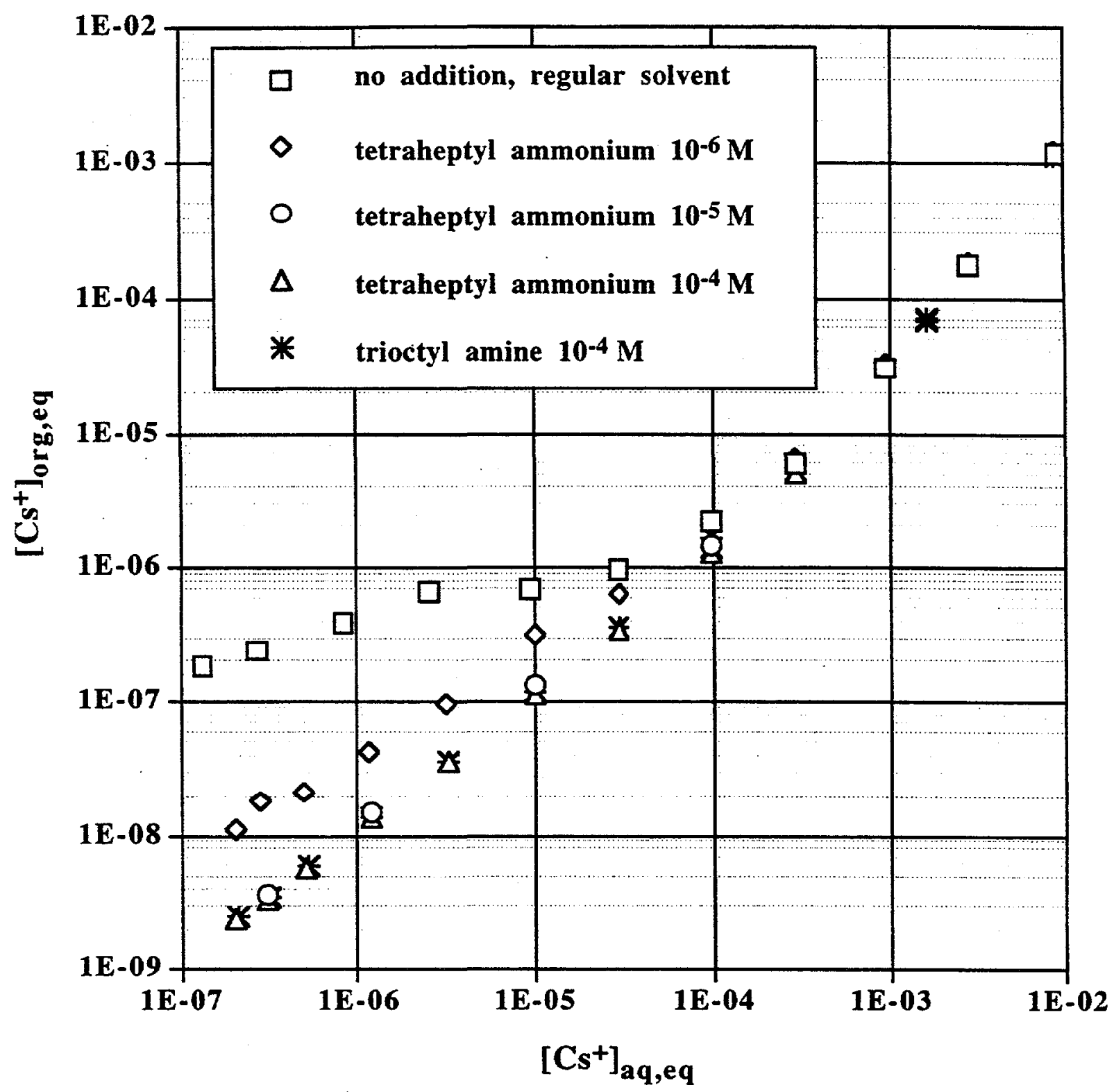

Figure 3.4. Cesium nitrate concentration in the organic phase as a function of cesium nitrate concentration in a $0.5 \mathrm{mM}$ nitric acid aqueous phase for extraction by $\mathrm{Cs} 3 \mathrm{C} / 120 \mathrm{~L}-2$ solvent alone, or containing trioctyl amine at $0.1 \mathrm{mM}$, or tetraheptyl ammonium nitrate at various concentrations, at $25{ }^{\circ} \mathrm{C}$. 


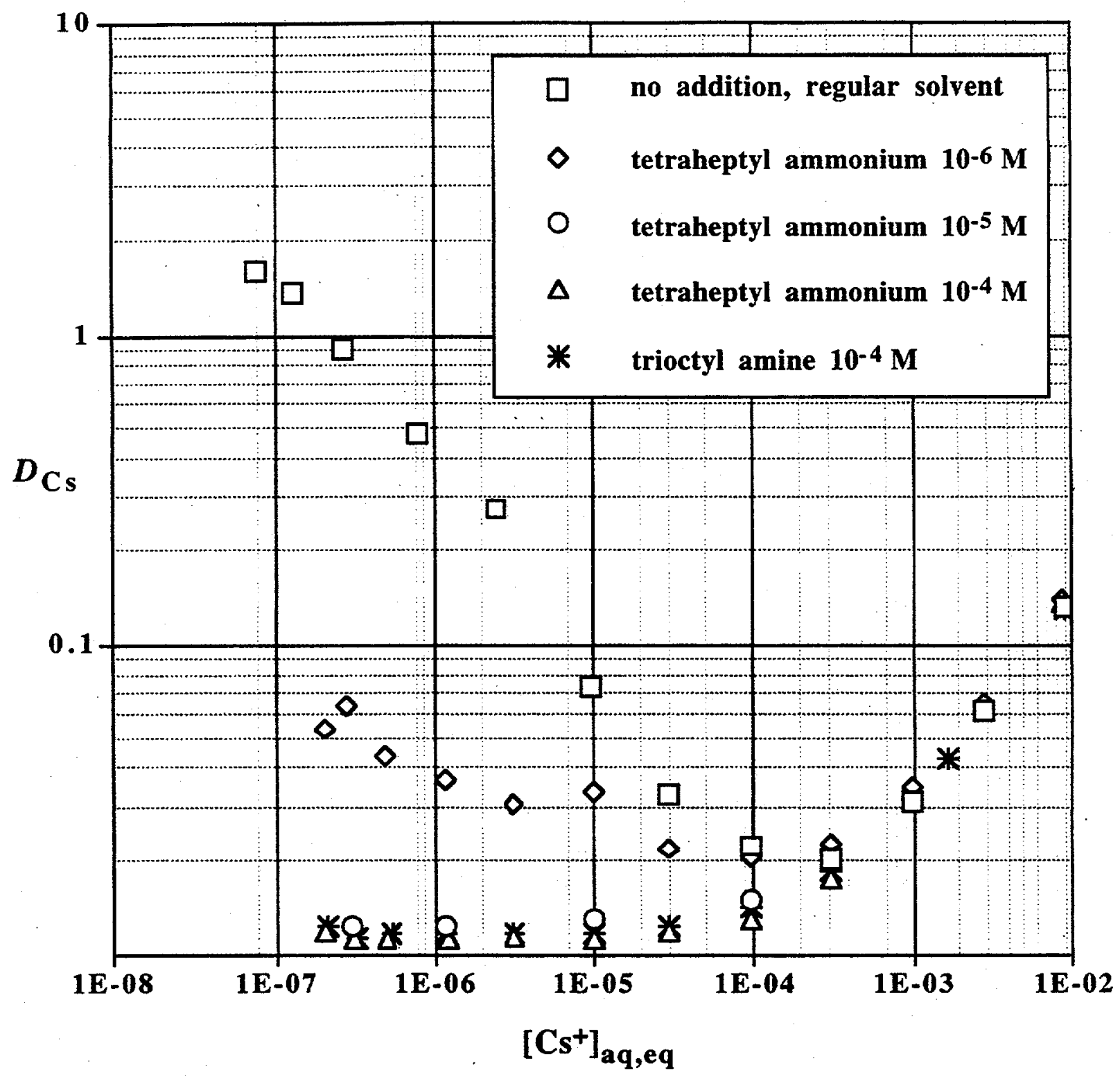

Figure 3.5. Distribution behavior of cesium nitrate as a function of cesium nitrate concentration in the aqueous phase at $25{ }^{\circ} \mathrm{C}$. Addition of tetraheptyl ammonium nitrate or trioctyl amine to the solvent, as per Figure 3.). 


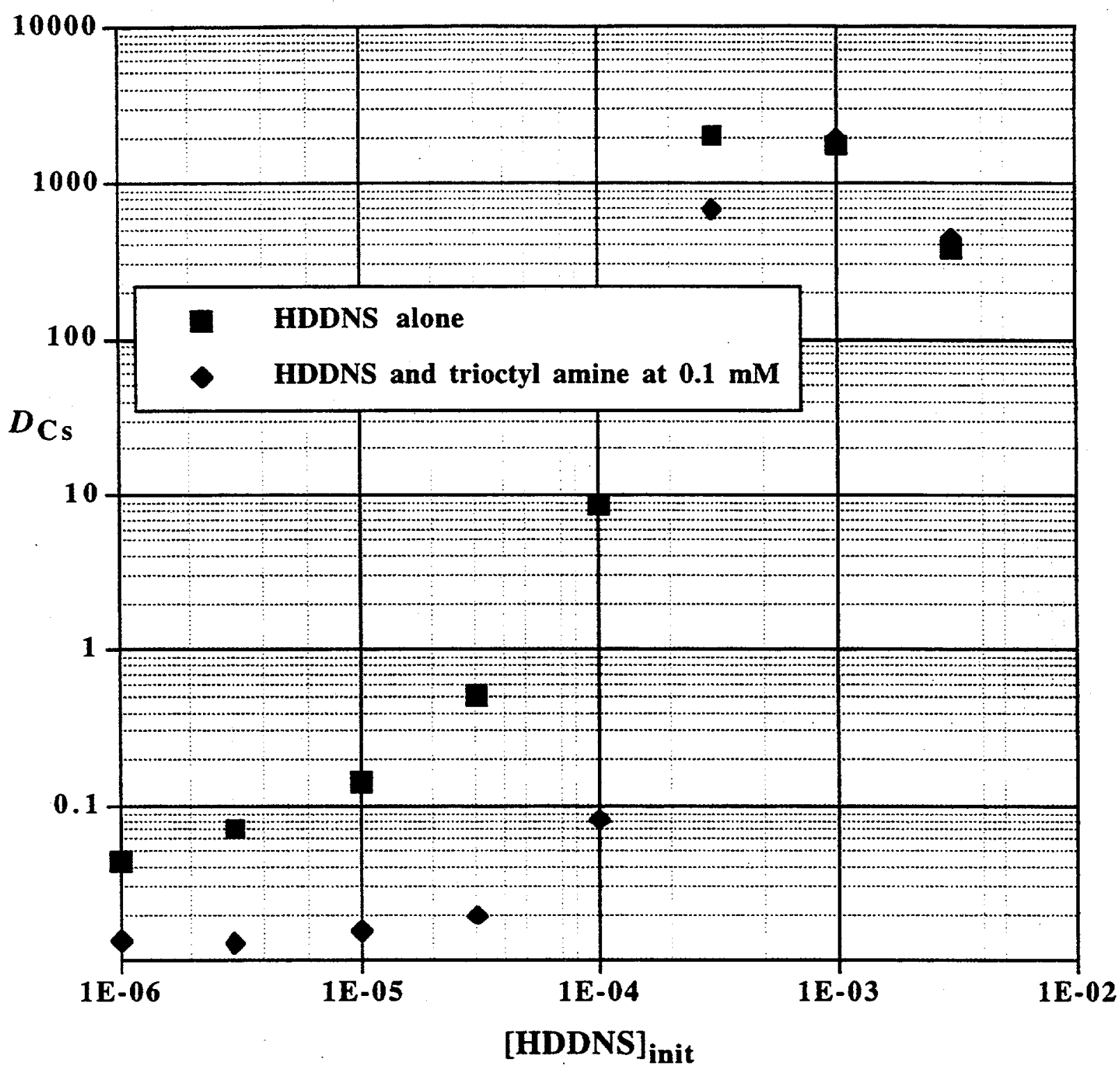

Figure 3.6. Distribution behavior of cesium nitrate as a function of HDDNS concentration in the solvent, with and without trioctyl amine added at $0.1 \mathrm{mM}$, at $25{ }^{\circ} \mathrm{C}$. Aqueous phase: cesium nitrate at $0.1 \mathrm{mM}$ with nitric acid at $0.5 \mathrm{mM}$, plus Cs-137 tracer. Organic phase: solvent Cs3D/120L-2. 
the usual range $0.6-0.8$, with allowance for extra loading. Thus, the TOA has no effect on extraction and scrubbing of cesium. On stripping, behavior much like that which would be predicted from Fig. 3.5 is obtained, in which one moves from right to left on the plot, with corresponding decreases in $D_{\mathrm{Cs}}$. The Fig. 3.5 suggests that $D_{\mathrm{Cs}}$ on continued stripping past the third contact would continue to fall to approximately 0.02 .

Table 3.2. Batch tests of extraction, scrubbing, and stripping contacts at $25{ }^{\circ} \mathrm{C}$ with cesium, after adding trioctylamine to the solvent. ${ }^{a}$

\begin{tabular}{|c|c|c|c|c|}
\hline Operation & $D_{\text {Cs }}$ & $D_{\text {Cs }}$ duplicate & O/A ratio & Avg. [Cs] $]_{\text {org }}$ \\
\hline Extraction \#1 & 10.6 & 10.2 & 0.5 & $1.18 \times 10^{-3}$ \\
\hline Extraction \#2 & 8.64 & 8.97 & 0.5 & $2.10 \times 10^{-3}$ \\
\hline Scrub \#1 & 0.579 & 0.579 & 5 & $1.56 \times 10^{-3}$ \\
\hline Scrub \#2 & 0.636 & 0.654 & 5 & $1.19 \times 10^{-3}$ \\
\hline Strip\#1 & 0.0935 & 0.0917 & 3 & $2.59 \times 10^{-4}$ \\
\hline Strip\#2 & 0.0536 & 0.0603 & 3 & $3.77 \times 10^{-5}$ \\
\hline Strip\#3 & 0.0440 & 0.0424 & 3 & $4.32 \times 10^{-6}$ \\
\hline
\end{tabular}

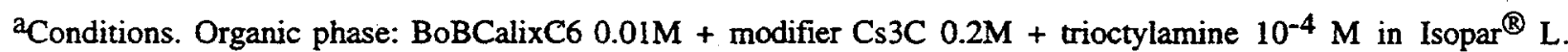
Aqueous phases: ORNL simulant SRS \#2-1 for the extractions, $50 \mathrm{mM}$ nitric acid for the scrubs, $2 \mathrm{mM}$ nitric acid for the stripping. Contacts were run at $25^{\circ} \mathrm{C}$.

\subsubsection{Kinetics and Effect of Temperature on Stripping Performance}

As mentioned above, stripping has been considered a critical aspect of process performance and has received particular attention after the test conducted at Argonne on July 22, 1998. Several issues raised as a result of that test and continuing interaction with ANL and SRS have been addressed. Accordingly, one necessary experiment to perform involved checking whether the system studied was actually at equilibrium. Kinetics tests were therefore performed, first at $25{ }^{\circ} \mathrm{C}$, then at two other temperatures $\left(34^{\circ} \mathrm{C}\right.$ and $\left.43{ }^{\circ} \mathrm{C}\right)$, to determine the time required for the system to reach equilibrium, and to determine if this time was temperature dependent.

Figure 3.7 shows that kinetics of stripping is very fast. Vortexing for 15 seconds is sufficient to be within $10 \%$ of the distribution ratio value at equilibrium. This experiment proves that contacts in centrifugal contactors, where the efficiency is greater than with a regular vortex device, should give a system close to equilibrium. Hence, kinetics issues do not appear to have a particular role in the contactor tests at ANL, in agreement with both batch and stage-efficiency 
results at ANL. In addition, within the large uncertainty at short times for the three temperatures, the distribution ratios reach their equilibrium values for the same vortexing time (see Fig. 3.8). The main difference is thermodynamic: the lower the temperature, the higher the distribution ratios. The apparent exothermic property of this extraction system should be kept in mind, in case process control based on temperature is desired. According to the data shown in Fig. 3.8, the $D_{\mathrm{Cs}}$ value in stripping can potentially be decreased a factor of 1.7 by raising the temperature from $25^{\circ} \mathrm{C}$ to 43 ${ }^{\circ} \mathrm{C}$.

\subsection{THEORY AND DISCUSSION}

\subsubsection{Extraction and Stripping Mechanism}

The extraction mechanism of the new cesium-selective extractants from the calix[4]arenecrown- 6 family has recently been explored by collaborating European investigators [2-12] and conforms well to what is known about the extraction chemistry of crown ethers in general [14]. We recently extended this understanding to BoBCalixC6 itself in 1,2-dichloroethane, looking for evidence that two $\mathrm{Cs}^{+}$ions could simultaneously occupy the two crown-ether binding sites in BoBCalixC6, and obtaining information on the role of the nitrate anion [13]. Overall, it was found that binding of the second $\mathrm{Cs}^{+}$ion is weak and can only be expected under strongly loading conditions. In the alkaline-side CSEX process, the condition of high loading is not approached, and thus, only 1:1 Cs:calix complexes need be considered here. Our work, and that of the Europeans, indicate that two 1:1 organic-phase $\mathrm{Cs}^{+}$complexes are formed, $\mathrm{CsBNO}_{3}$ and $\mathrm{CsB}^{+}$, where $\mathrm{B}$ is the calixarene. In both complexes, the $\mathrm{Cs}^{+}$ion is bound inside the calixarene to give a cationic complex. This may be ion-paired with nitrate ion to give $\mathrm{CsBNO}_{3}$, or this ion-pair may be dissociated to give the free ions $\mathrm{CsB}^{+}$and $\mathrm{NO}_{3}{ }^{-}$. The extraction processes may be represented accordingly:

$$
\begin{array}{ll}
\mathrm{Cs}^{+}(\mathrm{aq})+\mathrm{NO}_{3}^{-}(\mathrm{aq})+\mathrm{B} \text { (org) } \rightleftharpoons \mathrm{CsBNO}_{3} \text { (org) } & K_{\mathrm{ex}} \\
\mathrm{Cs}^{+}(\mathrm{aq})+\mathrm{NO}_{3}^{-}(\mathrm{aq})+\mathrm{B} \text { (org) } \rightleftharpoons \mathrm{CsB}^{+}(\mathrm{org})+\mathrm{NO}_{3}^{-} \text {(org) } & K_{\mathrm{ex} \pm}
\end{array}
$$




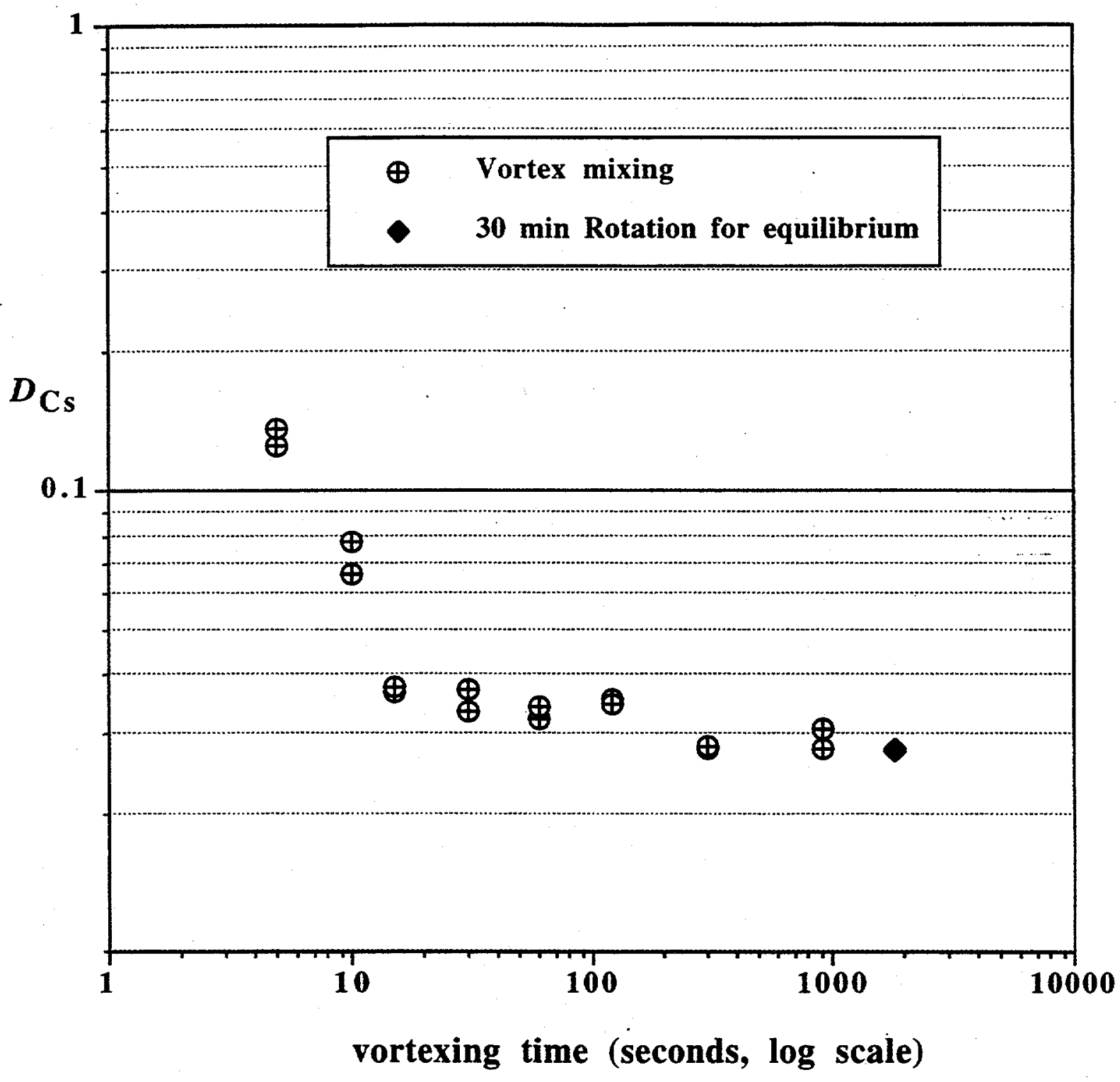

Figure 3.7. Kinetics of cesium stripping at $25^{\circ} \mathrm{C}$. Solvent Cs3C/120L-2 was first pre-equilibrated with simulant without tracer, then equilibrated with simulant containing tracer, and finally scrubbed with $50 \mathrm{mM}$ nitric acid. Stripping $(0.1 \mathrm{mM}$ cesium nitrate in $0.5 \mathrm{mM}$ nitric acid) was then performed by vortex mixing, with a 30 minute equilibrium contact obtained using the Glass-Col rotator. 


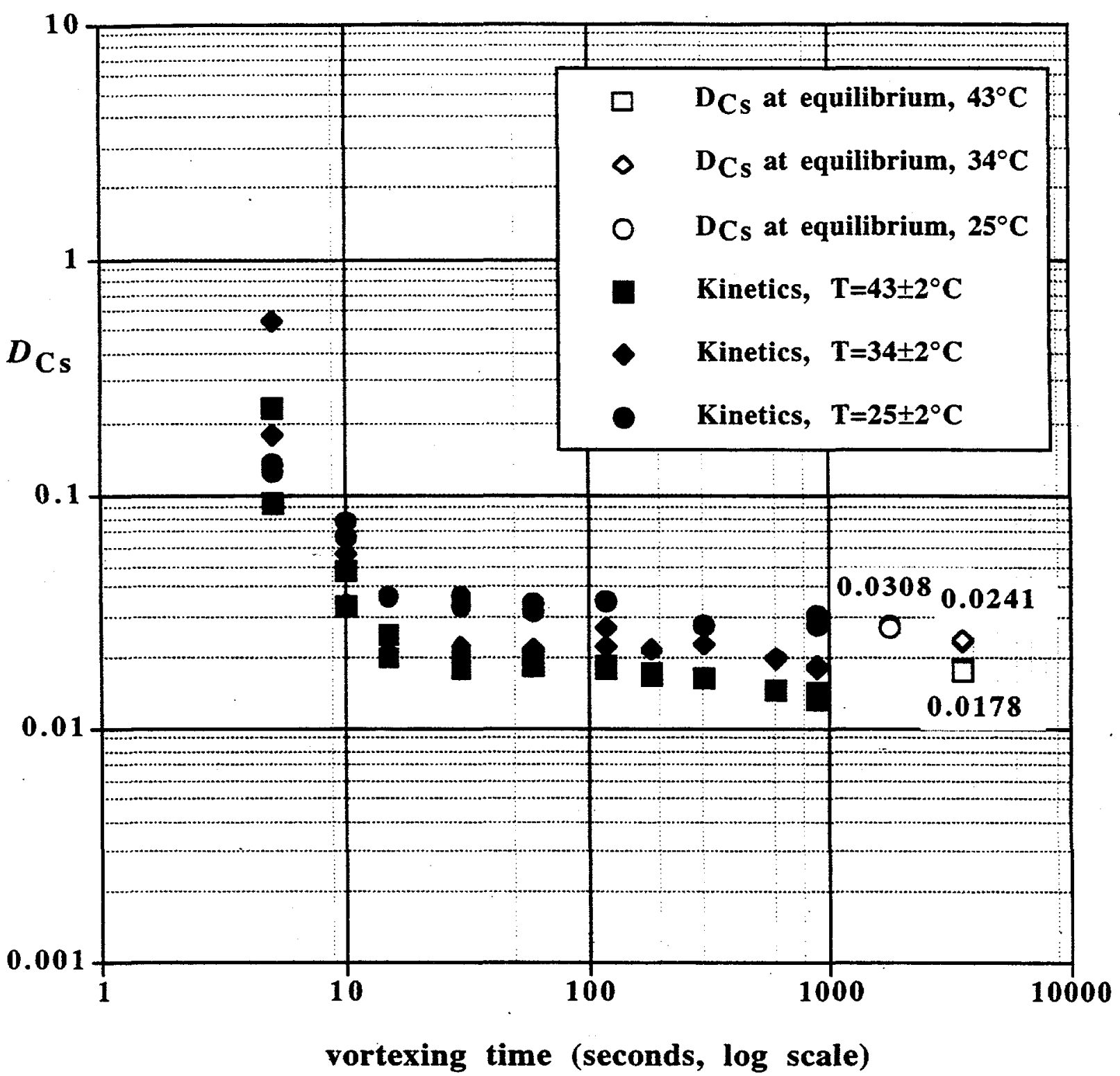

Figure 3.8. Kinetics of cesium stripping from solvent $\mathrm{Cs} 3 \mathrm{C} / 120 \mathrm{~L}-2$ at various temperatures. Solvent was first pre-equilibrated with simulant without tracer, then equilibrated with simulant containing tracer, and finally scrubbed with $50 \mathrm{mM}$ nitric acid. Stripping was then performed with a solution of $0.1 \mathrm{mM}$ cesium nitrate in $0.5 \mathrm{mM}$ nitric acid. The $25^{\circ} \mathrm{C}$ experiment was performed in an air box; the $34{ }^{\circ} \mathrm{C}$ and $43{ }^{\circ} \mathrm{C}$ experiments were performed in an incubator. Owing to temperature fluctuations, the data points in the range 120-1800 seconds for $34^{\circ} \mathrm{C}$ and $43^{\circ} \mathrm{C}$ drifted to increasingly warmer temperatures, giving decreasing cesium distribution ratio values. Under stable temperatures, the open points were obtained. 
Under ordinary experimental conditions in the laboratory, nonpolar diluents such as alkanes, aromatic hydrocarbons, and low-polarity halocarbons (e.g., chloroform) give behavior that conforms to practically complete ion pairing (eq. 1) $[14,15]$. Polar diluents such as nitrobenzene give behavior that conforms to organic-phase ionic species (eq. 2). Partial ionpairing occurs with diluents like 1,2-dichloroethane having intermediate dielectric constants in the approximate range of 5-20. Since the diluent used in the alkaline-side CSEX process is an aliphatic hydrocarbon with only a moderate concentration of modifier, it was at first expected that extraction and stripping would obey eq. 1. To derive the expected isotherm, it is first necessary to write the equilibrium expression corresponding to eq. 1 and convert it to an expression relating the organic-phase $\mathrm{Cs}$ concentration $[\mathrm{Cs}]_{\text {org }}$ to the aqueous-phase $\mathrm{Cs}$ concentration $[\mathrm{Cs}]_{\mathrm{aq}}$ Accordingly, the corresponding equilibrium constant is defined, where overbars indicate organicphase species:

$$
K_{\mathrm{ex}}\left(\overline{\mathrm{CsBNO}}{ }_{3}\right)=\frac{\bar{y}_{\mathrm{CsBNO}_{3}}\left[\overline{\mathrm{CsBNO}_{3}}\right]}{y_{\mathrm{Cs}}\left[\mathrm{Cs}^{+}\right] y_{\mathrm{NO}_{3}}\left[\mathrm{NO}_{3}^{-}\right] \bar{y}_{\mathrm{B}}[\overline{\mathrm{B}}]}
$$

Under conditions where the extraction defined by eq. 1 predominates, the expected isotherm may be obtained by taking the logarithm of both sides of eq. 3, rearranging, setting [Cs $]_{\text {org }}=$ $[\mathrm{CsBNO}]_{\text {org }}$, and setting $[\mathrm{Cs}]_{\mathrm{aq}}=\left[\mathrm{Cs}^{+}\right]_{\mathrm{aq}}$ :

$$
\log [\mathrm{Cs}]_{\text {org }}=\log [\mathrm{Cs}]_{\mathrm{aq}}+\log \left[\mathrm{NO}_{3}{ }^{-}\right]_{\mathrm{aq}}+\log [\mathrm{B}]_{\mathrm{org}}+\log K_{\mathrm{ex}}+\log \Gamma
$$

Here, $\Gamma$ is the quotient of activity coefficients from eq. 3 . Since $D_{\mathrm{Cs}}=[\mathrm{Cs}]_{\mathrm{org}} /[\mathrm{Cs}]_{\mathrm{aq}}$, eq. 4 becomes:

$$
\log D_{\mathrm{Cs}}=\log \left[\mathrm{NO}_{3}{ }^{-}\right]_{\mathrm{aq}}+\log [\mathrm{B}]_{\mathrm{org}}+\log K_{\mathrm{ex}}+\log \Gamma
$$

In subsequent qualitative discussion, we will treat $\Gamma$ as an approximate constant, recognizing that for modeling and quantitative equilibrium computations $\Gamma$ is not a constant and must be calculated using an appropriate aqueous treatment of ionic activity coefficients.

The isotherm based on eq. 4 at constant aqueous nitrate concentration $\left[\mathrm{NO}_{3}{ }^{-}\right]_{\text {aq }}$ gives a slope of 1 for plots of $\log [\mathrm{Cs}]_{\text {org }}$ vs. $\log [\mathrm{Cs}]_{\text {aq }}$. According to eq. $5, \log D_{\mathrm{Cs}}$ should therefore be a constant. It is obvious that the aqueous nitrate concentration should be kept low to obtain a low value of $D_{\mathrm{Cs}}$ for stripping. We considered that for process purposes, a reasonable value for the aqueous $\mathrm{HNO}_{3}$ concentration in the strip solution is approximately $0.001 \mathrm{M}$, or perhaps as low as $0.0005 \mathrm{M}$. (This would require that the scrub solution be at least an order of magnitude higher in $\mathrm{HNO}_{3}$ concentration to guard against process upset in case caustic from the waste feed is entrained in the solvent exiting the extraction section.) Setting the aqueous $\mathrm{HNO}_{3}$ concentration at $0.0005 \mathrm{M}$ 
in the process, the aqueous nitrate concentration will begin to increase significantly as aqueous $\mathrm{CsNO}_{3}$ concentrations increase above approximately $0.0001 \mathrm{M}$, and correspondingly $\log D_{\mathrm{Cs}}$ then increases with approximate unit slope with respect to the value of $\log \left[\mathrm{NO}_{3}^{-}\right]_{\mathrm{aq}}$. According to this analysis, the plot of $\log D_{\mathrm{Cs}}$ vs. $\log [\mathrm{Cs}]_{\text {aq }}$ should be flat up to approximately $0.0001 \mathrm{M}$ aqueous $\mathrm{CsNO}_{3}$ whereupon it increases with unit slope. In the process, the solvent could typically contain $0.0035 \mathrm{M}$ Cs. Stripping behavior at an O/A ratio of 3 would then be expected to exhibit decreasing values of $D_{C s}$ in the first few stages followed by constant $D_{\mathrm{Cs}}$ in all of the later strip stages.

Unfortunately, this expected stripping behavior was not borne out. Table 3.1 shows that on successive stripping, $D_{\mathrm{Cs}}$ values do not decrease and then level off, but rather $D_{\mathrm{Cs}}$ starts at a very good value of 0.034 on the first strip contact and rises in each strip contact thereafter, eventually exceeding 5 . The same behavior was seen in "forward" strip experiments in which fresh solvent was contacted with aqueous solutions containing $\mathrm{HNO}_{3}$ and varying $\mathrm{CsNO}_{3}$ concentrations plus ${ }^{137} \mathrm{Cs}$ tracer. Such plots are shown in Figs. 3.2 and 3.3. Over a sufficiently wide range of aqueous $\mathrm{HNO}_{3}$ concentrations, plots of $\log D_{\mathrm{Cs}}$ vs. $\log [\mathrm{Cs}]_{\text {aq }}$ may be seen to have a " $\mathrm{U}$ " shape, where $\log D_{\mathrm{Cs}}$ decreases with decreasing $\log [\mathrm{Cs}]_{\mathrm{aq}}$, reaches a minimum in the range $\log [\mathrm{Cs}]_{\mathrm{aq}}=0.0001-0.0005 \mathrm{M}$, and then rises.

Such behavior may suggest the possible presence of an impurity in the system that ends up in the solvent and in some manner retains the Cs. Such an impurity could in principle be a highly lipophilic anion, as suggested by ANL. Although we consider this to be likely in solvents that have been contacted with simulant or waste, or that have been degraded, it did not seem to be an adequate hypothesis for fresh solvent used in "forward" experiments such as shown in Figs. 3.2 and 3.3, because the " $U$ " shape persisted over several batches of calixarene and modifier (albeit with some scatter at $[\mathrm{Cs}]_{\mathrm{aq}}<10^{-5} \mathrm{M}$ ).

Instead, prior experience [13] with systems featuring anion dissociation as given in eq. 2 suggested another explanation in which the extraction mechanism is hypothesized to undergo a transition from predominantly ion-paired complexes $\mathrm{CsBNO}_{3}$ (eq. 1) to predominantly dissociated ions $\mathrm{CsB}^{+}$and $\mathrm{NO}_{3}{ }^{-}$(eq. 2) in the solvent. By analogy to eqs. $3-5$, the following relationships may be written to describe the expected stripping behavior under conditions in which eq. 2 represents the effective extraction mechanism:

$$
K_{\mathrm{ex \pm}}\left(\overline{\mathrm{CsB}^{+}}+\overline{\mathrm{NO}_{3}^{-}}\right)=\frac{\bar{y}_{\mathrm{CsB}}\left[\overline{\left.\mathrm{CsB}^{+}\right]} \bar{y}_{\mathrm{NO}_{3}}\left[\overline{\mathrm{NO}_{3}^{-}}\right]\right.}{y_{\mathrm{Cs}}\left[\mathrm{Cs}^{+}\right] \mathrm{y}_{\mathrm{NO}_{3}}\left[\mathrm{NO}_{3}^{-}\right] \bar{y}_{\mathrm{B}}[\overline{\mathrm{B}}]}
$$

Setting $\left[\mathrm{CsB}^{+}\right]_{\text {org }}=\left[\mathrm{NO}_{3}{ }^{-}\right]_{\text {org }}$ gives:

$$
\log [\mathrm{Cs}]_{\mathrm{org}}=1 / 2 \log [\mathrm{Cs}]_{\mathrm{aq}}+1 / 2 \log \left[\mathrm{NO}_{3}{ }^{-}\right]_{\mathrm{aq}}+1 / 2 \log [\mathrm{B}]_{\text {org }}+1 / 2 \log K_{\mathrm{ex}}+1 / 2 \log \Gamma
$$

and 


$$
\log D_{\mathrm{Cs}}=-1 / 2 \log [\mathrm{Cs}]_{\mathrm{aq}}+1 / 2 \log \left[\mathrm{NO}_{3}{ }^{-}\right]_{\mathrm{aq}}+1 / 2 \log [\mathrm{B}]_{\mathrm{org}}+1 / 2 \log K_{\mathrm{ex}}+1 / 2 \log \Gamma
$$

Equation 8 predicts that the dependence of $\log D_{\mathrm{Cs}}$ on $\log [\mathrm{Cs}]_{\mathrm{aq}}$ should have a slope of $-1 / 2$, and this is approximately what is observed (Figs. 3.4 and 3.5).

To increase our confidence in the correctness of the explanation of the isotherm, we modeled the observed curves at different aqueous $\mathrm{HNO}_{3}$ concentrations by computer based on eqs. 1 and 2. The computer program employed, SXLSQI, was written at ORNL by C. F. Baes, Jr., and takes into account activity coefficients of species in both aqueous and organic phases [17-19]. In the modeling, the only adjustable parameters included $\log K_{\mathrm{ex}}$ and $\log K_{\mathrm{ex}}$, corresponding to the assumed species $\mathrm{CsCalixNO}{ }_{3}, \mathrm{CsCalix}^{+}$, and $\mathrm{NO}_{3}{ }^{-}$. The results are shown in Fig. 3.9. Given the unknown degree of extraction of $\mathrm{HNO}_{3}$, each curve was fit separately. It may be seen that the observed data are modeled reasonably well by the equilibria defined in eqs. 1 and 2 . The value of $\log K_{\text {ex }}$ was, however, consistent overall at 3.2, whereas the value of $\log K_{\text {ex }}$ decreased as the aqueous nitric acid concentration increased. This makes sense if some $\mathrm{HNO}_{3}$ extraction occurs and by a common-ion effect displaces eq. 2 to the left, in other words by suppressing the dissociation of the ion-pair $\mathrm{CsBNO}_{3}$. Obviously, it will be desirable to pursue a chemical model in more detail for greater understanding as well as input for more sophisticated flowsheet design.

\subsubsection{Theory of Ion-Pair Dissociation}

The explanation based on eqs. 1 and 2 thus accounts for the data reasonably well, and it may also be argued that it is also physically reasonable. The dissociation of the ion-pair $\mathrm{CsBNO}_{3}$ in the solvent may be written:

$$
\mathrm{CsBNO}_{3} \text { (org) } \rightleftharpoons \mathrm{CsB}^{+} \text {(org) }+\mathrm{NO}_{3}^{-} \text {(org) } \quad K_{\text {diss }}
$$

This reaction is obtained by subtraction of eq. 1 from eq. 2 , whence

$$
K_{\text {diss }}=K_{\text {ext }} / K_{\text {ex }}
$$

The equilibrium and mass-balance expressions corresponding to the dissociation process in eq. 9 are given as:

$$
\begin{aligned}
& K_{\text {diss }}=\left[\mathrm{CsB}^{+}\right]_{\text {org }}\left[\mathrm{NO}_{3}{ }^{-}\right]_{\text {org }}\left[\mathrm{CsBNO}_{3}\right]_{\text {org }} \\
& {[\mathrm{Cs}]_{\text {org,tot }}=\left[\mathrm{CsB}^{+}\right]_{\text {org }}+\left[\mathrm{CsBNO}_{3}\right]_{\text {org }}}
\end{aligned}
$$


Noting that $\left[\mathrm{CsB}^{+}\right]_{\text {org }}=\left[\mathrm{NO}_{3}{ }^{-}\right]_{\text {org }}$, the total organic-phase Cs concentration at which half of the ion pairs $\mathrm{CsBNO}_{3}$ have dissociated ([Cs] $]_{\text {org,tot, } 1 / 2}$ ) may be found from eqs. 11 and 12 to be simply:

$$
[\mathrm{Cs}]_{\mathrm{org}, \mathrm{tot}, 1 / 2}=2 K_{\text {diss }}
$$

Since the minimum in the "U" shaped curve in Figs. 1 and 2 corresponds to $[\mathrm{Cs}]_{\mathrm{org}, \text { tot }}=2 \times 10^{-6}$ $\mathrm{M}$, eq. 13 would imply that $K_{\text {diss }}$ is on the order of $10^{-6} \mathrm{M}$. Is this physically reasonable?

The degree to which the ion-pair $\mathrm{CsBNO}_{3}$ dissociates to the free ions $\mathrm{CsB}^{+}$and $\mathrm{NO}_{3}{ }^{-}$in the solvent may be predicted approximately according to the treatment of Fuoss [20]. This

Table 3.3. Dissociation constants calculated by the Fuoss treatment.a

\begin{tabular}{cccc}
\hline $\begin{array}{c}a \\
(\mathbf{n m})\end{array}$ & $\begin{array}{c}\varepsilon \\
\left(\begin{array}{c}\text { Dielectric } \\
\text { constant) }\end{array}\right.\end{array}$ & $\boldsymbol{K}_{\mathbf{2}}$ & $\begin{array}{c}{[\mathbf{C s}]_{\text {org,tot, } 1 / 2}} \\
\mathbf{= 2} \boldsymbol{K}_{\text {diss }}\end{array}$ \\
\hline 0.365 & 3 & $2.1 \times 10^{21}$ & $9.5 \times 10^{-22}$ \\
& 5 & $2.7 \times 10^{12}$ & $7.4 \times 10^{-13}$ \\
& 10 & $6.0 \times 10^{5}$ & $3.3 \times 10^{-6}$ \\
0.6 & 3 & $1.7 \times 10^{13}$ & $1.2 \times 10^{-13}$ \\
& 5 & $7.2 \times 10^{7}$ & $2.8 \times 10^{-8}$ \\
& 10 & $6.0 \times 10^{3}$ & $3.3 \times 10^{-4}$ \\
0.8 & 3 & $1.7 \times 10^{10}$ & $1.2 \times 10^{-10}$ \\
& 5 & $1.6 \times 10^{6}$ & $1.2 \times 10^{-6}$ \\
& 10 & $1.4 \times 10^{3}$ & $1.4 \times 10^{-3}$ \\
1.0 & 3 & $3.3 \times 10^{8}$ & $6.1 \times 10^{-9}$ \\
& 5 & $1.8 \times 10^{5}$ & $1.1 \times 10^{-5}$ \\
& 10 & $6.8 \times 10^{2}$ & $2.9 \times 10^{-3}$ \\
\hline
\end{tabular}

${ }^{\text {a }}$ As evaluated at $25^{\circ} \mathrm{C}$ by the Fuoss treatment [20], the ion association constant $K_{\mathrm{a}}\left(K_{\text {diss }}{ }^{-1}\right)$ is related to the dielectric constant $\varepsilon$ and internuclear separation $a(n m)$ by the following relation: $K_{\mathrm{a}}=2.522 a^{3} \exp [56.047 / \varepsilon a]$. 


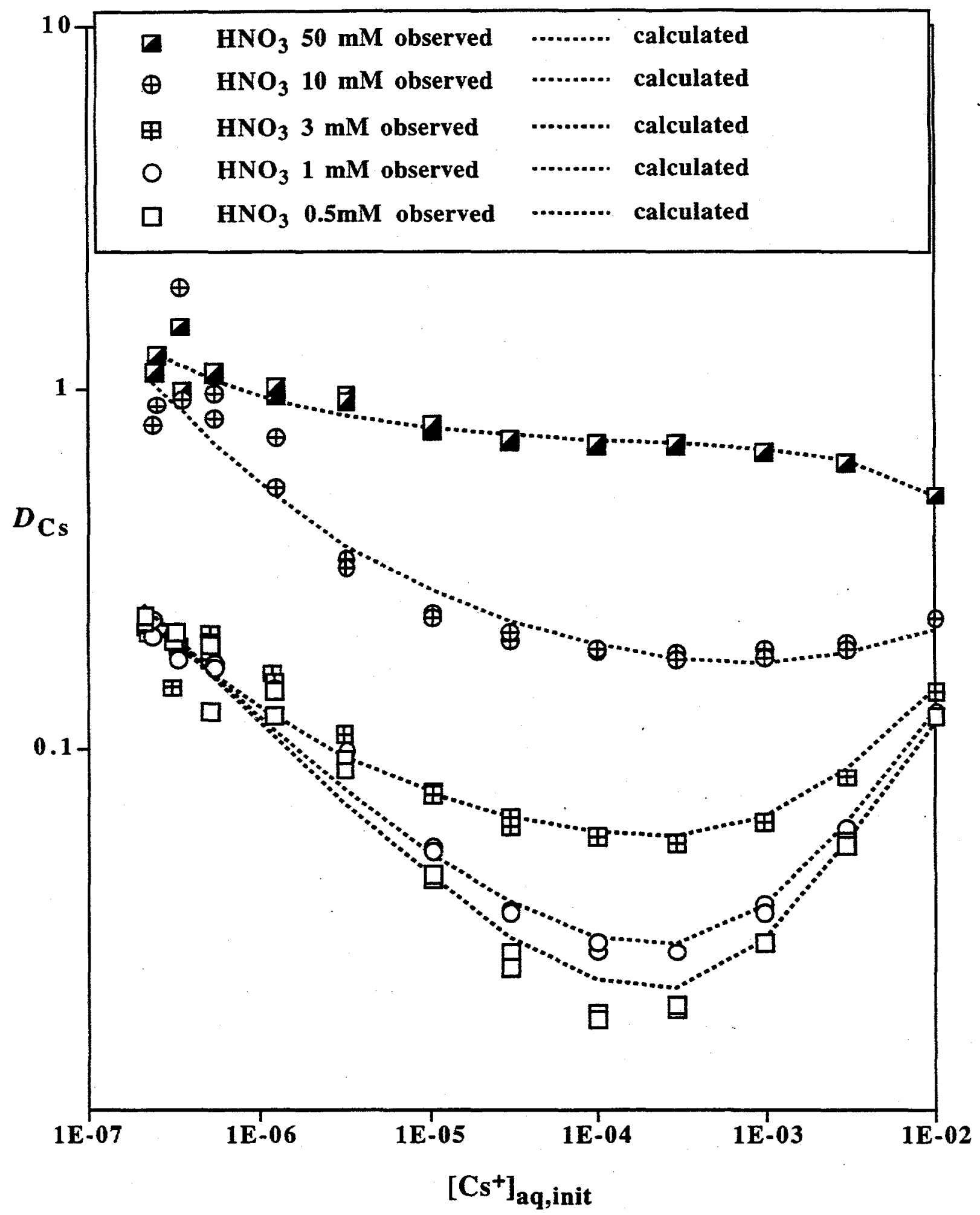

Figure 3.9. Distribution behavior of cesium nitrate as a function of initial cesium nitrate concentration at various dilute nitric acid concentrations. Modeling with SXLSQI. For experimental conditions, see Figure 3.2. 
straightforward relation gives the ion-pair association constant as a function of the bulk dielectric constant, temperature, and internuclear distance between the ionic centers. Under ordinary conditions at constant temperature, the calculated association constants increase with decreasing dielectric constant and decreasing internuclear distance. To illustrate these trends, Table 3.3 shows some values calculated for $25^{\circ} \mathrm{C}$ for trial values of dielectric constant and total organic-phase salt concentrations. It may be seen that values of $K_{\text {diss }}$ on the order of $10^{-6} \mathrm{M}$ are obtainable if the internuclear distance is $>0.8 \mathrm{~nm}$ and the dielectric constant is $3-5$. Considering that the modifier is polar with a concentration of $0.2 \mathrm{M}$, a dielectric constant of 3 - 5 appears reasonable. A large internuclear separation is also reasonable if it is considered that the modifier solvates the anion and the complex cation, thereby preventing close $\mathrm{Cs}^{+}-\mathrm{NO}_{3}{ }^{-}$contact. The modifier has both hydrogenbonding ability and electron-pair donating ability, characteristics that would indeed give rise to the needed solvation ability $[15,21]$.

\subsubsection{Why add Cesium Nitrate to the Strip Solution?}

Equation 8 showed the futility of successive stripping with dilute $\mathrm{HNO}_{3}$ solutions (e.g.; 0.0005 or $0.001 \mathrm{M}$ ), owing to the $-1 / 2$ slope in the dependence of $\log D_{\mathrm{Cs}}$ on $\log [\mathrm{Cs}]_{\text {aq. }}$. However, this same equation suggests that a way to achieve good stripping entails adding nonradioactive $\mathrm{CsNO}_{3}$ to the strip solution. One could so benefit by adding $\mathrm{CsNO}_{3}$ up to a concentration that would begin to increase $\left[\mathrm{NO}_{3}{ }^{-}\right]_{\mathrm{aq}}$. For economic reasons, the concentration must also be kept low. A reasonable compromise is the addition of $0.0001 \mathrm{M} \mathrm{CsNO}_{3}$ to $0.0005 \mathrm{M} \mathrm{HNO}_{3}$. As shown in Figs. 3.4 and 3.5, this corresponds to approximately the minimum in the " $U$ " shaped curve. Hence, on successive stripping with this strip solution, the aqueous $\mathrm{CsNO}_{3}$ will stabilize in several stages to $0.0001 \mathrm{M}$, and $D_{\mathrm{Cs}}$ should thereafter remain invariant. The effect is dramatically demonstrated in Fig. 3.1. The constancy of $D_{\mathrm{Cs}}$ at a value of 0.043 out to 8 contacts was demonstrated by performing a similar extract-scrub-strip experiment in which the strip solution was $0.0001 \mathrm{M} \mathrm{CsNO}_{3}$ and $0.0005 \mathrm{M} \mathrm{HNO}_{3}$ to which was added a spike of ${ }^{137} \mathrm{Cs}$.

Since the total organic-phase Cs concentration will be held constant by the addition of $0.0001 \mathrm{M} \mathrm{CsNO}_{3}$ to the strip solution, the decontamination of the solvent in the strip section may be viewed as isotopic dilution. From stage to stage, the ratio of ${ }^{137} \mathrm{Cs}$ to ${ }^{133} \mathrm{Cs}$ in the solvent decreases until an acceptable decontamination is achieved, namely at a concentration of ${ }^{137} \mathrm{Cs}$ on the order of $10^{-9} \mathrm{M}$. 


\subsubsection{Alkylamine Alternative Improves Stripping}

The extraction/stripping mechanism based on eqs. 1 and 2 above leads to useful alternative approaches to achieving good stripping performance without the necessity of adding $\mathrm{CsNO}_{3}$ to the strip solution. An alternative entails the addition of a low concentration $\left(10^{-5}-10^{-3} \mathrm{M}\right)$ of an alkylamine extractant to the solvent. This saves the cost of $\mathrm{CsNO}_{3}$ and its attendant effect on vitrification, but more important it was also shown that a) $D_{\mathrm{Cs}}$ can be lowered by a factor of at least 2 compared with stripping with $0.0001 \mathrm{M} \mathrm{CsNO}_{3}$ and $0.0005 \mathrm{M} \mathrm{HNO}_{3}$ (see Fig. 3.5) and b) the amine makes the solvent tolerant of impurities that impair stripping (see Fig. 3.6).

Qualitatively, the extraction process given by eq. 2 is undesirable because of the unfavorable $-1 / 2$ dependence of $\log D_{\mathrm{Cs}}$ on $\log [\mathrm{Cs}]_{\mathrm{aq}}$. By inspection of eq. 2 , it is possible to suggest that any source of $\mathrm{NO}_{3}{ }^{-}$in the organic-phase will displace the reaction to the left by a common-ion mass-action effect. Since eq. 2 is the predominant process in stripping, displacing this reaction to the left amounts to improved stripping. We already noted above that adding $\mathrm{CsNO}_{3}$ to the aqueous phase acts to ensure a constant concentration of $\mathrm{CsNO}_{3}$ in the organic phase of approximately $2 \times 10^{-6} \mathrm{M}$. One could add any number of extractable nitrate salts to the strip solution to achieve the same effect. In the case of alkali metal salts, $\mathrm{RbNO}_{3}$ and $\mathrm{KNO}_{3}$ represent candidates, but they would respectively need to be added at 0.001 and $0.01 \mathrm{M}$ to have a comparable effect. This was not tried, as it was considered costly, both in terms of the cost of the chemicals and the impact on vitrification (glass volume). Nevertheless, it represents an option likely to work.

On the other hand, an obvious source of nitrate in the solvent would be the addition of an alkylammonium extractant. A quaternary ammonium nitrate extractant like tetraheptylammonium nitrate or Aliquat ${ }^{\circledR} 336$ in the nitrate form adds nitrate independent of $\mathrm{pH} . \quad$ A $1^{\circ}-3^{\circ}$ alkylamine would be neutral at the high $\mathrm{pH}$ conditions of extraction but would convert to the alkylammonium form under the acid conditions of scrubbing and stripping. Because the neutral form would be expected to have little effect on extraction, addition of $1^{\circ}-3^{\circ}$ alkylamine would be preferable to addition of a quaternary ammonium nitrate extractant. A variety of alkylamine extractants are known and have been commonly used in process hydrometallurgy for 40 years. To know how much is needed, we may consider that the dissociation of the organic-phase complex $\mathrm{CsBNO}_{3}$ apparently begins when it is at approximately $10^{-6} \mathrm{M}$. To suppress the dissociation of this ionpair, the alkylammonium nitrate should be added in at least 10-fold excess. Thus, $10^{-5}$ or $10^{-4} \mathrm{M}$ alkylammonium nitrate should have the desired effect. In Figs. 3.4 and 3.5, it is shown that this is indeed the case, and a prototype flowsheet based on batch extraction, scrub, and strip contacts shown in Table 3.2 shows excellent performance. 
It was in fact possible to model the extraction equilibria based on eqs. 1 and 2 together with the dissociation of the alkylammonium nitrate extractant:

$$
\mathrm{RNO}_{3} \text { (org) } \rightleftharpoons \mathrm{R}^{+} \text {(org) }+\mathrm{NO}_{3}^{-} \text {(org) } \quad K_{\text {diss, } \mathrm{RNO}_{3}}
$$

The results of the modeling are given in Fig 3.10. In this case, three adjustable parameters were

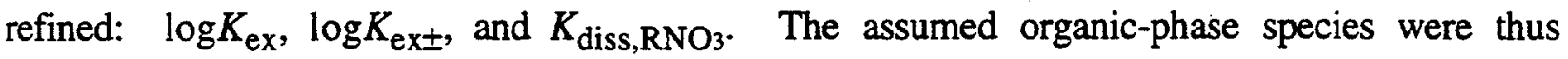
$\mathrm{CsCalixNO}_{3}, \mathrm{CsCalix}^{+}, \mathrm{NO}_{3}{ }^{-}, \mathrm{Hep}^{+}$, and $\mathrm{HepNO}_{3}$ (Hep = tetraheptylammonium). The positive effect of the alkylamines together with the modeling serve as evidence that the proposed extraction model is reasonable. In addition, the alkylamine approach offers a viable alternative to use of $\mathrm{CsNO}_{3}$ in the strip solution.

The alkylamine addition offers an important secondary effect in neutralizing the effect of impurities that retain $\mathrm{Cs}^{+}$ion in the solvent. Such impurities could logically be highly lipophilic anions of strong acids. A possible extraction process involving the anion $\mathrm{A}^{-}$may be written as follows:

$$
\mathrm{Cs}^{+}(\mathrm{aq})+\mathrm{HA} \text { (org) }+\mathrm{B} \text { (org) } \rightleftharpoons \mathrm{CsB}^{+} \text {(org) }+\mathrm{A}^{-}(\text {org })+\mathrm{H}^{+} \text {(aq) }
$$

The effect of the amine is to displace the reaction to the left, resulting in stripping, by removing HA as the salt RA. Data presented above (Fig. 3.6) confirmed this effect in an experiment in which the lipophilic anion didodecylnaphthalene sulfonate was added to the solvent. The anion indeed strongly impairs stripping, but addition of trioctylamine to the solvent in a comparable concentration to the anion effectively counters the effect of the anion.

\subsubsection{Process Experience with Amine Extractants in Nitrate Systems}

Alkylamine extractants have been one of the major classes of solvent extraction reagents since the inception of solvent extraction as a large-scale hydrometallurgical technique [22-31]. These extractants have figured prominently in hydrometallurgical recovery of $U, M o$, and $V$ from ores, for example, where they have proven to be robust reagents capable of duty in the presence of oxidants, impurities, and thermal effects. Literature dealing with the use of alkylamines for reprocessing applications (e.g., TRAMEX and EUREX), including stability issues, has been reviewed [24,27]. 


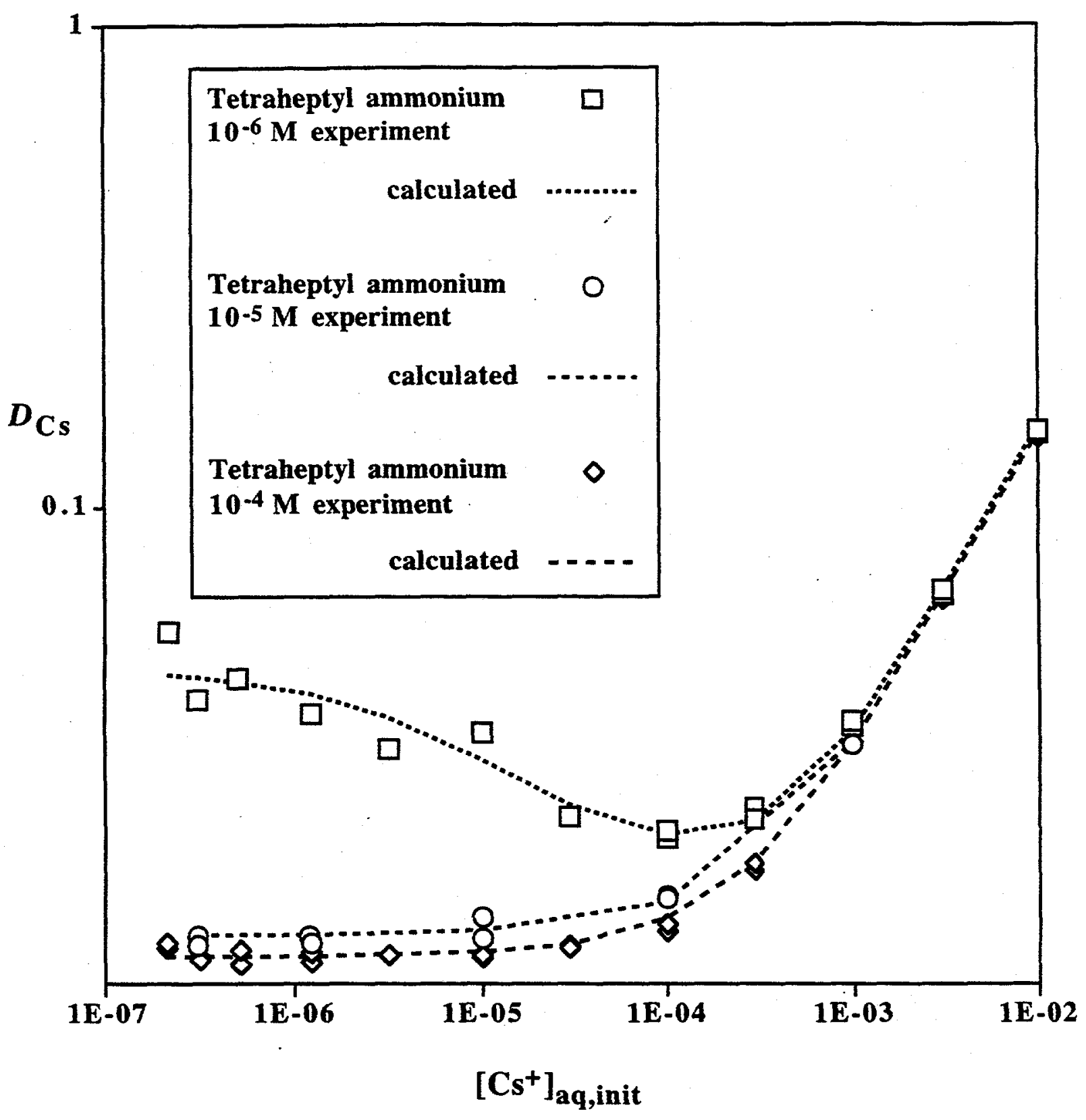

Figure 3.10. Extraction with $\mathrm{Cs} 3 \mathrm{C} / 120 \mathrm{~L}-2$ solvent containing tetraheptyl ammonium nitrate at various concentrations. For experimental conditions, see Figure 3.5. 


\subsection{CONCLUSIONS}

A good understanding of the extraction/stripping mechanism has been obtained, leading to an effective means of stripping the extracted $\mathrm{CsNO}_{3}$ down to the extremely low levels needed for solvent recycle. By using a strip solution consisting of $0.0001 \mathrm{M} \mathrm{CsNO}_{3}$ and $0.0005 \mathrm{M} \mathrm{HNO}_{3}$, it was shown in our batch tests at ORNL that $D_{\mathrm{Cs}}$ values on stripping lie in the range $0.02-0.05$, depending on the conditions of the test. This could be further lowered, up to a factor of 1.7 , by raising the temperature of the strip section to $43^{\circ} \mathrm{C}$. Addition of a trialkylamine extractant at $10^{-4}$ $M$ to the solvent offers several important improvements. First, it makes the solvent tolerant of anionic impurities and therefore more robust for process use. Second, it eliminates the need for $\mathrm{CsNO}_{3}$ in the aqueous strip solution. Third, it provides lower $D_{\mathrm{Cs}}$ values on stripping than obtainable with $\mathrm{CsNO}_{3}$ in the aqueous strip solution, and finally it allows the use of somewhat higher $\mathrm{HNO}_{3}$ concentrations in the strip solutions (e.g., $0.002 \mathrm{M}$ ), making the strip solution easier to control. At our present state of knowledge, the addition of the trialkylamine does not come at the price of decreased solvent performance in extraction or scrubbing. Chemical stability, radiation stability, and behavior of minor components remain uncertainties that need to be addressed. However, the extensive processing experience with alkylamine extractants in nuclear applications and the extensive literature pertaining to stability and other properties of these extractants give a degree of confidence that use of a low concentration of trialkylamine does not entail large risk:.

\subsection{REFERENCES}

1. Bonnesen, P.V.; Moyer, B.A.; Presley, D.J.; Armstrong, V.S.; Haverlock, T.J.; Counce, R.M.; and Sachleben, R.A. Alkaline-Side Extraction of Technetium from Tank Waste Using Crown Ethers and Other Extractants; Report ORNL/TM-13241, Oak Ridge National Laboratory: Oak Ridge, TN, June, 1996.

2. Ungaro, R.; Casnati, A.; Ugozzoli, F.; Pochini, A.; Dozol, J.-F.; Hill, C.; Rouquette, H. Angew. Chem. Int. Ed. Engl. 1994, 33, 1506.

3. Asfari, Z.; Wenger, S.; and Vicens, J. J. Inclusion Phenom. 1994, 19, 137.

4. Hill, C.; Dozol, J.-F.; Lamare, V.; Rouquette, H.; Eymard, S.; Tournois, B.; Vicens, J.; Asfari, Z.; Bressot, C.; Ungaro, R.; Casnati A. J. Inclusion Phenom. Mol. Recognit. Chem., 1994, 19, 399 
5. Hill, C., Ph. D. Thesis, Université Louis Pasteur de Strasbourg, 1994.

6. Casnati, A.; Pochini, A.; Ungaro, R.; Ugozzoli, F.; Arnaud, F.; Fanni, S.; Schwing, M.J.; Egberink, R. J. M.; de Jong, F.; Reinhoudt, D. N. J. Am. Chem. Soc., 1995, 117, 2767.

7. Asfari, Z.; Bressot, C.; Vicens, J.; Hill, C.; Dozol, J.-F.; Rouquette, H.; Eymard, S.; Lamare, V.; Tournois, B. Anal. Chem., 1995, 67, 3133.

8. Arnaud-Neu, F.; Asfari, Z.; Souley, B.; Vicens J. New J. Chem., 1996, 20, 453.

9. Asfari, Z.; Nierlich, M.; Thuéry, P.; Lamare, V.; Dozol, J.-F.; Leroy, M.; Vicens J. Anales de Quimica Int. Ed., 1996, 92, 260.

10. Asfari, Z.; Naumann, C.; Vicens, J.; Nierlich, M.; Thuery, P.; Bressot, C.; Lamare, V.; Dozol, J.-F. New J.Chem., 1996, 20, 1183.

11. Dozol, J.-F.; Bohmer, V.; McKervey, A.; Lopez Calahorra, F.; Reinhoudt, D.; Schwing, M.-J.; Ungaro, R.; Wipff, G. New. Macrocyclic Extractants for Radioactive Waste Treatment: Ionizable Crown Ethers and Functionalized Calixarenes; Report EUR-17615, European Communities: Luxembourg, 1997.

12. Dozol, J.-F.; Simon, N.; Lamare, V.; Rouquette, H.; Eymard, S.; Tournois, B.; De Marc, D.; Macias, R. M. Sep. Sci. Technol. (In press).

13. Haverlock, T.J.; Bonnesen, P.V.; Sachleben, R.A.; Moyer, B.A. J. Inclusion Phenom. Mol. Recognit. Chem. (Submitted).

14. Moyer, B.A. Complexation and Transport. In Molecular Recognition: Receptors for Cationic Guests, Gokel, G. W., Ed.; Comprehensive Supramolecular Chemistry, Atwood, J. L., Davies, J. E. D., MacNicol, D. D., Vögtle, F., Lehn, J.-M., Eds.; Pergamon, Elsevier: Oxford, 1996, pp 377-416. 
15. Moyer, B.A.; Sun, Y. In Ion Exchange and Solvent Extraction, Vol. 13, Marcus, Y., Marinsky, J. A., Eds.; Marcel Dekker: New York, 1997; Chap. 6, pp 295-391.

16. McDowell, W.J.; Case, G.N.; McDonough, J.A.; Bartsch, R.A. Anal. Chem.1992, 64, 3013-3017.

17. Baes, C.F., Jr. SXLSQI, A Program for Modelling Sovent Extraction Systems; Report ORNL/TM-13604, Oak Ridge National Laboratory, Oak Ridge: Tennessee, 1998.

18. Deng, Y.; Sachleben, R.A.; Moyer, B.A. J. Chem. Soc., Faraday Trans. 1995, 9l, 4215.

19. Baes, C.F., Jr.; Moyer, B.A.; Case, G.N.; Case, F.I. Sep. Sci. Technol. 1990, 25, 1675.

20. Fuoss, R.M. J. Am. Chem. Soc. 1958, 80, 5059.

21. Moyer, B. A.; Bonnesen, P. V. Physical Factors in Anion Separations. In Supramolecular Chemistry of Anions; Bianchi, A., Bowman-James, K., Garcia-España, E., Eds.; VCH: New York, 1977, Chap. 1.

22. Coleman, C. F.; Brown, K. B.; Moore, J. G.; Crouse, D. J. Industrial Engineering Chemistry 1958, 50, 1756-1762.

23. Coleman, C. F. Nuclear Science and Engineering 1963, 17, 274-286.

24. Coleman, C.F. In Prog. Nucl. Energy, Series III, Process Chemistry, Vol. 4, Pergamon: New York, 1969; pp 233-285.

25. Moore, F. L. "Liquid-Liquid Extraction with High-Molecular Weight Amines," National Academy of Sciences, 1960.

26. Marcus, Y.; Kertes, A. S. Ion Exchange and Solvent Extraction of Metal Complexes; Wiley Interscience: New York, 1969. 
27. Shmidt, V.S. Ekstraktsiya Aminami, Atomizdat: Moscow, 1970; Engl. transl.: Amine Extraction, Israel Program for Scientific Translations: Jerusalem, 1971.

28. Sekine, T. Solvent Extraction Chemistry: Fundamentals and Applications; Marcel Dekker: New York, 1977.

29. Ritcey, G. M.; Ashbrook, A. W. Solvent Extraction, Principles and Applications to Process Metallurgy; Elsevier: New York, 1984; Vol. Part I.

30. Cox, M. In Science and Practice of Liquid-Liquid Extraction; J. D. Thornton, Ed.; Clarendon Press: Oxford, 1992; Vol. 2; pp 1-101.

31. Principles and Practices of Solvent Extraction; Rydberg, J.; Musikas, C.; Choppin, G. R., Ed.; Marcel Dekker: New York, 1992. 


\section{PARTITIONING OF SOLVENT COMPONENTS AND SELECTED POTENTIAL IMPURITIES}

\subsection{INTRODUCTION}

In a solvent extraction process, it is important to know to what extent the solvent components, especially expensive extractants, are lost from the solvent to the aqueous phases. If losses are large, then returning the solvent to its initial potency by replenishing the solvent with extractant and/or modifier could become a significant operating expense. In such case, an additional contacting stage (with, for example, the diluent alone as the organic phase) would be necessary at the very least to recover the more expensive extractant from the aqueous phases. The main avenues by which the components could be lost to the aqueous phases are by dissolution and by entrainment. Here, we wanted to determine the extent to which the BoBCalixC6 extractant and the Cs3 modifier (1-(1,1,2,2-tetrafluoroethoxy),-3-[4-(t-octyl)phenoxy]-2-propanol) would be lost to the various aqueous phases comprising the flowsheet (the feed simulant SRS\#2-1, the $50 \mathrm{mM}$ nitric acid scrub solution, and the $0.5 \mathrm{mM}$ nitric acid/0.1 mM cesium nitrate strip solution) on the basis of solubility. We additionally wanted to measure the extent to which trace organics in the solvent (which could arise from both chemical and radiolytic degradation) would partition to not only aqueous phases comprising the flowsheet, but also specific solutions which could be used to wash out these impurities from the solvent. The two main trace organics we have actually observed in the solvent are 4-t-octylphenol (which is the starting material for the synthesis of the modifier, and is always present in the solvent at very low levels, usually at 0.5 millimolar), and 2 nitro-4-t-octylphenol, which can be formed in trace amounts from the parent phenol during the scrub stages with 50 millimolar nitric acid. It is possible that these and other phenolic species could form during the radiolytic breakdown of both the BoBCalixC6 extractant and the Cs3 modifier, and the partitioning behavior of these two phenols to various aqueous phases can provide a reasonable assessment of how other phenolic species might partition.

\subsection{EXPERIMENTAL}

\subsubsection{Materials and Contacting Procedure}

Reagents. See section 2.2.1. Hexamethyl benzene (99+\%), 4-tert-octylphenol (97\%), and deutero-chloroform (99.8 atom \% D) were obtained from Aldrich Chemical Company, and were used as received. 
Synthesis of 2-nitro-4-t-octyl phenol. A $5 \mathrm{~mL}$ solution containing $1.0 \mathrm{mmol} 4$-tertoctylphenol $(0.20 \mathrm{M})$ in deutero-chloroform was contacted with $5.4 \mathrm{~mL}$ of $1.0 \mathrm{M}$ nitric acid in a 30 $\mathrm{mL}$ Teflon ${ }^{\circledR}$ FEP centrifuge tube for 23 hours by end-over-end rotation using a Glas-Col ${ }^{\circledR}$ rotator at $25^{\circ} \mathrm{C}$. Although the organic solution had a bright yellow color, proton NMR revealed that nitration was only about $1 \%$ complete, so after returning the NMR sample to the reaction mixture, the nitric acid concentration was raised to about $3.2 \mathrm{M}$ by the addition of $1 \mathrm{~mL}$ of concentrated nitric acid, and contacting continued for an additional $46 \mathrm{hr}$; proton NMR on an aliquot of the deep amber solution showed that nitration was about $85 \%$ complete, but that some dinitrated product was starting to form. The acid solution was diluted with $1.5 \mathrm{~mL}$ deionized water to bring the nitric acid solution down to $2.6 . \mathrm{M}$, and the rotation contact continued for an additional $36 \mathrm{hr}$. Proton NMR revealed complete conversion to the mono-nitrated product with only a small amount of higher nitrated products. The reaction mixture was transferred to a separatory funnel, where the aqueous phase was diluted with about $20 \mathrm{~mL}$ deionized water, and the organic phase was diluted with about $10 \mathrm{~mL}$ dichloromethane. The aqueous phase was drained off, and the organic layer washed with $20 \mathrm{~mL}$ water, followed by $20 \mathrm{~mL}$ saturated sodium bicarbonate, followed again by 20 $\mathrm{mL}$ water. The solvent was removed from the deep yellow solution by rotary evaporation, and the light amber oil (230 mg) that remained was chromatographed on silica. The yellow band that eluted with 1:1 vol/vol hexanes/dichloromethane was collected. The yield is $199 \mathrm{mg}(79 \%)$ of a deep yellow oil, which is spectroscopically pure for 2-nitro-4-t-octylphenol by proton NMR. A stock solution of 2-nitro-4-t-octylphenol $(0.069 \mathrm{M})$ in Isopar ${ }^{\circledR} \mathrm{L}$ was prepared, and used to prepare solvent solutions.

Contacting. Solvents (typically 5-20 mL aliquots) were generally contacted with at least 10 times the volume of the desired aqueous phase in a Nalgene ${ }^{\text {TM }}$ Teflon ${ }^{\circledR}$ FEP separatory funnel. For partitioning components of the solvent $\mathrm{Cs} 3 \mathrm{C} / 120 \mathrm{~L}-2$ to the feed, scrub, and strip stages of the process, a 5-mL volume of solvent was contacted with 1 liter of aqueous phase. The contacting was accomplished by hand-shaking, and the phases were allowed to separate by gravity. All contents of the separatory funnel were placed in $250 \mathrm{~mL}$ Teflon ${ }^{\circledR}$ FEP centrifuge bottles and centrifuged at 2700 RPM (Beckman TJ-6 centrifuge, about $1500 \times g$ force) for 10 minutes. As much solvent as possible was removed from the top, and the aqueous phase was carefully transferred to a Nalgene ${ }^{\mathrm{TM}}$ polypropylene graduated cylinder to measure the precise volume to be back-extracted. The measured volume of aqueous phase was contacted in a clean Teflon ${ }^{\circledR}$ FEP separatory funnel three times successively with $50 \mathrm{~mL}$ dichloromethane. The dichloromethane layer was drained each time into a clean Teflon ${ }^{\circledR}$ FEP bottle. (Teflon ${ }^{\circledR}$ is preferred to glass in these operations because any aqueous phase accidentally drained will bead and float to the top of the dichloromethane, and can be readily withdrawn via pipet. However, in glass the aqueous droplets will stick to the sides of the flask, and can be difficult to separate from the 
dichloromethane.) After the combined dichloromethane back-extracts were drained into the Teflon ${ }^{\circledR}$ FEP bottle, and any aqueous droplets removed, the dichloromethane solution was carefully transferred by plastic pipet to a large (e.g., $500 \mathrm{~mL}$ ) round bottom flask. The dichloromethane solution was evaporated to near dryness by rotary evaporation, then the remaining solution transferred via glass Pasteur pipet to a tared $25 \mathrm{~mL}$ pear-shaped flask, along with the dichloromethane rinses from the round bottom flask. The contents of the flask were dried for several hours under oil pump vacuum, and the flask re-weighed to determine the mass of the residue.

\subsubsection{NMR Analysis}

The residue from each partition experiment was dissolved in a solution consisting of a known concentration of hexamethylbenzene (internal integration standard) in deutero-chloroform. The hexamethylbenzene solution concentration was typically on the order of 1.5 millimolar, and was accurately known to three significant digits. A volume of $1.00 \mathrm{~mL}$ was transferred to a $5 \mathrm{~mm}$ NMR tube. For proton NMR acquisition parameters (Bruker MSL-400; $400.13 \mathrm{MHz}$ proton), a relaxation delay $\left(D_{0}\right)$ of 20 seconds was employed to ensure complete relaxation of all relevant protons (those protons selected to be integrated) [1]. The $T_{1}$ 's are rather long, on the order of 4 seconds for the aromatic protons selected for integration, and it is customary to set the relaxation delay three to five times longer than the longest $T_{1}$. The 18 protons on the six methyl groups of hexamethylbenzene appear as a singlet at $2.24 \mathrm{ppm}$ (referenced to chloroform at $7.26 \mathrm{ppm}$ ). Table 4.1 shows the chemical shifts of the proton(s) that were integrated to determine the concentration of each solvent component. For the Cs3 modifier, the two protons on the aromatic ring ortho to the oxygen appear as a "doublet" (actually part of an AA'BB' quartet) centered at $6.83 \mathrm{ppm}$, and are clear enough to integrate. Other resonances of interest for the Cs-3 modifier include a triplet of triplets centered at about $5.7 \mathrm{ppm}$ for the single proton bound to the tetrafluoroethoxy group, though this set of peaks can be difficult to integrate. For the 4-t-octylphenol, the two protons on the aromatic ring ortho to the oxygen also appear as a "doublet" centered at $6.75 \mathrm{ppm}$, close to the corresponding doublet from the modifier, but still separated enough to integrate cleanly. For 2nitro, 4-t-octylphenol, the single proton at the five-position on the aromatic ring (para to the nitro group) appears as a doublet of doublets centered at $7.63 \mathrm{ppm}$, downfield and well-separated from other peaks of interest. The resonances for the tert-octyl group are virtually identical for the 4-toctylphenol, Cs-3 modifier, and the BoBCalixC6 (and only very slightly down-shifted for 2-nitro4-t-octylphenol), so these cannot be used to distinguish between the three components. Both the modifier and the calix have overlapping resonances in the "ether" region between 4.3 and $3.5 \mathrm{ppm}$. 
The calix has an extremely low partitioning to aqueous phases, and is difficult to locate, but there exists a triplet centered at $6.68 \mathrm{ppm}$, slightly upfield from the modifier and phenol doublets mentioned above, that could be integrated. The triplet represents four protons (the proton para to the oxygen on each of the four aromatic rings comprising the belt of the calix).

Table 4.1. Chemical shifts of peaks used to determine the concentration of solvent components.

\begin{tabular}{|l|c|c|c|}
\hline Component & $\begin{array}{c}\text { Chemical shift in } \\
\text { ppm, splitting } \\
\text { patterna }\end{array}$ & $\begin{array}{c}\text { Number } \\
\text { of } \\
\text { protons }\end{array}$ & Position on component \\
\hline Cs3 Modifier & 6.83 , doublet & 2 & Aromatic protons ortho to \\
oxygen
\end{tabular}

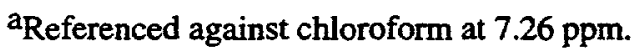

The concentration of the component (modifier, phenol, or calix) was determined by comparison of the integral area (adjusted for number of protons) to the integral area for the hexamethylbenzene methyl protons (adjusted for number of protons), where the concentration of the hexamethylbenzene is known. With the concentration of the component in the $1.0 \mathrm{~mL}$ of NMR solvent now known, the concentration of the component in the volume of aqueous phase that was back-extracted can be determined, and the partition ratio between the solvent and the aqueous phase calculated as the $P=\{$ [component in solvent] - [component in aqueous phase] $\} /$ [component in aqueous phase]. 


\subsection{RESULTS AND DISCUSSION}

\subsubsection{Partitioning Behavior of Solvent Components and Impurities to Flowsheet Aqueous Phases.}

The partitioning of the BoBCalix 6 extractant and $\mathrm{Cs} 3$ modifier was determined to the three aqueous phases in the flowsheet using the method described above, using solvent Cs3C/120L-2 (0.20 M Cs3 lot C modifier, $0.01 \mathrm{M} \mathrm{BoBCalixC6}$ in Isopar ${ }^{\circledR} \mathrm{L}$ ). A large volume of aqueous phase in each case was required, in order to obtain enough material to quantify by NMR. The results, shown below in Table 4.2, indicate that neither the calix nor the modifier is especially soluble in the aqueous phases, preferring to remain in the solvent phase by factors of $10^{4}$ to $10^{5}$. Thus, losses of these solvent components from the solvent during the process will be very low.

Table 4.2. Partition ratio $P$ of solvent components to aqueous flowsheet solutions.

\begin{tabular}{|l|c|c|c|}
\hline Aqueous Solution & $\begin{array}{c}\text { Aqueous } \\
\text { Volume }\end{array}$ & $\begin{array}{c}\boldsymbol{P} \\
(\text { Cs3C Modifier) }\end{array}$ & $\begin{array}{c}\boldsymbol{P} \\
\text { (BoBCalix C6) }\end{array}$ \\
\hline SRS\#2-1 simulant (feed) & $993 \mathrm{~mL}$ & $4.05 \times 10^{4}$ & $7.25 \times 10^{4}$ \\
\hline $50 \mathrm{mM} \mathrm{HNO}_{3}$ (scrub) & $983 \mathrm{~mL}$ & $4.69 \times 10^{4}$ & $2.98 \times 10^{5}$ \\
\hline $0.5 \mathrm{mM} \mathrm{HNO}_{3} / 0.1 \mathrm{mM} \mathrm{CsNO}_{3}$ (strip) & $983 \mathrm{~mL}$ & $3.00 \times 10^{4}$ & $4.85 \times 10^{4}$ \\
\hline
\end{tabular}

To evaluate the partitioning of 4-t-octylphenol, a sample solvent Cs3C/120L-2 was prepared which additionally contained the phenol at $0.02 \mathrm{M}$ ( $10 \%$ of the modifier). The results, shown below in Table 4.3, reveal the solubility of the phenol to be extremely low in any of these aqueous phases. (Due to the low volumes of aqueous phases employed here, the amount of BoBCalixC6 that transferred was too small to quantify using proton NMR.) The partitioning to the acidic phases was expected to be low, but it was surprising to see that the phenol partitioning to the alkaline simulant phase (mostly in the form of sodium phenolate) was also very low. One explanation for the low partitioning of the phenolate to the simulant was that due to the very high concentration of salts, the phenolate was prevented from transferring appreciably due to a "salting out" phenomenon. A second explanation could be that the phenolate anion would serve as an effective lipophilic counterion for the BoBCalixC6-Cs cation in the solvent phase. The latter may also contribute to lowering the solubility of the BoBCalixC6 in the alkaline phase as well. Thus it 
is clear that phenolic impurities will not effectively wash out into the alkaline waste/simulant during the extraction contacts.

Table 4.3. Partition ratio $P$ of solvent components and 4-t-octylphenol to aqueous flowsheet solutions.

\begin{tabular}{|l|c|c|c|c|}
\hline Aqueous Solution & $\begin{array}{c}\text { Aqueous } \\
\text { Volume }\end{array}$ & $\begin{array}{c}\boldsymbol{P} \\
(\mathbf{C s 3 C})\end{array}$ & $\begin{array}{c}\boldsymbol{P} \\
\text { (Phenol) }\end{array}$ & $\begin{array}{c}\boldsymbol{P} \\
\text { (Calix) }\end{array}$ \\
\hline SRS\#2-1 simulant (feed) & $87 \mathrm{~mL}$ & $6.26 \times 10^{4}$ & $>1.2 \times 10^{6}$ & BDL $^{\mathrm{a}}$ \\
\hline $50 \mathrm{mM} \mathrm{HNO}_{3}$ (scrub) & $177 \mathrm{~mL}$ & $5.52 \times 10^{4}$ & $>1.2 \times 10^{6}$ & BDL $^{\mathrm{a}}$ \\
\hline $0.5 \mathrm{mM} \mathrm{HNO}_{3} / 0.1 \mathrm{mM} \mathrm{CsNO}$ (strip) & $175 \mathrm{~mL}$ & $5.07 \times 10^{4}$ & $1.2 \times 10^{6}$ & BDL $^{\mathrm{a}}$ \\
\hline
\end{tabular}

${ }^{a} \mathrm{BDL}=$ below detection limits by proton NMR, where detection limit would correspond to a $P$ of $2 \times 10^{5}$.

\subsubsection{Partitioning Behavior of Solvent Components and Impurities to Candidate Wash Solutions.}

Since 4-t-octylphenol did not effectively partition to any of the flowsheet aqueous phases, it was of interest to determine whether the phenol (and the nitrated material 2-nitro, 4-t-octylphenol) would partition better to a less concentrated alkaline phase. If so, those alkaline phases might serve as effective wash solutions to clean up degraded solvent by extracting out the phenolic impurities. Initially, the partitioning of 4-t-octylphenol $\left(0.02 \mathrm{M}\right.$ in Isopar $\left.^{\circledR} \mathrm{L}\right)$ to $0.5 \mathrm{M} \mathrm{NaOH}$ both with and without $\mathrm{Cs} 3 \mathrm{C}$ modifier $(0.20 \mathrm{M})$ was examined with no BoBCalixC6 present. In addition, the partitioning of the $\mathrm{Cs} 3 \mathrm{C}$ modifier alone at 0.20 in Isopar ${ }^{\circledR} \mathrm{L}$ to $0.50 \mathrm{M} \mathrm{NaOH}$ was examined, as well as the partitioning of both the phenol and the modifier to $0.5 \mathrm{M}$ sodium carbonate. The results, shown in Table 4.4, reveal that while the modifier does not partition appreciably to the sodium hydroxide phase, the phenol does (the smaller the $P$ value, the higher the partitioning to the aqueous phase). With the modifier present, the phenol does not partition quite as well to $0.5 \mathrm{M}$ sodium hydroxide (in this sample, the modifier could not be adequately quantified). Finally, use of the weaker base sodium carbonate not surprisingly results in less deprotonation of the phenol, and hence a much lower partitioning of the phenol(ate) to the aqueous phase (higher $P$ ). Thus, $0.5 \mathrm{M} \mathrm{NaOH}$ might be an effective wash solution. 
Table 4.4. Partition ratio $P$ of 4-t-octylphenol and/or $\mathrm{Cs} 3 \mathrm{C}$ modifier to various alkaline candidate wash solutions.

\begin{tabular}{|l|c|c|c|}
\hline Aqueous Solution & $\begin{array}{c}\text { Aqueous } \\
\text { Volume }\end{array}$ & $\begin{array}{c}\boldsymbol{P} \\
(\text { Cs3C) }\end{array}$ & $\begin{array}{c}\boldsymbol{P} \\
\text { (4-t-octylphenol) }\end{array}$ \\
\hline $0.5 \mathrm{M} \mathrm{NaOH}$ & $225 \mathrm{~mL}$ & Not present & 11.93 \\
\hline $0.5 \mathrm{M} \mathrm{NaOH}$ & $220 \mathrm{~mL}$ & $2.45 \times 10^{4}$ & Not present \\
\hline $0.5 \mathrm{M} \mathrm{NaOH}$ & $225 \mathrm{~mL}$ & $\mathrm{BDL}^{\mathrm{a}}$ & 13.48 \\
\hline $0.5 \mathrm{M} \mathrm{Na}_{2} \mathrm{CO}_{3}$ & $227 \mathrm{~mL}$ & $2.08 \times 10^{4}$ & $1.06 \times 10^{3}$ \\
\hline
\end{tabular}

a $\mathrm{BDL}=$ below detection limits by proton NMR

It was next of interest to examine the partitioning of two phenols to various alkaline solutions when present separately in the Cs3C/120L-2 solvent. For partitioning of 4-toctylphenol, Cs3C/120L-2 solvent containing only that phenol at $0.02 \mathrm{M}$ (as above) was employed. For partitioning of 2-nitro-4-t-octylphenol, Cs3C/120L-2 solvent containing the nitrated phenol at $0.01 \mathrm{M}$ was employed. Solvents containing both phenols together were not examined, since the NMR spectra would be overly complex.

The partitioning of 4-t-octylphenol (and the modifier) to a variety of alkali metal hydroxide solutions of various concentrations is shown below in Table 4.5. It can be seen that while the presence of the BoBCalix 6 in the solvent raises the partition value (decreases the partitioning to the aqueous phase) for the 4-t-octylphenol to $0.5 \mathrm{M} \mathrm{NaOH}$ from 13.48 (Table 4.3) to 29.41, the partition value is much lower than it was to the alkaline simulant $\left(>1.2 \times 10^{6}\right.$, Table 4.2). Furthermore, it can be seen that for the $\mathrm{NaOH}$ solutions, the partition value goes through a minimum at $0.5 \mathrm{M}$; as the base concentration increases, the partition value increases, indicative of a possible salting out effect, as is hypothesized for the high $P$ for the phenol to the simulant. Also, the identity of the alkali metal has an effect on partitioning, as the partitioning of the phenol to the aqueous hydroxide phase decreases ( $P$ increases) as the extractability of the alkali metal increases. Potassium is much more strongly complexed by the BoBCalixC6 than is sodium or lithium; thus there is more cationic BoBCalixC6-alkali metal present for a lipophilic anion such as phenolate to pair up with for potassium than there is for sodium or lithium. Hence, the phenolate is held in the solvent better, and partitions to the aqueous phase less well, as the size of the alkali metal (and thus the extent of complexation) increases.

Finally, the partitioning of 2-nitro-4-t-octylphenol to $0.5 \mathrm{M} \mathrm{NaOH}$ and sodium carbonate was determined. As the nitrophenol is expected to be somewhat more acidic than the parent phenol due to the electron withdrawing power of the ortho-nitro group (which renders the phenolic 
oxygen less basic and thus weakens the $\mathrm{O}-\mathrm{H}$ bond strength), it was not surprising to find that the nitrophenol partitions somewhat better to $0.5 \mathrm{M} \mathrm{NaOH}$ than the parent phenol, and also mildly partitions to $0.5 \mathrm{M}$ sodium carbonate.

Table 4.5. Partition ratio $P$ of solvent components and 4-t-octylphenol or 2 nitro-4-t-octylphenol to various alkaline candidate wash solutions.

\begin{tabular}{|l|c|c|c|c|c|}
\hline Aqueous Solution & $\begin{array}{c}\text { Aqueous } \\
\text { Volume }\end{array}$ & $\begin{array}{c}\boldsymbol{P} \\
(\mathbf{C s 3 C})\end{array}$ & $\begin{array}{c}\boldsymbol{P} \\
(\text { Phenol })\end{array}$ & $\begin{array}{c}\boldsymbol{P} \\
(\text { Calix })\end{array}$ & $\begin{array}{c}\boldsymbol{P} \\
\left(\text { NO }_{2} \text { Phenol }\right)\end{array}$ \\
\hline $0.1 \mathrm{M} \mathrm{LiOH}$ & $140 \mathrm{~mL}$ & $2.84 \times 10^{3}$ & 28.55 & BDL $^{\mathrm{a}}$ & Not present \\
\hline $0.5 \mathrm{M} \mathrm{LiOH}$ & $132 \mathrm{~mL}$ & $2.51 \times 10^{3}$ & 23.06 & BDL $^{\mathrm{a}}$ & Not present \\
\hline $0.1 \mathrm{M} \mathrm{NaOH}$ & $145 \mathrm{~mL}$ & $3.22 \times 10^{3}$ & 31.64 & BDL $^{\mathrm{a}}$ & Not present \\
\hline $0.5 \mathrm{M} \mathrm{NaOH}$ & $90 \mathrm{~mL}$ & $>6.26 \times 10^{4}, \mathrm{~b}$ & 29.41 & BDL $^{\mathrm{a}}$ & Not present \\
\hline $1.0 \mathrm{M} \mathrm{NaOH}$ & $143 \mathrm{~mL}$ & $1.06 \times 10^{4}$ & 59.7 & BDL $^{\mathrm{a}}$ & Not present \\
\hline $3.0 \mathrm{M} \mathrm{NaOH}$ & $143 \mathrm{~mL}$ & $2.453 \times 10^{3}$ & 150 & BDL $^{\mathrm{a}}$ & Not present \\
\hline $0.5 \mathrm{M} \mathrm{KOH}$ & $136 \mathrm{~mL}$ & $7.21 \times 10^{3}$ & 207 & BDL $^{\mathrm{a}}$ & Not present \\
\hline \hline $0.5 \mathrm{M} \mathrm{NaOH}$ & $134.5 \mathrm{~mL}$ & $2.481 \times 10^{3}$ & Not present & BDL $^{\mathrm{a}}$ & 22.56 \\
\hline $0.5 \mathrm{M} \mathrm{Na} \mathrm{CO}_{3}$ & $245 \mathrm{~mL}$ & $5.388 \times 10^{3}$ & Not present & $2.024 \times 10^{4}$ & $5.291 \times 10^{3}$ \\
\hline
\end{tabular}

a $\mathrm{BDL}=$ below detection limits by proton NMR.

b This number reflects low aqueous volume extracted as well as a higher integration standard; integration to the low concentration modifier was not possible.

${ }^{c}$ Phenol impurity was observed in sample at $6.6 \times 10^{-6} \mathrm{M}$. Using partition of 29.41 , the [impurity] in the modifier is $1.96 \times 10^{-4} \mathrm{M}(0.1 \%)$.

In general, the amount of BoBCalixC6 that partitioned was too small to be quantified by NMR. The Cs3C modifier appears to partition somewhat better to dilute base than to either the simulant or the acid strip and scrub solutions (see Table 4.1 above). Nonetheless, it appears that there is at least a two order of magnitude difference between the partition coefficient of the Cs3C modifier and either phenol to $0.5 \mathrm{M} \mathrm{NaOH}$, which can allow for the phenols to be effectively washed out of the solvent while allowing the bulk of both the modifier and the BoBCalixC6 to remain in solution. 


\subsection{CONCLUSIONS AND RECOMMENDATIONS FOR SOLVENT CLEANUP}

Partitioning, and therefore loss, of the Cs3C modifier and the BoBCalixC6 to both the aqueous phases comprising the flowsheet, as well as to potential solvent cleanup solutions such as $0.5 \mathrm{M} \mathrm{NaOH}$, is very low. This is especially good for the BoBCalixC6, due to its expense. Since extractant losses due to solubility are low, the replacement expense for the extractant should not be excessive. Nevertheless, it would be recommended that aqueous phases in the flowsheet be contacted with an organic solution such as Isopar ${ }^{\circledR} \mathrm{L}$ to back-extract out any extractant and modifier that does partition, as well as material that could be entrained. The phenols 4-toctylphenol and 2-nitro-4-t-octylphenol can be washed away from the modifier using $0.5 \mathrm{M}$ $\mathrm{NaOH}$. Thus, a solvent cleanup and recovery scheme could entail washing the solvent with $0.5 \mathrm{M}$ $\mathrm{NaOH}$ to remove most phenolic impurities. Recovery of BoBCalixC6 and Cs3C modifier from the raffinate, scrub, and strip solutions could be accomplished by washing with Isopar ${ }^{\circledR} \mathrm{L}$, followed by a wash with $0.5 \mathrm{M} \mathrm{NaOH}$, since any residual phenols back-extracted from the flowsheet solutions would partition well to the $\mathrm{NaOH}$ phase, leaving the bulk of the modifier and BoBCalixC6 in the Isopar ${ }^{\circledR} \mathrm{L}$ phase. The washed Isopar ${ }^{\circledR} \mathrm{L}$ extracts could then be used to prepare makeup solvent.

\subsection{REFERENCES}

1. Haverlock, T.J.; Bonnesen, P.V.; Sachleben, R.A.; Moyer, B.A. J. Inclusion Phenom. Mol. Recognit. Chem. (Submitted). 


\section{MINOR COMPONENTS: THEIR DISTRIBUTION, AND THEIR EFFECT ON CESIUM EXTRACTION AND STRIPPING PERFORMANCE}

\subsection{INTRODUCTION}

In this chapter we discuss effects that the presence of various amounts of potential impurities, both in the alkaline waste feed simulant and in the solvent, could have on the distribution of $\mathrm{Cs}$ during the extraction, scrubbing, and stripping contacts. Perchlorate is a potential impurity in the waste, and is a highly extractable anion. There was concern that the presence of perchlorate might have an adverse effect on the scrubbing and stripping efficiencies. As mentioned previously in Chapter 4, trace organics such as 4-t-octylphenol and 2-nitro-4-toctylphenol could be present in the solvent, and it was of interest to determine what effect their presence would have on the distribution of cesium in the flowsheet. In addition, ORNL leamed from Savannah River that there could potentially be trace quantities of iron, mercury, lead; and silicon in the waste. A special waste simulant (SRS\#3) containing these metals and silicate at nominal concentrations (in addition to the constituents present in SRS\#2-1) was prepared. The cesium distribution behavior using this simulant was investigated, and compared to the cesium distribution behavior observed using simulant SRS\#2-1. Finally, it was of interest to determine how many of the various metal ions in this simulant (specifically $\mathrm{Al}, \mathrm{Cr}, \mathrm{Fe}, \mathrm{Hg}, \mathrm{K}, \mathrm{Na}, \mathrm{Pb}$, and $\mathrm{Si}$ ) would distribute during the extraction, scrubbing, and stripping stages in the flowsheet. For waste disposal considerations, it is most desirable for the stripping solutions to contain as much of the target materials (here cesium) and as little of the "secondary" waste (e.g., sodium and potassium salts) as possible, so that the bulk of the waste form selected to incarcerate the target waste material can be minimized. It is additionally desirable to minimize the amount of toxic metals such as $\mathrm{Hg}$ and $\mathrm{Pb}$ that would be contained in the waste form. Thus, achieving a high concentration factor of cesium relative to other salts in the waste feed would reduce waste form bulk, and would consequently reduce waste disposal costs.

\subsection{EXPERIMENTAL}

\subsubsection{Materials and Simulants}

Reagents. See sections 2.2 .1 and 4.2.1. Solvents used were $\mathrm{Cs} 3 \mathrm{C} / 120 \mathrm{~L}-2$ alone, $\mathrm{Cs} 3 \mathrm{C} / 120 \mathrm{~L}-2$ containing 4-t-octylphenol at $0.02 \mathrm{M}, \mathrm{Cs} 3 \mathrm{C} / 120 \mathrm{~L}-2$ containing 2-nitro-4-toctylphenol at $0.01 \mathrm{M}$; and Cs3D/120L-2. Sodium perchlorate was $99 \%$ reagent grade from 
Aldrich, and was dried at room temperature under vacuum before use. Aliquots of SRS\#2-1 simulant were spiked with the appropriate volume of a $1.0 \mathrm{M}$ sodium perchlorate solution to prepare the simulants containing perchlorate at 10 and $1 \mathrm{mM}$, whereas a $0.01 \mathrm{M}$ solution was used to prepare the simulants containing perchlorate at 0.1 and $0.01 \mathrm{mM}$.

Preparation of SRS\#3 Simulant. The simulant $(500 \mathrm{~mL})$ was prepared directly in a $500 \mathrm{~mL}$ Nalgene Teflon ${ }^{\circledR}$ FEP bottle using distilled deionized water (Barnstead still) and reagent grade salts in the same manner as SRS\#2-1, except that $\mathrm{Si}, \mathrm{Pb}, \mathrm{Hg}$, and $\mathrm{Fe}$ were additionally added following the order indicated in Table 5.1. Individual Inductively Coupled Plasma (ICP) standard solutions (Aldrich) for $\mathrm{Pb}, \mathrm{Hg}$, and $\mathrm{Fe}$ were used to deliver these elements. Sodium fluoride was omitted from this simulant, since its addition tends to cause excessive precipitation.

\subsubsection{Contacting Procedures}

Cs-137 Tracer Experiments. All contacts were performed at $25^{\circ} \mathrm{C}$ with an O/A phase ratio of 1 , using Teflon ${ }^{\circledR}$ FEP or polypropylene vials or tubes. The contacting method consisted of first inverting the vial or tube twice, followed by hand-shaking 10 times. After completion of the shaking operation, a stopwatch was started to record the time-to-break (essentially when all the small droplets at the interface between the two phases have disappeared). The appearance of the phases (e.g., clear aqueous, hazy organic, etc.), and the overall phase coalescence behavior (e.g., aqueous continuous or organic continuous) were recorded. The vials or tubes were then rotated end-over-end at $30-40 \mathrm{RPM}$ using a Glass-Col ${ }^{\circledR}$ rotator for 30 minutes at $25^{\circ} \mathrm{C}$, or alternatively vortexed (VWR Scientific Vortex Genie ${ }^{\mathrm{TM}}$ 2) for $5 \mathrm{~min}$ at $25^{\circ} \mathrm{C}$. Following contacting, the vials or tubes were centrifuged as described in section 2.2.1, and aliquots of each phase removed, and counted for Cs-137 activity. Two extraction contacts with the simulant were typically performed. The first extraction contact was performed using "cold" (no Cs-137 tracer) simulant, and constituted a "pre-equilibration" step. The second extraction contact was performed using simulant containing Cs-137 tracer. The solvent was then scrubbed once with $50 \mathrm{mM}$ nitric acid, followed by three successive stripping contacts with 0.5 millimolar nitric acid containing 0.1 millimolar cesium nitrate.

\subsubsection{Elemental Analyses by Inductively Coupled Plasma (ICP) Spectroscopy}

The distribution behavior of selected metals present in the SRS\#3 simulant during extraction, scrubbing, and stripping contacts was studied by analyzing the aqueous phases from these contacts by Inductively Coupled Plasma (ICP) Spectroscopy. The contacting procedure was performed in the same manner as above, except no Cs-137 tracer was employed, and a second scrubbing contact was added. Thus the contacting procedure consisted of two extraction contac 
Table 5.1. Formulation of SRS\#3 simulant at ORNL.

\begin{tabular}{|c|c|c|c|c|c|c|c|c|c|c|}
\hline $\begin{array}{l}\text { C.A.S. } \\
\text { Regiatry. }\end{array}$ & $\begin{array}{c}\text { Salt } \\
\text { Manufacturor }\end{array}$ & Component & $\begin{array}{l}\text { Chemical } \\
\text { Formule }\end{array}$ & $\begin{array}{l}\text { Formulo } \\
\text { Welght }\end{array}$ & $\begin{array}{l}\text { Desired } \\
\text { Molarity }\end{array}$ & $\begin{array}{l}\text { g neoded } \\
\text { per } 0.5 \text { Llier }\end{array}$ & $\begin{array}{c}\text { data } \\
\text { amount } \\
\text { welghed }\end{array}$ & $\begin{array}{c}\text { (10r } 500 \mathrm{~mL} \text { ) } \\
\text { Actual } \\
\text { Molarity } \\
\end{array}$ & Species & $\begin{array}{c}\text { Concentration } \\
M\end{array}$ \\
\hline $7631.99-4$ & J.T. Baker (analyzod) & sodium nitrate & NaNO3 & 85.00 & $1.48 E+00$ & 62.900 & 62.9019 & $1.480 E+00$ & Motals & \\
\hline $7757-79-1$ & EM Scionce & potasium nitrate & KNO3 & 101.11 & $2.00 \mathrm{E}-02$ & 1.011 & 1.0111 & $2.000 E \cdot 02$ & Al (as Al(OH)4-) & 4.000E-01 \\
\hline $7789 \cdot 18 \cdot 6$ & Alpha Aesar $99.99 \%$ & cesium nitrate & $\mathrm{CsNO3}$ & 194.92 & $7.00 E-04$ & 0.068 & 0.068 & $6.977 \mathrm{E} \cdot 04$ & $\mathrm{Cr}$ (as $\mathrm{CrO} 4-$ ) & $1.500 E-02$ \\
\hline $7757 \cdot 82 \cdot 6$ & EM Sctence & sodium sultate & $\mathrm{Na2SO4}$ & 142.05 & $2.20 \mathrm{E} \cdot 01$ & 15.626 & 15.6214 & 2.199E.01 & Cs+ (total) & $6.977 E-04$ \\
\hline $1310 \cdot 73 \cdot 2$ & J.T. Baker (analyzed) & sodium hydroxide & $\mathrm{NaOH}$ & 40.00 & $3.50 E+00$ & 70.000 & 70.0677 & $3.503 E+00$ & $k+$ & 2.000E-02 \\
\hline $1344 \cdot 09 \cdot 8$ & EM Sclence & sodium sllicate $40-42 \mathrm{Be}^{\prime}$ & Na2Si307 (36 wt\%) & 242.23 & $1.10 \mathrm{E}-02$ & 1.234 & 1.241 & $1.107 \mathrm{E} \cdot 02$ & $\mathrm{Na}+$ & $6.959 E+00$ \\
\hline $7784 \cdot 27 \cdot 2$ & J.T. Baker (analyzed) & aluminum nitrate & Al(NO3)3.9H2O & 375.15 & $4.00 E-01$ & 75.030 & 75.0321 & $4.000 E-01$ & Si (as $\mathrm{SiO}_{-.}$) & $1.107 E-02$ \\
\hline $497-19-8$ & Fisher Sclentific & sodium carbonate & $\mathrm{Na} 2 \mathrm{CO} 3$ & 105.99 & $2.00 \mathrm{E}-01$ & 10.599 & 10.6002 & $2.000 E-01$ & & \\
\hline $7647-14 \cdot 5$ & EM Sclencos & sodium chloride & $\mathrm{NaCl}$ & 58.44 & $1.00 E-01$ & 2.922 & 2.9259 & $1.001 \mathrm{E} \cdot 01$ & Aniơns & \\
\hline $10034-82.9$ & J.T. Baker (analyzed) & sodium chromate & $\mathrm{Na2CrO4.4H2O}$ & 234.07 & $1.50 \mathrm{E} \cdot 02$ & 1.756 & 1.7553 & $1.500 \mathrm{E}-02$ & $\mathrm{Cr}$ & $1.001 E=01$ \\
\hline $7632 \cdot 00 \cdot 0$ & EM Scienco & sodium nitrite & $\mathrm{NaNO} 2$ & 69.00 & $1.00 E+00$ & 34.500 & 34.4519 & $9.986 \mathrm{E}-01$ & NO2- & $9.986 E-01$ \\
\hline \multirow{12}{*}{ Notes: } & \multirow{6}{*}{\multicolumn{8}{|c|}{$\begin{array}{l}\text { The solution was prepared in a } 500 \mathrm{~mL} \text { Teflone FEP bottle, using Bamstead Nanopure } 18 \mathrm{M} \Omega \text { water } \\
\text { Each component was added in the above order as a solid unless otherwise noted below, and each } \\
\text { component was in solution before adding the next one. }\end{array}$}} & NO3- (includes MNO3) & $2.705 E+00$ \\
\hline & & & & & & & & & $\cos$ & $2.000 E-01$ \\
\hline & & & & & & & & & so4.. & 2.199E-01 \\
\hline & & & & & & & & & $\mathrm{OH}$ - (total) & $3.503 E+00$ \\
\hline & & & & & & & & & $\mathrm{OH}$ - (Free) & $1.899 E+00$ \\
\hline & & & & & & & & & Theor $\mathrm{pH}$ & 14.28 \\
\hline & \multicolumn{8}{|c|}{$\begin{array}{l}\text { For sodium silicate solution } 40.42 \text { degrees Baume, weight is of the solution to deliver } \\
\text { the correct amount of } \mathrm{Si} \text {. }\end{array}$} & Redionuclides & Splke leved \\
\hline & \multicolumn{8}{|c|}{ NaF was omitted from this simulant. } & Cs.137 & $0.7 \mu \mathrm{Cl} / \mathrm{mL}$ \\
\hline & & & & & & & & & Ratio & Value \\
\hline & \multirow{2}{*}{\multicolumn{8}{|c|}{ Added the $\mathrm{Fe}, \mathrm{Hg}$, and $\mathrm{Pb}$ last as solutions, as shown below: }} & $\mathrm{Na} / \mathrm{Cs}$ & 9975 \\
\hline & & & & & & & & & $\mathrm{Na} / \mathrm{K}$ & 348 \\
\hline & & & & & & & & & $\mathrm{K} / \mathrm{Cs}$ & 29 \\
\hline Other motala & $\mathbf{M W}$ & $\begin{array}{c}\text { ICP Standards } \\
\text { Concentration, ppm }\end{array}$ & concentration, $M$ & & & $\mathrm{~mL}$ & $\stackrel{\mathrm{mL}}{\mathrm{L}}$ & & Other Metals & actual \\
\hline Fe & 55.847 & 10150 & $1.817 E-01$ & 6.00 & $9.950 E-01$. & 2.75E-02 & $2.75 E-02$ & $9.996 \mathrm{E}-06$ & $\mathbf{F e}$ & $?$ \\
\hline $\mathrm{Hg}$ & 200.59 & 10000 & $4.985 E \cdot 02$ & 10.00 & $1.690 E+00$ & $1.00 E-01$ & $1.02 E+00$ & $1.017 E-04$ & $\mathrm{Hg}$ & $?$ \\
\hline Po & 207.2 & 10210 & $4.928 E-02$ & 3.00 & $4.856 \mathrm{E} \cdot 01$ & 1.01E-01 & $1.02 E+00$ & $1.005 E-04$ & Pb & $?$ \\
\hline
\end{tabular}

- Total (HNO3) is 4.493E.03 
with cold simulant, two scrubbing contacts with $50 \mathrm{mM}$ nitric acid, and three stripping contacts with 0.5 millimolar nitric acid containing 0.1 millimolar cesium nitrate.

Instrumentation. ICP analyses were performed using a Thermal Jarell Ash (Franklin, MA) IRIS Inductively Coupled Argon Plasma Optical Emission Spectrometer, equipped with a chargeinjection device (CD) capable of recording atomic emission lines in the wavelength range 177 to $780 \mathrm{~nm}$. Plasma conditions were as follows: auxiliary gas $=0.5 \mathrm{~L} / \mathrm{min}$; RF Power $=1150$ watts; nebulizer $=$ fixed cross-flow at 30 psi; delay time $=0.0$ seconds; sample flush time $=30$ seconds. The CID maximum integration time was 40 seconds for the low wavelength range, and 10 seconds for the high wavelength range.

Sample Preparation. The simulant feed and extraction raffinates were diluted ten-fold with $1 \mathrm{M} \mathrm{LiOH}$ for the $\mathrm{Hg}, \mathrm{Pb}$, and Fe analyses, and 150-fold with $1 \mathrm{M} \mathrm{LiOH}$ for the $\mathrm{Al}, \mathrm{Cr}, \mathrm{K}, \mathrm{Na}$, and $\mathrm{Si}$ analyses. The metal ion standards used in the analysis of $\mathrm{LiOH}$-diluted solutions were also prepared in $1 \mathrm{M} \mathrm{LiOH}$ where possible. The minor components of interest $(\mathrm{Fe}, \mathrm{Hg}, \mathrm{Pb})$ have limited solubility in basic solutions; therefore, to ensure integrity of the standard, these metals were prepared in 2\% nitric acid (Baker Ultrex II). Chromium was analyzed in the $1 \mathrm{M} \mathrm{LiOH}$ diluted sample against the acid standard as a check for matrix effects. This analysis was consistent within $1 \%$ of gravimetric value regardless of the standard matrix. The aqueous phases from the scrubbing and stripping contacts were analyzed directly, with no dilution, and were analyzed against standards prepared in $2 \%$ nitric acid. Detection limits were determined by three times the standard deviation of the blank analysis (see Table 5.4)

\subsection{RESULTS AND DISCUSSION}

\subsubsection{Effect of Perchlorate in the SRS\#2-1 Simulant on $D_{\mathrm{Cs}}$.}

The effect the presence of perchlorate has on the distribution behavior of cesium in the extraction, scrubbing, and stripping stages at $25^{\circ} \mathrm{C}$ is shown in Figure 5.1 . As perchlorate is generally a more extractable anion than nitrate [1], it was thought perhaps that the presence of perchlorate, especially at concentrations above $1 \mathrm{mM}$, might alter the cesium distribution behavior. In particular, it was thought that perchlorate might lead to higher $D_{C s}$ 's on stripping. As can be seen from the plot, the presence of perchlorate, even at $10 \mathrm{mM}$, had essentially no effect on the cesium distribution ratios for all contacts (within the normal $\pm 5 \%$ experimental uncertainty), with the exception of the second stripping contact, where the distribution ratios for the simulants containing perchlorate (at any concentration) were about twice that of the control (SRS\#2-1 without added perchlorate). It is unclear why higher cesium distribution ratios are observed only for the 


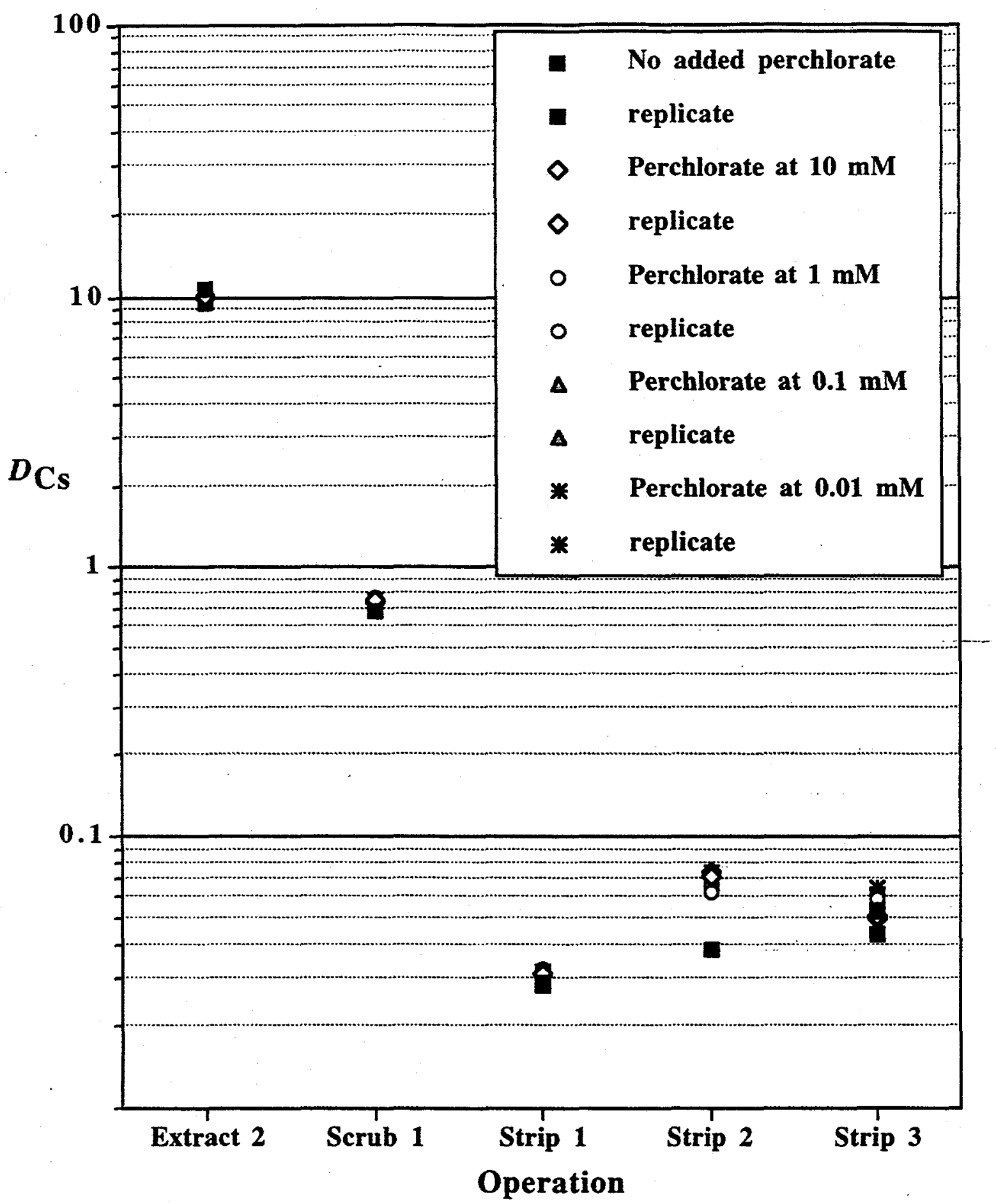

Figure 5.1. Dependence of cesium distribution on perchlorate concentration in SRS\#2-1 simulant (Cs3C/120L-2 solvent). All cesium distribution ratios have an uncertainty of $\pm 5 \%$. 
second stripping contact, but for the most part it can be concluded that the presence of even high amounts of perchlorate (up to $10 \mathrm{mM}$ ) does not adversely affect the distribution of cesium in the process flowsheet.

\subsubsection{Effect of the Presence of Phenols in the Solvent on $D_{\mathrm{Cs}}$.}

The possibility that 4-t-octylphenol and 2-nitro-4-t-octylphenol could be present in the solvent was discussed in the previous chapter. Accordingly, it was necessary to determine what effect these phenols would have on the cesium distribution behavior for each contact in the flowsheet. As can be seen in the cesium distribution data presented in Table 5.2 and in Figure 5.2, both phenols significantly increase the $D_{\mathrm{Cs}}$ on the extraction contact from the alkaline waste simulant, though the nitrated phenol produces the higher $D_{\mathrm{Cs}}$. The manner by which the phenols enhance the cesium extraction strength may include a contribution from the direct extraction of cesium by the phenolate anion, similar to the manner in which 4-sec-butyl-2-( $\alpha$ methylbenzyl)phenol (BAMBP) [2a] and 4-tert-butyl-2-( $\alpha$-methylbenzyl)phenol [2b] extract cesium. In addition, the phenols may act synergistically with the BoBCalixC6 by serving as lipophilic counter-anions for the cesium complexed by the BoBCalixC6, thus increasing the solvation of the BoBCalixC6-Cesium-anion complex. The reason 2-nitro, 4-t-octylphenol leads to stronger extraction than 4-t-octylphenol could include the possibility that it is more acidic, and that the nitro group ortho to the phenolate oxygen may be capable of forming a weak interaction with the cesium ion.

Table 5.2." Cesium distribution ratios for $\mathrm{Cs3C} / 120 \mathrm{~L}-2$ solvent, with and without added phenols at $25^{\circ} \mathrm{C}$ (Simulant SRS\#2-1).

\begin{tabular}{|l|c|c|c|}
\hline $\begin{array}{l}\text { Contact } \\
\text { Stage }\end{array}$ & $\begin{array}{l}D_{\text {Cs }} \text { Cs3C/120L-2 } \\
\text { Pristine }\end{array}$ & $\begin{array}{l}D_{\text {Cs }} \text { Cs3C/120L-2 } \\
\mathbf{0 . 0 2} \text { M 4-t-octylphenol }\end{array}$ & $\begin{array}{l}D_{\text {Cs }} \text { Cs3C/120L-2 } \\
\text { 0.01 M 2-nitro- } \\
\text { 4-t-octylphenol }\end{array}$ \\
\hline Extraction 2 & 10.78 & $13.93 ; 13.82$ & $18.48 ; 18.19$ \\
\hline Scrub 1 & 0.688 & $0.848 ; 0.842$ & $0.628 ; 0.642$ \\
\hline Strip 1 & $0.028 ; 0.029$ & $0.039 ; 0.039$ & $0.030 ; 0.032$ \\
\hline Strip 2 & $0.038 ; 0.038$ & $0.062 ; 0.060$ & $0.046 ; 0.052$ \\
\hline Strip 3 & $0.052 ; 0.044$ & $0.064 ; 0.064$ & $0.051 ; 0.057$ \\
\hline
\end{tabular}




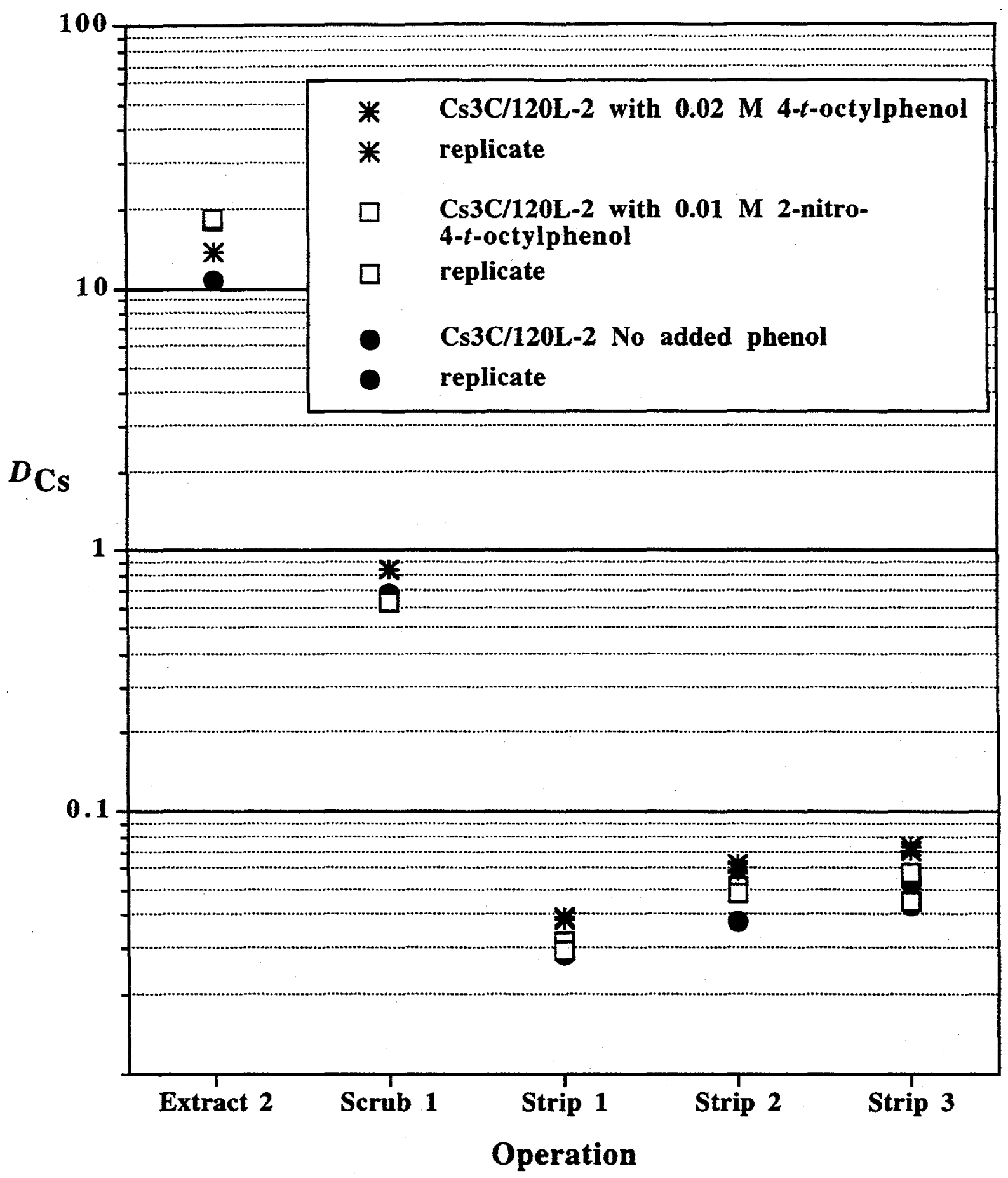

Figure 5.2. Dependence of cesium distribution on the presence of 4-t-octylphenol $(0.02 \mathrm{M})$ or 2-nitro-4-t-octylphenol $(0.01 \mathrm{M})$ in the Cs3C/120L-2 solvent. All cesium distribution ratios have an uncertainty of $\pm 5 \%$. 
Interestingly, 2-nitro, 4-t-octylphenol does not appear to influence the cesium distribution behavior for the scrubbing and stripping contacts. The presence of 4 -t-octylphenol very slightly increases all the scrubbing and stripping distribution ratios by $20-30 \%$ (except for the second stripping contact, where the increase in $D_{\mathrm{Cs}}$ was about $60 \%$ ). Overall, the effect these phenols have on the cesium distribution behavior on scrubbing and stripping is small, as the acidity of the scrub and strip solutions effectively keeps the phenols protonated.

\subsubsection{Effect of Minor Inorganic Components on $D_{\mathrm{Cs}}$.}

Simulant SRS\#3, containing $\mathrm{Fe}, \mathrm{Hg}, \mathrm{Pb}$, and $\mathrm{Si}$ at concentrations nominally of respectively $1 \times 10^{-5} \mathrm{M}, 1 \times 10^{-4} \mathrm{M}, 1 \times 10^{-4} \mathrm{M}$, and $1.1 \times 10^{-2} \mathrm{M}$, was prepared as described above (see section 5.2.1 and Table 5.1) following the basic recipe for SRS \#2-1. Sodium fluoride was omitted from this simulant to reduce the degree of precipitation. The cesium distribution behavior using solvent Cs3D/120L-2 for two extraction contacts, one scrubbing contact, and three stripping using SRS\#3 simulant is shown in Table 5.3, with corresponding data using SRS\#2-1 simulant for comparison.

It can be seen that within the normal experimental uncertainty of $\pm 5 \%$, the cesium distribution ratios obtained are the same using the two simulants.

Table 5.3. Cesium distribution ratios for Cs3D/120L-2 solvent with simulants SRS \#2-1 and SRS \#3 at $25^{\circ} \mathrm{C}$.

\begin{tabular}{|l|c|c|}
\hline $\begin{array}{l}\text { Contact } \\
\text { Stage }\end{array}$ & $\begin{array}{l}D_{\text {Cs }} \text { Cs3D/120L-2 } \\
\text { with Simulant SRS \#2-1 }\end{array}$ & $\begin{array}{l}D_{\text {Cs }} \text { Cs3D/120L-2 } \\
\text { with Simulant SRS \#3 }\end{array}$ \\
\hline Extraction 1 & $11.60 ; 11.88$ & $11.71 ; 11.95$ \\
\hline Extraction 2 & $10.70 ; 10.78$ & $10.73 ; 10.71$ \\
\hline Scrub 1 & $0.660 ; 0.664$ & $0.663 ; 0.670$ \\
\hline Strip 1 & $0.030 ; 0.030$ & $0.031 ; 0.031$ \\
\hline Strip 2* & $0.045 ; 0.046$ & $0.054 ; 0.053$ \\
\hline Strip 3* & $0.071 ; 0.065$ & $0.086 ; 0.079$ \\
\hline
\end{tabular}

* Additional cesium-137 nitrate tracer added to the strip solution. 


\subsubsection{Distribution of Minor Inorganic Components in SRS\#3 Simulant.}

The distribution of $\mathrm{Al}, \mathrm{Cr}, \mathrm{Fe}, \mathrm{Hg}, \mathrm{K}, \mathrm{Na}, \mathrm{Pb}$, and $\mathrm{Si}$ during two extraction, two scrubbing, and three stripping contacts was determined by ICP analysis of the aqueous phases for extraction of SRS\#3 simulant by solvent Cs3D/120L-2. The ICP detection limits, and the concentration of the metals found by ICP in the SRS\#3 simulant, are shown in Table 5.4, along with the nominal metal concentrations based on the preparation of the simulant (from Table 5.1). Sodium analyzed low in the simulant, since even after dilution to about $1000 \mathrm{ppm}$, the concentration in the sample analyzed was near the upper limit of the linear range. Most other metals gave analytic concentration values that were in reasonably good agreement with the nominal values. It was surprising to actually find $\mathrm{Fe}, \mathrm{Hg}$, and $\mathrm{Pb}$ at near the nominal concentrations, as they normally would be expected to be insoluble at the high hydroxide concentration of the simulant. For the hydroxides $\mathrm{Fe}(\mathrm{OH})_{3}, \mathrm{~Pb}(\mathrm{OH})_{2}$, and $\mathrm{Hg}(\mathrm{OH})_{2}$, the solubility product constants $K_{\text {sp }}$ are respectively $2.64 \times 10^{-39}, 1.42 \times 10^{-20}$, and $3.13 \times 10^{-26}[3]$.

Table 5.4. ICP analysis of SRS\#3 Simulant.

\begin{tabular}{|l|l|l|l|}
\hline Metal & $\begin{array}{l}\text { ICP Detection } \\
\text { Limits (M) }\end{array}$ & $\begin{array}{l}\text { Nominal Concentration } \\
\text { in SRS\#3 Simulant (M) }\end{array}$ & $\begin{array}{l}\text { Concentration Found by } \\
\text { ICP Analysis (M) }\end{array}$ \\
\hline $\mathrm{Al}$ & $1.11 \times 10^{-6}$ & $4.00 \times 10^{-1}$ & $3.61 \times 10^{-1}$ \\
\hline $\mathrm{Cr}$ & $5.77 \times 10^{-7}$ & $1.50 \times 10^{-2}$ & $1.50 \times 10^{-2}$ \\
\hline $\mathrm{Fe}$ & $1.25 \times 10^{-7}$ & $1.0 \times 10^{-5}$ & $2.06 \times 10^{-5}$ \\
\hline $\mathrm{Hg}$ & $3.49 \times 10^{-7}$ & $1.0 \times 10^{-4}$ & $6.96 \times 10^{-5}$ \\
\hline $\mathrm{K}$ & $5.12 \times 10^{-6}$ & $2.0 \times 10^{-2}$ & $1.8 \times 10^{-2}$ \\
\hline $\mathrm{Na}$ & $5.65 \times 10^{-7}$ & $6.96 \times 10^{0}$ & $6.11 \times 10^{0}$ \\
\hline $\mathrm{Pb}$ & $4.83 \times 10^{-7}$ & $1.0 \times 10^{-4}$ & $1.39 \times 10^{-4}$ \\
\hline $\mathrm{Si}$ & $1.78 \times 10^{-6}$ & $1.10 \times 10^{-2}$ & $6.87 \times 10^{-3}$ \\
\hline
\end{tabular}

The concentrations of the metal ions in the aqueous solution at each contact are shown in Table 5.5. No metal ions were observed in the aqueous raffinates from the second and third stripping contacts. The metal ion concentration data obtained for the two scrubbing contacts and 
Table 5.5. ICP analyses of aqueous phases from extraction, scrubbing, and stripping contacts. ${ }^{a}$

\begin{tabular}{|l|l|l|l|l|l|}
\hline Metal & $\begin{array}{l}\text { (M) First } \\
\text { Extraction }\end{array}$ & $\begin{array}{l}\text { (M) Second } \\
\text { Extraction }\end{array}$ & $\begin{array}{l}\text { (M) First } \\
\text { Scrub }\end{array}$ & $\begin{array}{l}\text { (M) Second } \\
\text { Scrub }\end{array}$ & $\begin{array}{l}\text { (M) First } \\
\text { Strip }\end{array}$ \\
\hline $\mathrm{Al}$ & $3.03 \times 10^{-1}$ & $2.98 \times 10^{-1}$ & $1.14 \times 10^{-5}$ & BDL & $4.19 \times 10^{-6}$ \\
\hline $\mathrm{Cr}$ & $1.53 \times 10^{-2}$ & $1.5 \times 10^{-2}$ & $\mathrm{BDL}$ & $\mathrm{BDL}$ & $\mathrm{BDL}$ \\
\hline $\mathrm{Fe}$ & $2.01 \times 10^{-5}$ & $1.81 \times 10^{-5}$ & $2.38 \times 10^{-7}$ & $\mathrm{BDL}$ & $\mathrm{BDL}$ \\
\hline $\mathrm{Hg}$ & $4.37 \times 10^{-5}$ & $5.12 \times 10^{-5}$ & $2.22 \times 10^{-6}$ & $1.28 \times 10^{-6}$ & $\mathrm{BDL}$ \\
\hline $\mathrm{K}$ & $1.22 \times 10^{-2}$ & $1.32 \times 10^{-2}$ & $2.65 \times 10^{-3}$ & $\mathrm{BDL}$ & $\mathrm{BDL}$ \\
\hline $\mathrm{Na}$ & $5.07 \times 10^{0}$ & $4.99 \times 10^{0}$ & $4.0 \times 10^{-3}$ & $\mathrm{BDL}$ & $\mathrm{BDL}$ \\
\hline $\mathrm{Pb}$ & $1.17 \times 10^{-4}$ & $1.06 \times 10^{-4}$ & $9.98 \times 10^{-7}$ & $\mathrm{BDL}$ & $\mathrm{BDL}$ \\
\hline $\mathrm{Si}$ & $6.6 \times 10^{-3}$ & $6.0 \times 10^{-3}$ & $\mathrm{BDL}$ & $\mathrm{BDL}$ & $\mathrm{BDL}$ \\
\hline
\end{tabular}

${ }^{a}$ Values are the average of two analyses. $\mathrm{BDL}=$ below detection limits stated in Table 5.4.

the first stripping contact are of particular interest, for they indicate to what extent each metal is extracted and moves through the process flowsheet. (Since only the aqueous phases were analyzed directly, information regarding how much metal ion is retained in the solvent was not avaliable here, though based on the cesium scrubbing and stripping behavior, the concentration of metal ions retained in the solvent phase should be small. Also, it is difficult to reliably calculate the amount of metal that transferred to the solvent during extraction by taking the difference in metal ion concentration between the feed and raffinate solutions, since the uncertainties for some metals can be large, and there is no direct way to check for mass balances. The solvent would need to be decomposed and analyzed.) It can be seen that Si does not appear to distribute to the scrubbing or stripping aqueous phases at all, suggesting that it is likely not extracted to a significant extent. The concentrations of $\mathrm{Al}, \mathrm{Cr}, \mathrm{Fe}, \mathrm{Hg}, \mathrm{Pb}$ and $\mathrm{Si}$ in the first scrubbing contact are all very low, and only $\mathrm{Al}$ and $\mathrm{Hg}$ continue to be detected in subsequent scrubbing and stripping contacts. Sodium and potassium are the only metals that appear to be co-extracted to any extent, and which appear to be washed out of the solvent in the first scrubbing contact. The fact that these metals appear to distribute essentially quantitatively to the aqueous phase in the first scrubbing contact (and negligibly if at all to the subsequent contacts), means that the stripping solutions will not contain large amounts of non-cesium-containing salts. It is anticipated that the extracted Cs-137 will be disposed of by concentrating the cesium-bearing stripping solutions by evaporation, and 
incorporating the salt residue which remain into glass (vitrification). Minimizing the bulk of the non-cesium salts will reduce the amount of glass required to incarcerate the cesium, which will reduce the cost of waste disposal.

\subsection{CONCLUSIONS}

In this chapter we examined the effect minor aqueous feed and solvent components would have on the distribution of Cs during the extraction, scrubbing, and stripping contacts. Minor components that could be present in the aqueous feed include perchlorate, $\mathrm{Fe}, \mathrm{Hg}, \mathrm{Pb}$, and $\mathrm{Si}$. It. was found that perchlorate as a possible impurity up to $10 \mathrm{mM}$ in the SRS waste feed simulant (SRS\#3) is unlikely to have a significant effect on flowsheet performance. The trace metals Fe, $\mathrm{Hg}, \mathrm{Pb}$, and $\mathrm{Si}$ were a) found to minimally distribute to the scrubbing and stripping solutions, and b) had no effect on the cesium distribution behavior. Other metals in the feed ( $\mathrm{Al}, \mathrm{Cr}, \mathrm{K}$, and $\mathrm{Na}$ ) were mostly scrubbed out of the solvent in the first scrubbing contact, with very little if any of these metals being found in subsequent scrubbing and stripping contacts. The presence of 4-toctylphenol at $0.02 \mathrm{M}$ (10 mol\% on the modifier), and 2-nitro-4-t-octylphenol at $0.01 \mathrm{M}$ (5\% on the modifier) in the solvent were found to minimally impact the cesium distribution behavior during the scrubbing and stripping contacts, but to somewhat increase the cesium extraction strength.

\subsection{REFERENCES}

1. Moyer, B. A.; Bonnesen, P. V. Physical Factors in Anion Separations. In Supramolecular Chemistry of Anions; Bianchi, A., Bowman-James, K., Garcia-España, E., Eds.; VCH: New York, 1977, Chap. 1.

2. (a) Zingaro, R.A.; Coleman, C.F. J. Inorg. Nucl. Chem. 1967, 29, 1287-1300.

Rais, J.; Krtil, J.; Chotivka, V. Talanta, 1971, 18, 213-218.

3. CRC Handbook of Chemistry and Physics, $7^{\text {th }}$ Edition; Lide, D. R., Ed.; CRC Press Inc.: Boca Raton, FL, 1994; p 8-58. 


\section{SOLVENT INTEGRITY}

\subsection{INTRODUCTION}

In this section we report our investigations regarding the stability of the solvent following prolonged contact with various aqueous phases at both $25 \pm 0.2{ }^{\circ} \mathrm{C}$ and $53 \pm 2{ }^{\circ} \mathrm{C}$. Also reported here are performance tests of solvent $\mathrm{Cs} 3 \mathrm{~B} / 150 \mathrm{~L}$ following gamma-irradiation (cobalt-60 source) by colleagues at SRS. The practical longevity of the solvent will be of prime economic importance, as the faster the solvent irreparably degrades, the more frequently the solvent will need to be replaced, driving up operating expenses. The results we report here are only the initial results of lengthier studies, which are continuing.

\subsection{EXPERIMENTAL}

\subsubsection{Materials and Contacting Procedures}

Reagents. See section 2.2.1.

Contacting for Chemical Stability Tests. In general, equal volumes of the desired solvent and aqueous phases were placed in Teflon ${ }^{\circledR}$ FEP or polypropylene tubes, and rotated using Glas$\mathrm{Col}^{\circledR}$ rugged rotators for various time periods. Contacting at $25 \pm 0.2{ }^{\circ} \mathrm{C}$ was performed in the airbox (see section 2.2.4), and contacting at $53 \pm 2{ }^{\circ} \mathrm{C}$ was performed in a Lab-line ${ }^{\circledR}$ model Imperial III incubator (see also section 3.2.2).

\subsubsection{NMR Analyses}

Samples of solvent were analyzed directly by proton NMR (Bruker MSL-400, 400.13 $\mathrm{MHz}$ proton) by diluting $100 \mu \mathrm{L}$ aliquots with 900 or $920 \mu \mathrm{L}$ of $\mathrm{CDCl}_{3}$ containing hexamethylbenzene at $5.15 \mathrm{mM}$. A minimum of 256 scans was collected for each sample. The Isopar ${ }^{\circledR} \mathrm{L}$ aliphatic protons swamp the region upfield of $2 \mathrm{ppm}$, but with the exception of the protons from the $t$-octyl groups (which are not very sensitive to changes), all the protons of interest are downfield of $2 \mathrm{ppm}$, and these were examined by increasing the vertical display and performing a baseline correction. The region between 8 and $2 \mathrm{ppm}$ could then be plotted and the peaks integrated. 


\subsubsection{Solvent Irradiations at Savannah River}

Equal volumes of solvent (Cs3B/150L) and SRS\#2 simulant (prepared at SRS) were placed in vials and irradiated using a Co-60 source at Savannah River's facility, by Dr. Reid Peterson. Samples were separately irradiated for periods of $1,4,8$, and 25 hours, corresponding to approximately $1.14,4.56,9.12$, and 28.5 megarads exposure [1]. The samples were sent to ORNL, where $100 \mu \mathrm{L}$ aliquots were analyzed by proton NMR following the procedure above, and the remaining solvent (about $1 \mathrm{~mL}$ ) subjected to one extraction contact with SRS\#2-1 simulant containing Cs-137 tracer, one scrubbing contact with $50 \mathrm{mM}$ nitric acid, and two stripping contacts with $0.5 \mathrm{mM}$ nitric acid containing $0.1 \mathrm{mM}$ cesium nitrate. Since the starting volume for each sample was small, the solvent sub-samples submitted for gamma counting after each contact were recovered and carried back into the process for the subsequent contact.

\subsection{RESULTS AND DISCUSSION}

\subsubsection{Chemical Stability.}

As part of a separate project, deutero-chloroform solutions of the Cs3 modifier $(0.50 \mathrm{M})$, and the BoBCalixC6 $(0.020 \mathrm{M})$ were contacted with equal volumes of $4 \mathrm{M}$ nitric acid by end-overend rotation at $25^{\circ} \mathrm{C}$, and organic solutions periodically analyzed by proton NMR. These early tests showed that whereas the BoBCalixC6 is sensitive to $4 \mathrm{M}$ nitric acid, becoming extensively nitrated after only one week exposure, the modifier showed no indications of being nitrated, even after 4.5 months continuous exposure. (The modifier will become nitrated if contacted with concentrated nitric acid, however.) The BoBCalixC6 is much less nitrated at lower nitric acid concentrations, and in fact showed no visible sign of nitration following a month's exposure to 50 $\mathrm{mM}$ nitric acid at $25^{\circ} \mathrm{C}$. Conversely, prolonged contacting studies with alkaline simulant solutions revealed BoBCalixC6 to be quite stable, whereas the modifier showed indications of being degraded. Since relatively dilute nitric acid concentrations are used in the scrub and strip stages of the proposed flowsheet, chemical degradation is most likely to occur during the extraction stages when the solvent is exposed to the highly alkaline (1.9 M in free hydroxide) SRS\#2-1 simulant. Also during the extraction stages, the solvent will become loaded with Cs-137, where it will be exposed to high doses of radiation, and possibly be warmed to temperatures up to $50{ }^{\circ} \mathrm{C}$. (The waste feed itself may be as warm as $45^{\circ} \mathrm{C}$, with further heating caused by concentrating the radiation field.) Thus to evaluate the chemical stability of the solvent, initial studies have focused on what happens to the solvent when exposed to the simulant for prolonged time periods at both ambient $\left(25^{\circ} \mathrm{C}\right)$ and elevated $\left(53^{\circ} \mathrm{C}\right)$ temperatures. 
Studies Conducted at $53^{\circ} \mathrm{C}$. For contacts at $53^{\circ} \mathrm{C}$, two solvent samples were examined: a sample of Cs3B/120L which had been recovered from an earlier extraction, scrub, strip test, and which had sat over $30 \mathrm{mM}$ nitric acid for about one month; and a sample of pristine Cs3C/120L-2. The former sample was stripped of all measurable Cs-137 activity by washing three times with O/A $=0.3$ of the standard stripping solution $(0.5 \mathrm{mM}$ nitric acid/0.1 $\mathrm{mM}$ cesium nitrate). It was then

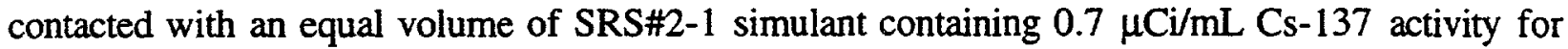
570 hours, in a Teflon ${ }^{\circledR}$ FEP centrifuge tube by end-over-end rotation at $53 \pm 2{ }^{\circ} \mathrm{C}$ in an incubator. The latter solvent sample was contacted with the same simulant for 375 hours, in the same manner. After removal from the $53{ }^{\circ} \mathrm{C}$ incubator, the samples were allowed to rotate at $25^{\circ} \mathrm{C}$ for 2.5 hours for equilibrium to be reached at $25^{\circ} \mathrm{C}$. Aliquots of the aqueous and organic phases for each sample were removed and the $D_{\mathrm{Cs}}$ at $25^{\circ} \mathrm{C}$ determined (first extraction contact). The solvent was then carried through the rest of the standard evaluation procedure of one scrub and three strips. (In this case, only one net extraction contact was performed.) A sample of pristine Cs3C/120L-2 that had not been exposed to heat or simulant was also carried through a one extraction, one scrub and three strip procedure as a control. The results, plotted in Figure 6.1, show that the most serious consequence of long term exposure to the alkaline simulant at $53^{\circ} \mathrm{C}$ is a decrease in the extraction distribution ratio (by greater than 50\%). The recovered solvent performed slightly worse than the pristine, which may simply be due to the longer exposure time. The $D_{\mathrm{Cs}}$ on scrubbing was lower than the control, but the stripping distribution ratios were slightly elevated. It was also noted during the contacting that the phase disengagement times were somewhat longer on the scrubbing contacts when compared to the control, but interestingly were slightly shorter on stripping, and about the same as the control on extraction.

It was of interest to discover what chemically happened to the solvent, specifically whether the modifier and/or the BoBCalixC6 degraded, and if they degraded, could the degradation products be identified and removed. Solvent samples from the third stripping contact, which contained cesium-137 activity levels of no more than twice background, were analyzed by proton NMR by the procedure described above in section 6.2.2. The results are presented in Table 6.1 The 920 microliters of deutero-chloroform used to dilute the 100 microliters of solvent sample contained hexamethybenzene (HMB) at $5.15 \mathrm{mM}$, which appears as a singlet at $2.21 \mathrm{ppm}$ (chloroform $=7.26 \mathrm{ppm}$ ). The concentration of $\mathrm{HMB}$ in the combined diluted solvent was calculated to be $4.65 \mathrm{mM}$. By comparing the integral of the triplet centered at 6.68 for BoBCalixC6 (see Table 4.1) with the integral from the HMB in the control solvent, and in the two thermally degraded solvents, it was evident that no detectable degradation of BoBCalixC6 had occurred. However, the NMR spectra did reveal extensive degradation of the modifier. Noteworthy was the appearance of a second triplet of triplets (tt) centered at $5.64 \mathrm{ppm}$ diagnostic 


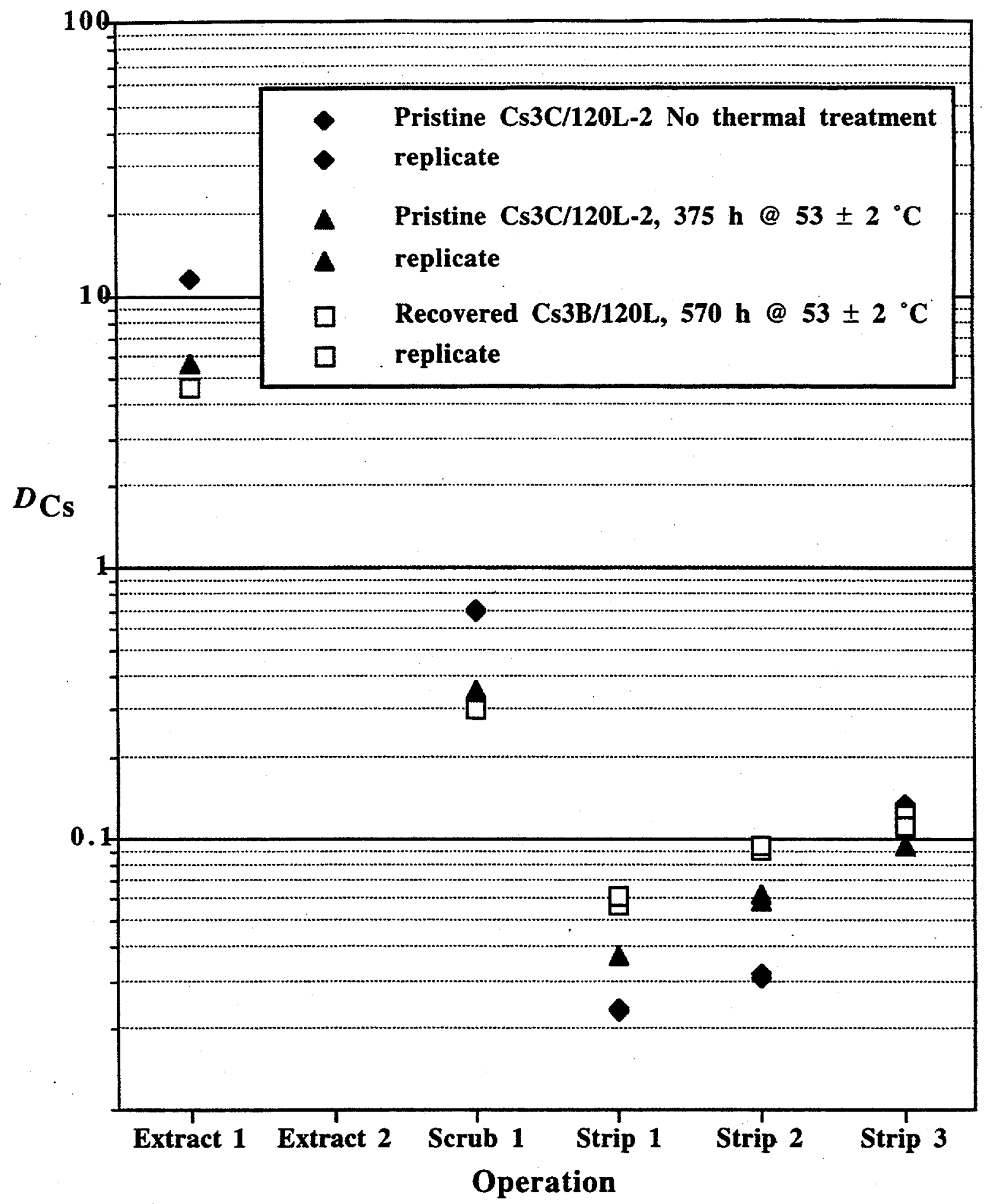

Figure 6.1. Solvent performance following thermal treatment. All distribution measurements were conducted with $\mathrm{O} / \mathrm{A}=1$ at $25^{\circ} \mathrm{C}$ in plastic vessels. Heated solvents were allowed to cool for $2.5 \mathrm{~h}$ at $25^{\circ} \mathrm{C}$ before $\mathrm{D}(\mathrm{Cs})$ extraction was measured. All other contacts used 30 minute rotation at $25^{\circ} \mathrm{C}$. 
for the (evidently still intact) $-\mathrm{OCF}_{2} \mathrm{CF}_{2} \mathrm{H}$ moiety (the triplet of triplets from the Cs3 modifier itself is centered at $5.70 \mathrm{ppm}$ ). The alcohol hydroxyl proton from the Cs3 (doublet at $2.44 \mathrm{ppm}$ ) had decreased proportionately with the tetrafluoroethoxy proton centered at $5.70 \mathrm{ppm}$, and there appeared to be some new resonances in the aromatic region. A combination of the hydroxyl and tetrafluoroethoxy protons from the Cs3 modifier was used to determine the modifier's remaining concentration. The cesium extraction distribution data and the amount of intact Cs 3 modifier in the solvent as a function of exposure time are shown in Table 6.1. While there is at least a $\pm 10 \%$ uncertainty in calculating the concentration of the remaining Cs3 using NMR, it can be seen that there is a correlation between the decrease in the [Cs3] and the decrease in the $D_{\mathrm{Cs}}$. However the "modifier effect" is non-linear. If one consults Figure 2.2 , which charts the $D_{\mathrm{Cs}}$ from SRS\#2-1 simulant as a function of [Cs3], one can see that the $D_{\mathrm{Cs}}$ obtained on extraction between a nonloaded solvent and SRS\#2-1 simulant with the Cs3 modifier at $0.10 \mathrm{M}$ is $4.73 \pm 0.03$. If one extrapolates the $D_{\mathrm{Cs}}$ from the [Cs3] using Figure 2.2 and the values for [Cs3] obtained from the NMR, one finds that the predicted $D_{\mathrm{Cs}}$ is in very good agreement with the $D_{\mathrm{Cs}}$ observed for the degraded solvents as a function of [Cs3].

Table 6.1. Comparison between decrease in $D_{C s}$ and decrease in [Cs3] for solvents contacted with SRS\#2-1 simulant containing $\mathrm{Cs}-137$ tracer at $53{ }^{\circ} \mathrm{C}$.

\begin{tabular}{|c|c|c|c|c|c|}
\hline Solvent, time at $53{ }^{\circ} \mathrm{C}$ & $\begin{array}{c}D_{\mathrm{Cs}} \\
( \pm \mathbf{5 \%})\end{array}$ & $\begin{array}{c}\% \text { of } \\
\text { maximum } \\
D_{\mathrm{Cs}}\end{array}$ & $\begin{array}{l}{[\mathrm{Cs} 3], \mathrm{M}} \\
( \pm 10 \%)\end{array}$ & $\begin{array}{c}\% \text { of } \\
\text { maximum } \\
{[\mathrm{Cs} 3]}\end{array}$ & $\begin{array}{c}\text { Predicted } \\
D_{\text {Cs from }} \\
\text { [Cs3] } \\
( \pm 10 \%)^{\mathrm{a}}\end{array}$ \\
\hline $\begin{array}{l}\text { Pristine Cs } 3 \mathrm{C} / 120 \mathrm{~L}-2 \text {, No heat } \\
\text { (Control) }\end{array}$ & 11.54 & 100 & $1.977 \times 10^{-1}$ & 100 & 11.2 \\
\hline Pristine $\mathrm{Cs} 3 \mathrm{C} / 120 \mathrm{~L}-2,375 \mathrm{hr}$ & 5.688 & 49.3 & $1.128 \times 10^{-1}$ & 57.1 & 5.8 \\
\hline Recovered Cs3B/120L, $570 \mathrm{hr}$ & 4.672 & 40.5 & $9.920 \times 10^{-2}$ & 50.2 & 4.7 \\
\hline
\end{tabular}

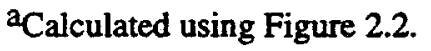

We next wanted to find out whether the degradation products could be washed out of the solvent. Whereas the degradation products themselves do not noticeably influence the cesium extraction performance, the degradation products do appear to slightly impact both the cesium distribution and the phase coalescence behavior during the scrubbing and stripping contacts (see above). To determine whether the degradation products could be washed out, a bulk portion of the recovered solvent that had been contacted for 570 hours was washed successively four times with stripping solution at $\mathrm{O} / \mathrm{A}=0.2$ to remove the $\mathrm{Cs}-137$ activity, and the washed sample analyzed by 
proton NMR spectrometry. The NMR spectrum was essentially the same as the one obtained previously on the solvent from the third stripping contact, with the concentration of Cs3 modifier and the degradation product(s) being essentially unchanged within the uncertainty ( $\pm 5 \%$ ) of the integration.

A further attempt was made to wash the degradation products out of the solvent. On the basis of the partitioning behavior investigated in Chapter 4, phenols such as 4-t-octylphenol should wash out upon extended contacts with $0.5 \mathrm{M} \mathrm{NaOH}$. Also, if the modifier did break down to give 4-t-octylphenol as one of the degradation products, the modifier fragment that remained would contain a - $\mathrm{OCF}_{2} \mathrm{CF}_{2} \mathrm{H}$ moiety, and thus could be $\mathrm{HCF}_{2} \mathrm{CF}_{2} \mathrm{OCH}_{2} \mathrm{CH}(\mathrm{OH}) \mathrm{CH}_{2} \mathrm{OH}$, which should be sufficiently hydrophilic to partition substantially to an aqueous washing phase. Therefore, the solvent was washed five times with $0.5 \mathrm{M} \mathrm{NaOH}$ at $\mathrm{O} / \mathrm{A}=0.2$, and a $100 \mu \mathrm{L}$ sample of this washed solvent analyzed by proton NMR spectrometry. The NMR spectrum again showed the solvent to be essentially unchanged; nothing appeared to have been washed out. It thus appears that the major degradation products of the modifier do not include 4-t-octylphenol. This is supported by the fact that the proton NMR chemical shifts for the new aromatic proton peaks did not match those of 4-t-octylphenol in the solvent. In addition, as was seen in Chapter 5, Table 5.2 , the presence of phenols such as 4-t-octylphenol in the solvent would tend toward raising $D_{\mathrm{Cs}}$ on extraction; since the observed decrease in $D_{\mathrm{Cs}}$ was extremely well-correlated with the decrease in the [Cs3], it does not appear that a phenolic species is present in the solvent.

Other chemical degradation tests conducted at $53 \pm 2{ }^{\circ} \mathrm{C}$ showed that when a solution of the Cs3 modifier alone at $0.50 \mathrm{M}$ in Isopar ${ }^{\circledR} \mathrm{L}$ was continuously contacted with SRS\#2-1 simulant for 575 hours, the degradation of the modifier was much less. NMR analysis revealed that the modifier had degraded by about $10 \%$, with an effective concentration of $0.45 \mathrm{M}$. The same unidentified degradation products were observed. Thus, it appears that the degradation of the modifier may be caused by the presence of hydroxide. When the BoBCalixC6 is present, much more hydroxide would be expected to be in the organic phase (as a counter ion to the cations extracted), and thus it is not surprising that the degradation of the modifier is more extensive when the BoBCalixC6 is present. It is quite possible that the modifier does not fragment, but instead rearranges, or even oligomerizes, in a base-catalyzed reaction. The mechanism of the modifier degradation and the identities of the degradation product(s) are still under investigation.

A solvent (pristine $\mathrm{Cs} 3 \mathrm{C} / 120 \mathrm{~N} 13$ ) in which the diluent was Norpar ${ }^{\circledR} 13$ (normal paraffinic diluent) in place of Isopar ${ }^{\circledR} \mathrm{L}$ was also subjected to continuous contact with SRS\#2-1 simulant for 570 hours at $53^{\circ} \mathrm{C}$. The $D_{\mathrm{Cs}}$ s obtained on the single extraction, single scrub, and three stripping contacts were virtually identical to those obtained using the recovered Cs3B/120L that was also contacted with the SRS\#2-1 simulant for 570 hours. Thus, it appears that the substitution of Norpar ${ }^{\circledR} 13$ for Isopar ${ }^{\circledR} \mathrm{L}$ has no affect on the extent of chemical degradation of the solvent. 
Interestingly, prior work with Norpar ${ }^{\circledR} 13$ [2] suggested that, all things being equal, phase coalescence times are longer with normal paraffinic diluents than with isoparaffinic diluents, but in this case, the phase behavior and coalescence times were the same as those for Cs3B/120L.

Finally, continuous contacting of solvent Cs $3 \mathrm{C} / 120 \mathrm{~L}-2$ with $50 \mathrm{mM}$ nitric acid scrub solution for 43 days at $53 \pm 2{ }^{\circ} \mathrm{C}$ resulted (by NMR analysis) in no detectable degradation of either the BoBCalixC6, or the Cs3 modifier, indicating that the components appear to be stable to exposure to low nitric acid concentrations for extended time periods even at elevated temperatures.

Restoration of Degraded Solvent. It was of interest to ascertain whether the performance of the degraded solvent could be restored by simply adding back to the degraded solvent the amount of Cs3 modifier that had decomposed. A bulk sample of the solvent that was exposed to the SRS\#2-1 simulant for 375 hours at $53{ }^{\circ} \mathrm{C}$ was bulk stripped of activity by washing with the standard stripping solution ( $\mathrm{O} / \mathrm{A}=0.2)$. Proton NMR analysis revealed the modifier concentration to be $0.1063 \mathrm{M}$. The amount of neat Cs3 (lot $\mathrm{D}$ ) modifier required to bring the Cs3 concentration back to $0.2 \mathrm{M}$ was calculated, and added to the solvent. The solvent was then subjected to two extraction contacts with SRS\#2-1 simulant containing Cs-137 tracer, followed by one scrubbing contact and three stripping contacts. The results are shown in Figure 6.2. It can be seen that the $D_{\mathrm{Cs}}$ s obtained on extraction and scrubbing are nearly the same as those obtained with pristine solvent. However, the stripping $D_{C s}$ s were still somewhat higher than those obtained for the pristine solvent, though generally still satisfactory $(<0.10$ on the first and second strips). (By the time the third strip was reached, the activity in the system was too low for accurate distribution ratios to be measured, so the $D_{\mathrm{Cs}}$ on the third stripping contact can be considered to be artificially high due to poor counting statistics.) Generally, it was encouraging to see that simply adding back lost modifier could for the most part restore the solvent.

Chemical Stability at $25^{\circ} \mathrm{C}$. It was also of interest to determine the rate of degradation of the solvent when contacted continuously with the SRS\#2 simulant at $25^{\circ} \mathrm{C}$. Since the most serious drop in performance at $53^{\circ} \mathrm{C}$ was observed for the extraction contacts, only the extraction performance at $25{ }^{\circ} \mathrm{C}$ was monitored during extended periods of contact between the SRS\#2-1 simulant and pristine Cs3C/120L-2 solvent. Contacting was performed in $1.8 \mathrm{~mL}$ polypropylene vials. Two vials were contacted for a given time period, with only one vial containing Cs-137 tracer; this vial was used to determine the $D_{\mathrm{Cs}}$, while the "cold" vial was used for direct NMR analysis. The results are shown in Table 6.2. The $D_{\mathrm{Cs}}$ was observed to decrease as expected, but at a much slower rate than that observed at $53^{\circ} \mathrm{C}$, with the $D_{\mathrm{Cs}}$ dropping by only about $80 \%$ after 27 days of continuous contact.

Proton NMR analysis of the solvent showed the modifier to be slowly degrading in the same manner as was observed at $53{ }^{\circ} \mathrm{C}$, but since the degradation was much less, it was more 


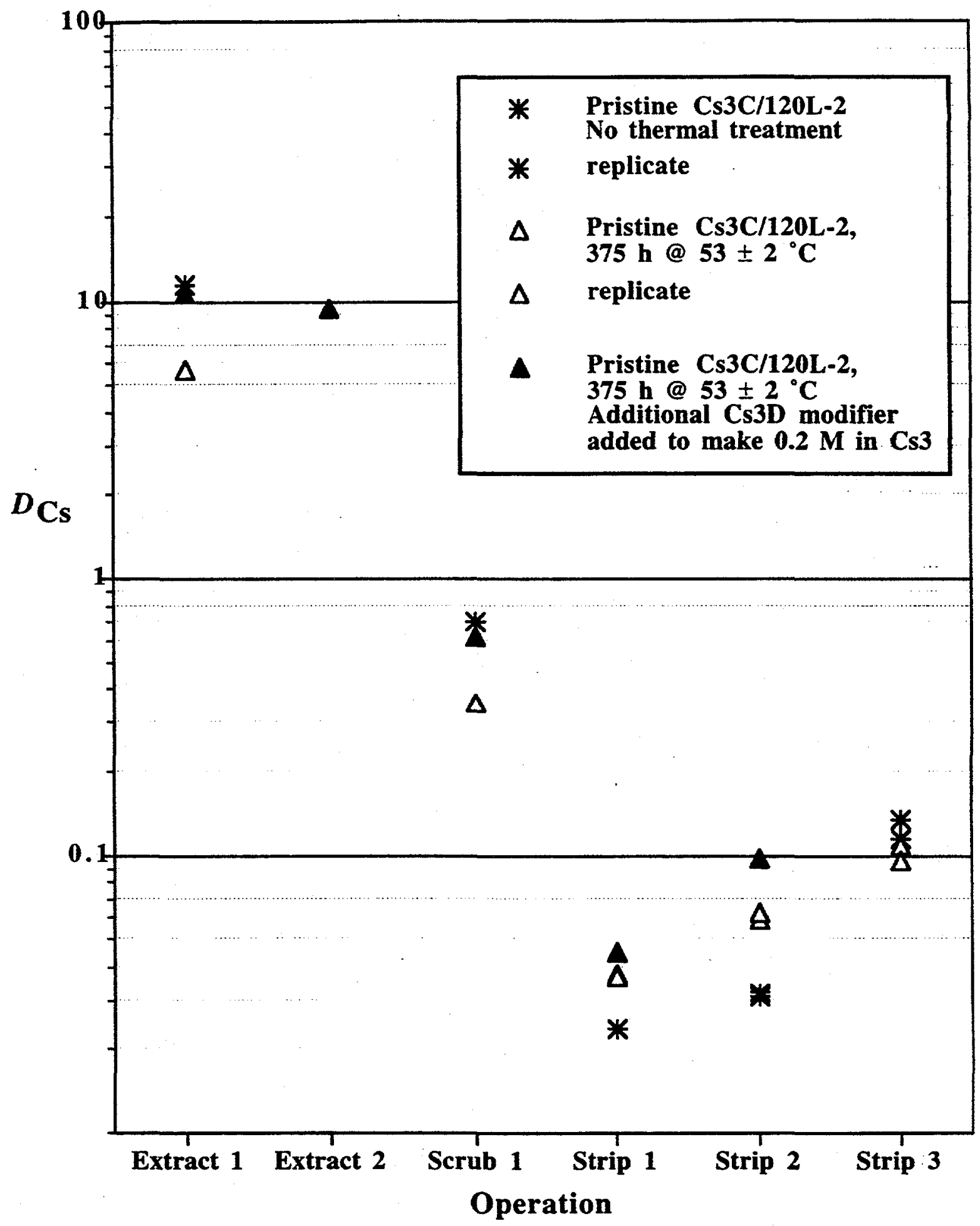

Figure 6.2. Solvent performance following reconstitution of the thermally degraded solvent. All distribution measurements conducted with $\mathrm{O} / \mathrm{A}=1$ at $25^{\circ} \mathrm{C}$, in plastic vessels. Heated solvents were allowed to cool for $2.5 \mathrm{~h}$ at $25^{\circ} \mathrm{C}$ before $\mathrm{D}(\mathrm{Cs})$ extraction was measured. All other contacts used 30 minute rotation at $25^{\circ} \mathrm{C}$. 
difficult to obtain accurate integrations. The Cs3 alcohol peak did not appear in the spectrum, possibly since there is hydroxide in the solvent (unlike the solvents analyzed for the $53{ }^{\circ} \mathrm{C}$ studies which had all been treated with weakly acidic stripping solution) which could deprotonate some fraction of the alcohol, and which could catalyze the exchange with the deuterium in the deuterochloroform. Indeed, the acidity of the alcohol portion of the modifier is of prime interest, as the mechanism by which the modifier decomposes under alkaline conditions likely involves deprotonation of the alcohol as a key step. Future work will also include examining the mechanism by which the modifier decomposes under alkaline conditions, so that perhaps structural modifications can be made to make the modifier more base stable (for example, the Cs3 modifier is a secondary alcohol, and a primary alcohol analog may be more stable).

Table 6.2. Comparison between decrease in $D_{\mathrm{Cs}}$ and decrease in [Cs3] for solvents contacted with SRS\#2-1 simulant containing Cs-137 tracer at $25{ }^{\circ} \mathrm{C}$.

\begin{tabular}{|l|c|c|c|}
\hline Solvent, time at $25{ }^{\circ} \mathbf{C}$ & $\begin{array}{c}\boldsymbol{D}_{\mathbf{C s}} \\
( \pm \mathbf{5 \% )}\end{array}$ & $\begin{array}{c}\text { \% of maximum } \\
\boldsymbol{D}_{\mathbf{C s}}\end{array}$ & \% of maximum [Cs3] a \\
\hline Pristine Cs3C/120L-2, 0.5 hr & 11.93 & 100 & 100 \\
\hline Pristine Cs3C/120L-2, $170 \mathrm{hr}$ & 11.65 & 97.6 & no visible sign of degradation \\
\hline Pristine Cs3C/120L-2, 360 hr & 10.52 & 88.2 & $91.0 \pm 0.2$ \\
\hline Pristine Cs3C/120L-2, 648 hr & 9.575 & 80.3 & $88 \pm 2$ \\
\hline
\end{tabular}

a Estimated from the extent of degradation of the $-\mathrm{OCF}_{2} \mathrm{CF}_{2} \mathrm{H}$ triplet of triplets from $\mathrm{Cs} 3$, and comparing to the ingrowth of a second $-\mathrm{OCF}_{2} \mathrm{CF}_{2} \mathrm{H}$ triplet of triplets from an as yet unidentified degradation product.

\subsubsection{Radiation Stability.}

A sample of solvent Cs3B/150L, the solvent used in the initial flowsheet development using modifier Cs3 (see section 2.3.3), was sent to Dr. Reid Peterson at Westinghouse Savannah River for irradiation. The solvent $(0.50 \mathrm{M}$ in $\mathrm{Cs} 3$ modifier) was irradiated as described above in the experimental section; the dose rate was about 1.14 megarad per hour [1]. Following the irradiations, the solvent phase was separated from the aqueous simulant phase, and sent to ORNL. The appearance of the irradiated samples as received is given in Table 6.3.

Some of the irradiated samples were analyzed by proton NMR by diluting $100 \mu \mathrm{L}$ aliquots of irradiated solvent with $900 \mu \mathrm{L}$ deutero-chloroform containing hexamethylbenzene at $5.15 \mathrm{mM}$ as described above. Due to the high concentration of modifier relative to BoBCalixC6, it was 
difficult to get a clear assessment of the BoBCalixC6 concentration, even after thousands of scans. It does appear by NMR that the BoBCalixC6 may have degraded to a minor degree following 25 hours of irradiation, as visualized by a broadening of the calix resonances, and the ingrowth of some small peaks in the same regions. Surprisingly, by NMR the Cs3 modifier showed no visible sign of decomposition. HPLC analysis performed at SRS on samples of both pristine solvent and solvent that had been exposed to $27 \mathrm{Mrad}$ revealed the Cs3 modifier and BoBCalixC6 degradation to be relatively minor (3\% and $1 \%$, respectively) [3].

Table 6.3. Appearance of Cs3B/150L solvent samples following Co-60 irradiation at SRS.

\begin{tabular}{|c|c|c|c|}
\hline Sample ID (SRS) & $\begin{array}{c}\text { Time Exposed } \\
(\mathbf{H r})\end{array}$ & $\begin{array}{c}\text { Dose } \\
(\text { MegaRad) }\end{array}$ & Appearance \\
\hline 301 & 0 & None & Colorless \\
\hline 102 & 1 & 1.14 & pale pink \\
\hline 114 & 4 & 4.56 & pale straw-colored \\
\hline 237 & 8 & 9.12 & straw-colored \\
\hline 300 & 25 & 28.5 & dark straw-colored/light brown \\
\hline
\end{tabular}

${ }^{\text {a }}$ Estimated from a dose rate of $1.14 \mathrm{Mrad} / \mathrm{hr}$ [1].

The triplet of triplets at $5.7 \mathrm{ppm}$ for the $-\mathrm{OCF}_{2} \mathrm{CF}_{2} \mathrm{H}$ moiety was used for integration, and even after extensive baseline correction, it was difficult to obtain accurate integrals; the modifier integrated higher than the nominal $0.50 \mathrm{M}$ relative to the HMB standard in all cases. It is possible that the radiation caused some of the branched aliphatic Isopar ${ }^{\circledR} \mathrm{L}$ diluent to break down into small aqueous-miscible hydrocarbon fragments, which washed into the aqueous simulant phase, and accordingly increased the modifier concentration in the remaining diluent (solvent). It will be interesting to see whether the radiation stability of Norpar ${ }^{\circledR}$ diluents will be better than that of Isopar $^{\circledR}$ diluents.

Radiolytic breakdown of even small portions of the BoBCalixC6 extractant could produce catecholic and/or phenolic species which could in part account for the coloration of the irradiated solvent samples. Table 6.4 summarizes the NMR analyses obtained thus far on these irradiated samples.

Extraction, Scrub, and Strip Testing of Irradiated Samples. The irradiated solvents were subjected to one extraction contact with SRS\#2-1 simulant containing Cs-137 tracer, followed by 
one scrubbing contact and two stripping contacts in the manner described in the experimental section above (there was not enough solvent to perform a third stripping contact). The results, shown in Figure 6.3, are intriguing in that the effect on $D_{\mathrm{Cs}}$ is different for each operation as the radiation dose increased. On extraction, the $D_{\mathrm{Cs}}$ dropped markedly following even $1 \mathrm{Megarad}$ exposure, reaching a minimum at $4.56 \mathrm{Mrad}$, before increasing to within $77 \%$ of the initial value after 28.5 Mrad. One possible explanation for this observation is that mild radiolysis of some of the BoBCalixC6 results in damage to the crown ether portion of the molecule (e.g., ring-opening) resulting in a drop in cesium complexation capability and selectivity, but that further irradiation results in further breakdown to form perhaps catechols or phenols, which, as was seen previously for the phenols studied in section 5.3.2, have ion exchange properties which could enhance the extractability of cesium. The $D_{\mathrm{Cs}}$ obtained on scrubbing was surprisingly unchanged throughout the range of radiation exposure. It could be that the acid strength in the scrub solution is sufficient to protonate anionic species such as phenols so that their ion-exchange behavior is minimized. The $D_{\mathrm{Cs}}$ on stripping increased as the radiation dose increased, with the second stripping contact having higher $D_{\mathrm{Cs}}$ values than the first strip. The stripping behavior becomes unacceptable following exposure to $4.56 \mathrm{Mrad}$.

It should be noted that the irradiated solvents were tested as received from SRS, and were not washed in any way. Experiments conducted at Savannah River on these same irradiated solvents involved subjecting the solvents to a post-irradiation scrub, prior to the extraction, scrub, and strip assay. The results [3] seemed to indicate that the degradation in extraction performance was less when the solvent was first scrubbed after irradiation, though a similar trend of first worsening extraction $D_{\mathrm{Cs}}$ followed by recovery as a function of dose was also observed.

Table 6.4. Modifier concentration and appearance of BoBCalixC6 in selected irradiated solvent samples.

\begin{tabular}{|c|c|c|c|}
\hline Sample ID (SRS) & $\begin{array}{c}\text { Dose } \\
(\text { MegaRad) }\end{array}$ & $\begin{array}{c}\text { [Cs3], M } \\
( \pm \mathbf{1 0 \%})\end{array}$ & Appearance of BoBCalixC6 \\
\hline 301 & None & 0.65 & $\begin{array}{c}\text { Calix peaks are still identifiable, and } \\
\text { calix appears intact }\end{array}$ \\
\hline 237 & 9.12 & 0.71 & $\begin{array}{c}\text { very broad peaks; calix may have } \\
\text { degraded slightly }\end{array}$ \\
\hline 300 & 28.5 & 0.61 & $\begin{array}{c}\text { very broad peaks; calix may have } \\
\text { degraded slightly }\end{array}$ \\
\hline
\end{tabular}




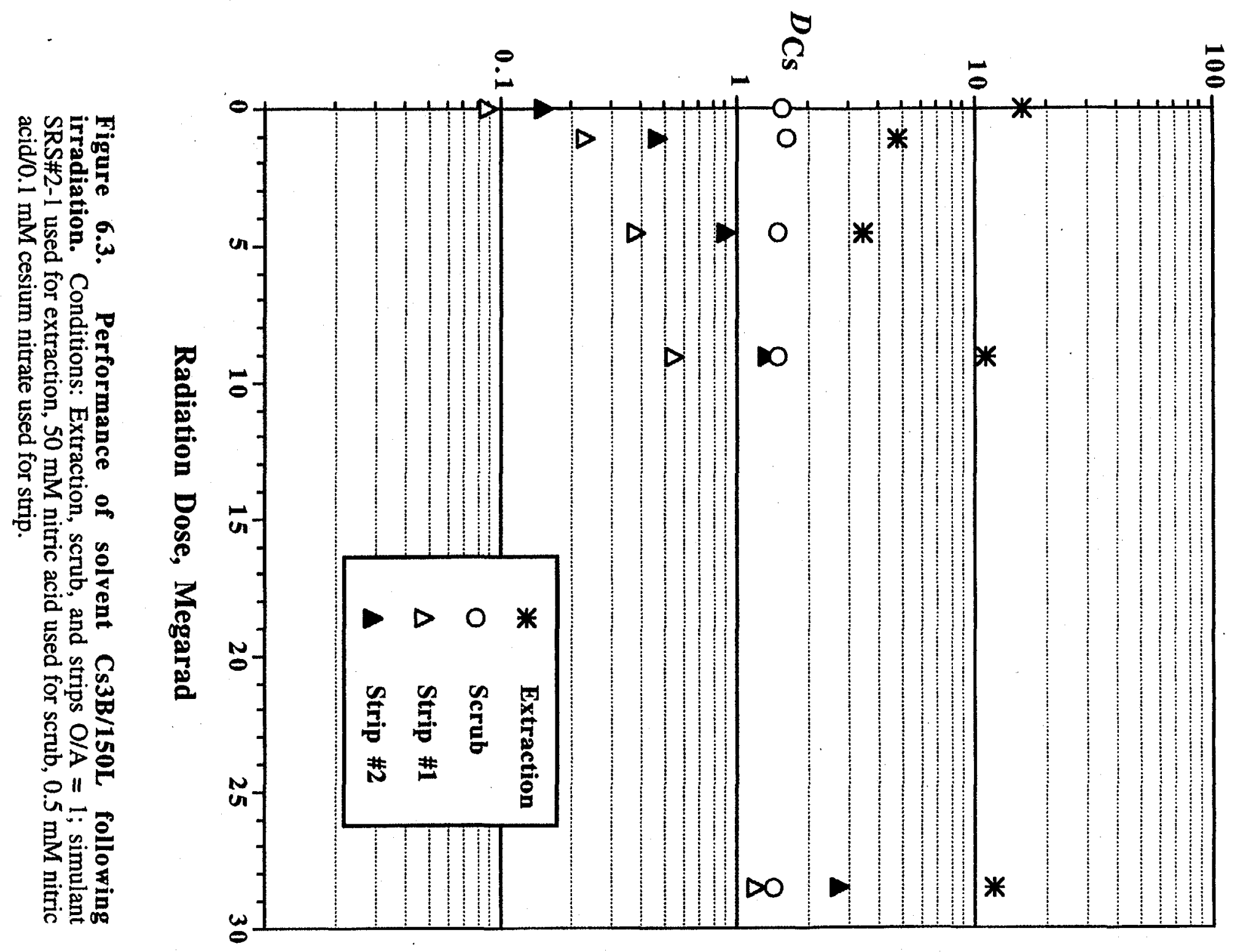




\subsection{CONCLUSIONS}

Tests of the stability of the solvent to continuous exposure to the alkaline SRS\#2-1 simulant at both "room" $\left(25^{\circ} \mathrm{C}\right)$ and "elevated" $\left(53^{\circ} \mathrm{C}\right)$ temperatures showed that whereas the BoBCalixC6 extractant appears to be stable, the Cs3 modifier degrades, with the rate of degradation being significantly higher at $53{ }^{\circ} \mathrm{C}$. Cesium extraction performance was found to decrease in proportion to the loss of the modifier, adding to the solvent the amount of fresh modifier corresponding to the amount destroyed could restore the extraction performance. The modifier degradation product(s), as yet unidentified, do not appear to unduly "poison" the solvent. However, the degradation products could not be washed out of the solvent by either dilute acid (stripping solution), or $0.5 \mathrm{M} \mathrm{NaOH}$.

Both the modifier and the BoBCalixC6 extractant were found to be satisfactorily stable to severe acid conditions for the proposed flowsheet, specifically, continuous contact with $50 \mathrm{mM}$ nitric acid at $53 \pm 2{ }^{\circ} \mathrm{C}$ for 43 days.

The stability of the solvent to radiolysis was also examined, though the results are more difficult to interpret. Examination of the cesium distribution behavior during extraction, scrubbing, and stripping contacts for solvents irradiated in the presence of the SRS simulant for various amounts of time showed that without any pre-treatment of the solvent (e.g., washing), the cesium extraction performance erodes following moderate doses of radiation, then recovers somewhat at the higher doses. Concomitant with increases in the absorbed dose is serious erosion in stripping performance that does not recover. The cesium distribution behavior on scrubbing was surprisingly the same regardless of dose. Taken together, the cesium distribution results indicate that the solvent is being damaged, yet NMR and HPLC analyses of irradiated solvents do not show that the solvent components are being significantly degraded, even though significant discoloration was observed for the highly irradiated solvents.

Further investigations regarding the chemical and especially the radiation stability of the solvent are warranted. Unresolved issues for chemical stability include the breakdown mechanism of the modifier under alkaline conditions, and the identity and properties of the breakdown products. Although modifier degradation products do not appear to "poison" the solvent, it would still be desirable to be able to remove these species before the solvent is rejuvenated by addition of fresh modifier. Unresolved issues for radiation stability include the disconnect between the solvent performance and the extent of degradation of the solvent, and exploring solvent clean up (e.g., washing) options. It will be important to understand which solvent components (including the diluent) are most sensitive to radiation, and how the breakdown products specifically affect solvent performance. Finally, chemical and radiation stability have so far been investigated somewhat "individually", but in the real system the chemical and radiation effects will be additive. Thus, 
more practical experiments involving longer contacting at lower radiation dose rates to better simulate the actual process should be performed.

\subsection{REFERENCES}

1. Peterson, R. A. Westinghouse Savannah River Co., Aiken, SC. Private communication, October, 1998

2. Bonnesen, P.V., Presley, D.J., Haverlock, T.J. Bonnesen, P.V., Oak Ridge National Laboratory, Oak Ridge, TN. Unpublished results, 1996.

3. Crawford, C.L.; Fondeur, F.F.; Peterson, R.A.; White, T.L. Radiation Stability of Calixarene Based Solvent System; Report WSRC-TR-98-00371; Westinghouse Savannah River Co.: Aiken, SC, October 2, 1998. 


\section{OTHER FACTORS AFFECTING STRIPPING PERFORMANCE}

\subsection{INTRODUCTION}

In the July 22, 1998 centrifugal contactor experiment performed at Argonne National Laboratory (ANL) using solvent Cs3B/120L (IBC calix batch 980508KC4-11-17) and SRS\#2 simulant (both prepared at $\mathrm{ANL}$ ), it was discovered that the $D_{\mathrm{Cs}}$ obtained upon stripping was on average about 5 times higher $\left(D_{\mathrm{Cs}}=0.2\right)$ than that obtained in the batch contacting tests at ORNL $\left(D_{\mathrm{Cs}}=0.04\right.$ on average). Since a lower stripping $D_{\mathrm{Cs}}$ promotes a higher decontamination factor, and since it was as yet unknown what the stripping performance would be with real waste, it became important to understand what factor(s) gave rise to the observed differences in stripping performance. In this chapter, questions dealing with stripping performance with regard to simulant makeup and impurities are taken up in detail, and efforts by both ORNL and ANL to solve this discrepancy are reported.

\subsection{EXPERIMENTAL}

\subsubsection{Materials and Contacting Procedures}

Reagents. See section 2.2.1. Solvents used were Cs3C/120L-2 and Cs3D/120L-2. Tributyl phosphate ("TBP", Aldrich Chemical Company, 99+\%), and butyl acid phosphate ("dibutyl phosphate", Mobil lot 12238, dated 9-5-79) were used as received. Tetraheptyl ammonium nitrate was prepared as described in reference [1].

Simulants from ANL. The following simulants were obtained from ANL: SRS\#2 (two samples, one received in August, and the other received in September 1998); and SRS\#4 (used in the September 25, 1998 centrifugal contactor experiment).

\subsubsection{NMR Analyses}

The solvent samples were analyzed directly by proton NMR $(400.13 \mathrm{MHz})$ by the same method described in Chapter 6. Samples analyzed by phosphorus-31 NMR (161.977 MHz) were analyzed as neat solvents (no deuterated solvents added). All phosphorus-31 NMR chemical shifts were referenced to the chemical shift of a separate $85 \%$ phosphoric acid standard, set to $0.0 \mathrm{ppm}$. The standard was rerun periodically to check for drift. The acquisition parameters included a spectral width of $50000 \mathrm{~Hz}$, such that the spectral region $+150 \mathrm{ppm}$ to $-150 \mathrm{ppm}$ could be examined, and broadband decoupling of protons (decoupler power $18 \mathrm{H}$ ). 


\subsubsection{Simulant Preparations (ORNL)}

Preparation of SRS\#2-2 Simulant. A second batch of SRS\#2 simulant was prepared in the same manner as the first batch (Table 2.1), with the following modifications. Solid $\mathrm{NaOH}$ was used in place of a $50 \%$ solution. $\mathrm{NaCl}, \mathrm{NaF}$, and $\mathrm{Na}_{2} \mathrm{CrO}_{4}$ were pre-dissolved (in that order) in $200 \mathrm{~mL}$ Barnstead Nanopure water, and that solution added to the mixture, following the addition of sodium carbonate, but before the addition of sodium nitrite. See Table 7.1.

Preparation of SRS\#40 Simulant (Standard ORNL Procedure). SRS\#4O simulant was prepared following new component concentration data received from SRS, and was prepared as described in Table 7.2 (it is very similar to SRS\#2-1 and SRS\#2-2.) The simulant was mixed in a Teflon ${ }^{\circledR}$ FEP bottle as per previous simulant preparations. The solution was cooled periodically in ice when the solution became excessively warm during the $\mathrm{NaOH}$ dissolution step.

- Preparation of SRS\#4A Simulant (Standard ORNL Procedure using ANL order of addition). A variant of SRS\#4 was prepared in the same manner as SRS\#4O with the exception that the order of addition of the chemicals was changed. The order used was that recommended by ANL, and is described in Table 7.3. Once again, the salts were mixed together in a Teflon ${ }^{\circledR}$ FEP bottle and the solution cooled periodically in ice whenever the solution became excessively warm during the $\mathrm{NaOH}$ dissolution step. This simulant was prepared to determine whether the order of addition of the chemicals might affect the stripping (by possibly affecting the speciation of the dissolved inorganics) in some manner.

Preparation of SRS\#4A-G Simulant (ANL order of addition using ANL procedure). This simulant was prepared as per SRS\#4A except that the chemicals were mixed together in a $2 \mathrm{~L}$ heavy-wall Kimax ${ }^{\circledR}$ beaker, on a stir plate. The solid $\mathrm{NaOH}$ was dissolved in $1 \mathrm{~L}$ of Barnstead Nanopure water over a period of about 30 minutes, and then the other salts added in the same manner as for SRS\#4A. . The method is further described in Table 7.4. This simulant was prepared to determine the glass . or "beaker" effect.- the warm $\mathrm{NaOH}$ solution will undoubtedly dissolve some of the glass, so that there will be some silicate material present in this simulant. It was of interest to determine whether preparing the simulant in a beaker could account for differences in stripping behavior. It was noted that, unlike the other simulants, this simulant retained a slight haze for several days. The haze eventually disappeared after about a week, and the solution then had essentially the same degree of clarity as the other simulants. Three samples of this simulant were examined: one sample was spiked with Cs-137 tracer three hours after preparation; a second sample was spiked with tracer two days after preparation, and a third sample was filtered successively through $0.45 \mu \mathrm{m}$ and $0.20 \mu \mathrm{m}$ Gelman ${ }^{\circledR}$ PTFE Acrodiscs two days after preparation, and then spiked with tracer. 
Table 7.1. Formulation of Simulant SRS\#2-2 at ORNL.

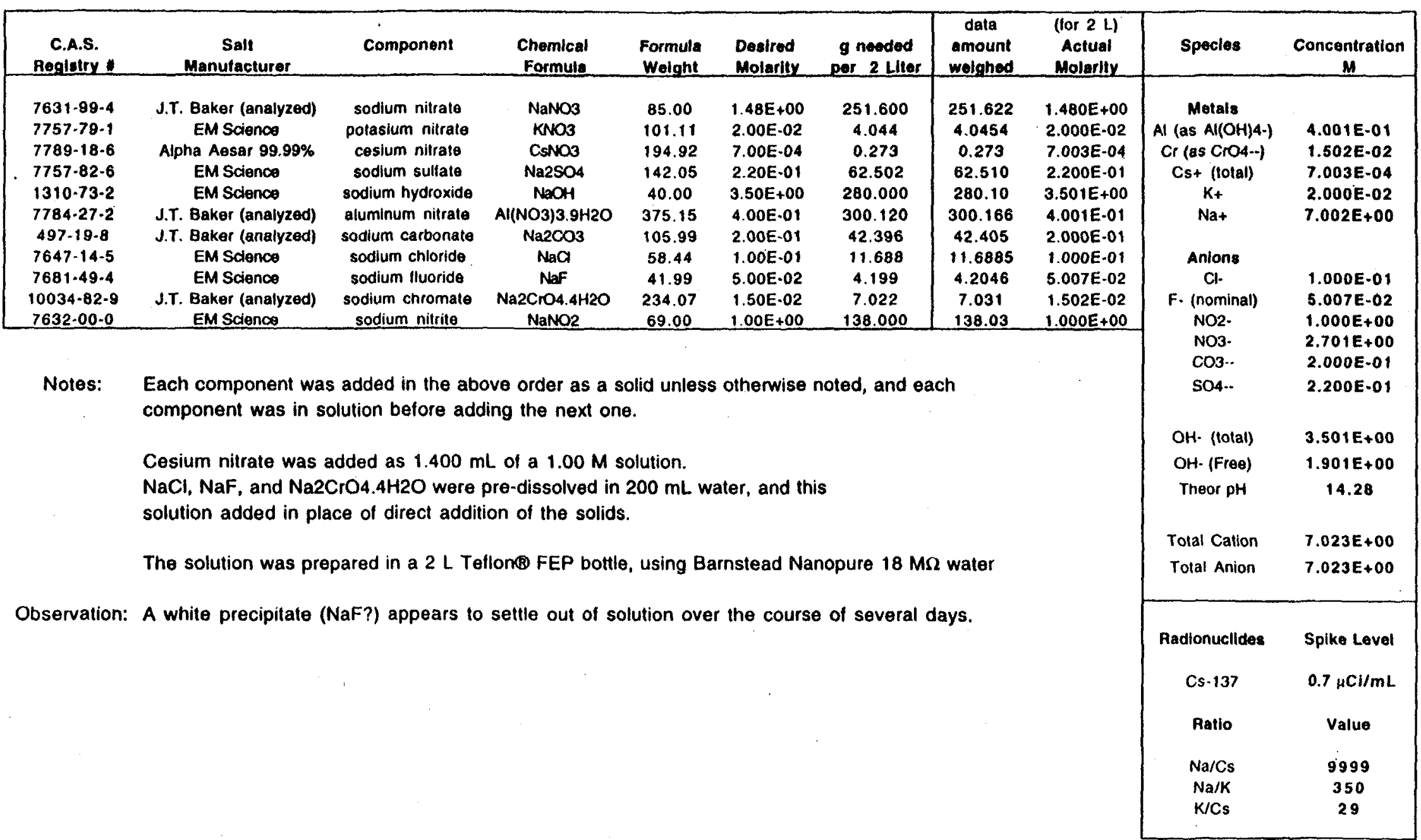


Table 7.2. Formulation of Simulant SRS\#4O-at ORNL.

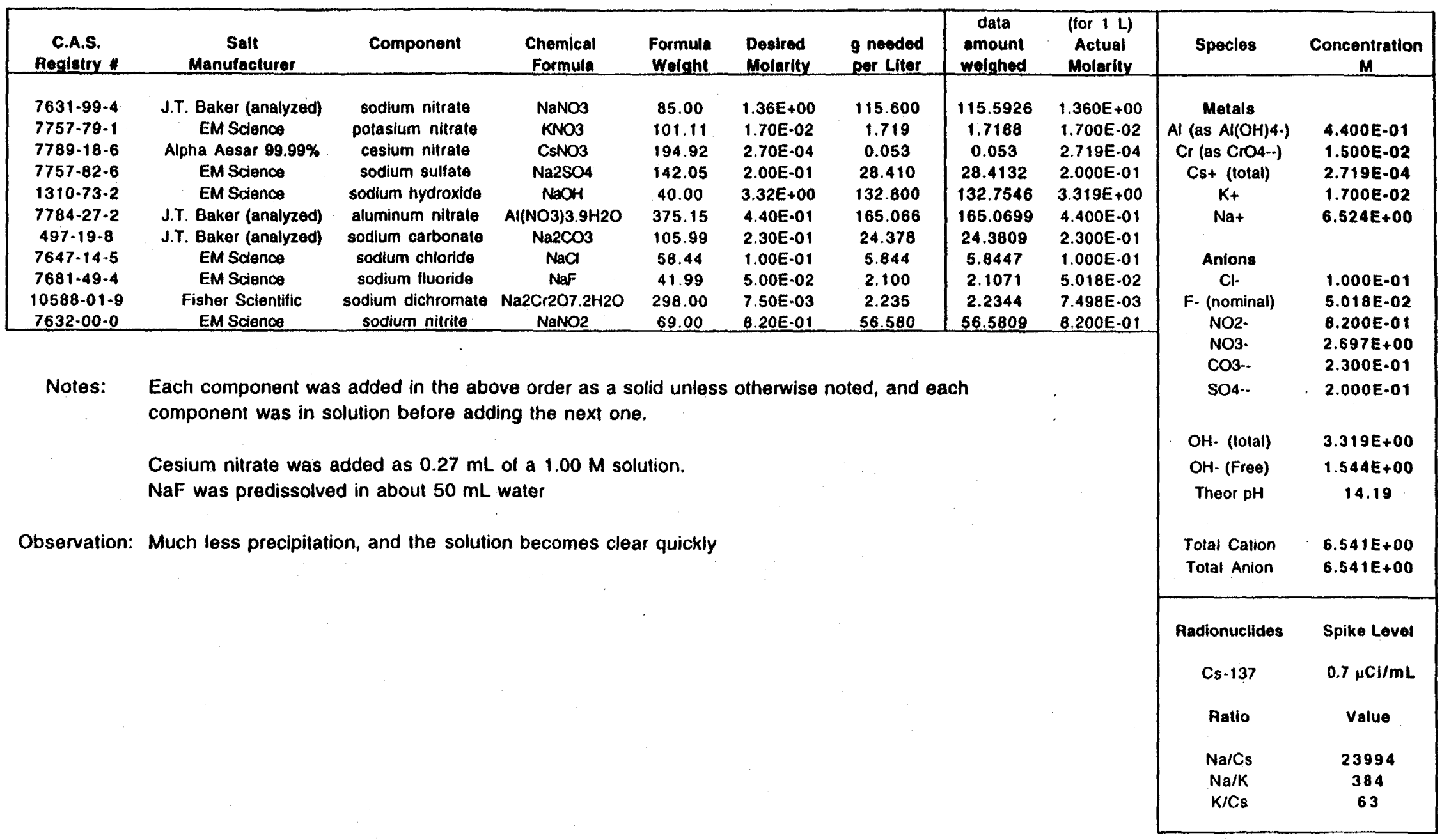


Table 7.3. Formulation of Simulant SRS\#4A at ORNL.

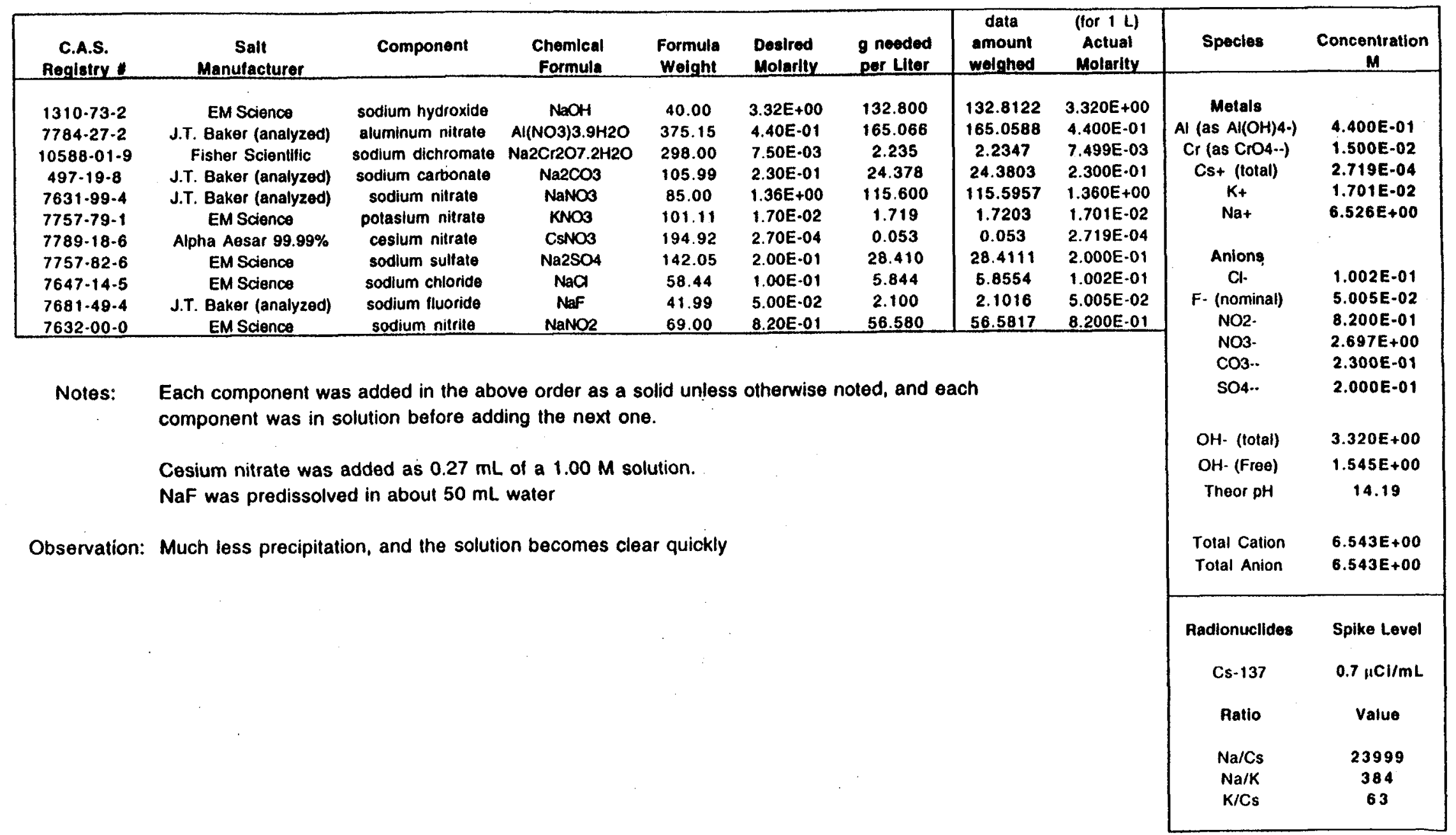


Table 7.4. Formulation of Simulant SRS\#4A-G at ORNL.

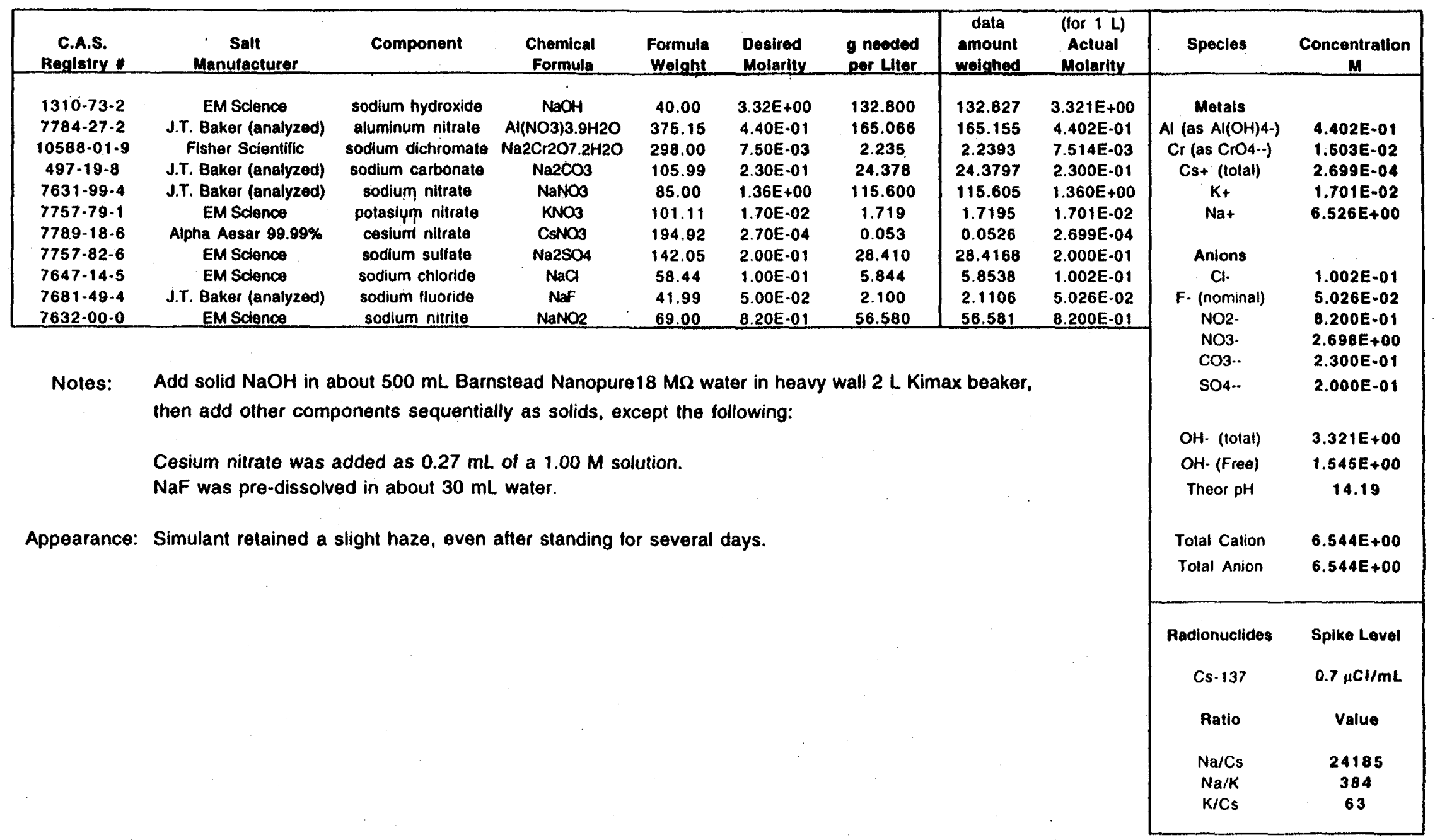




\subsubsection{ICP Analyses}

Aqueous solutions. See section 5.2.3 for a general description of contacting procedures and instrumental conditions. Specific to this chapter, ORNL Cs3D/120L-2 pristine solvent was contacted with ANL SRS\#2 and ANL SRS\#4 simulants, in Teflon ${ }^{\circledR}$ FEP tubes $(\mathrm{O} / \mathrm{A}=1)$. For each simulant, the solvent was contacted twice successively using fresh simulant for each contact. The solvent was then scrubbed $(\mathrm{O} / \mathrm{A}=1)$ with either $50 \mathrm{mM} \mathrm{HNO}_{3}$, or $2 \mathrm{M} \mathrm{NaOH}$ followed by 50 $\mathrm{mM} \mathrm{HNO}$.

Organic solutions. Samples of various solvents were contacted with equal volumes of various simulants in clean polypropylene centrifuge tubes at $25^{\circ} \mathrm{C}$ for 30 minutes by end-over-end rotation using a Glas-Col ${ }^{\circledR}$ laboratory rotator. Following centrifugation, aliquots of the solvent were transferred to clean polypropylene tubes. These solvent samples (along with several samples of pristine solvents) were submitted to the Radioactive Materials Analysis Lab in Building 2026 at ORNL, where they were microwave digested, and analyzed by ICP following Procedure No. SW846 6010A. No special effort was taken to eliminate glassware contamination during the digestion process, thus a substantial Si signal (background) was observed even for the pristine solvents. The aqueous solutions generated from the digestions (diluted on average by a factor of 132) were analyzed by ICP by performing scans over a $180-780 \mathrm{~nm}$ wavelength range (covering over 29 metals). Cesium and aluminum in each sample were separately analyzed by ICP/MS.

\subsection{RESULTS AND DISCUSSION}

\subsubsection{Analysis of Solvents Used in July 22, 1998 Centrifugal Contactor Test at Argonne National Laboratory}

Cesium Distribution Measurements with Pristine and Post-Contactor Solvents. It was of interest to determine whether the higher $D_{\mathrm{Cs}}$ values obtained on stripping were due to differences in the mode of contacting (batch measurements vs. centrifugal contactor measurements), or were due to something different in the solvent. Proton NMR analyses conducted at ORNL on the batch of BoBCalixC6 used at ANL in the July 22, 1998 ANL multistage contactor test (IBC lot 980508KC4-11-17, a different batch than IBC lot 980508KC4-114-17 used at ORNL) did show the presence of some "impurity" at an estimated concentration of $5 \mathrm{~mol} \%$ of the BoBCalixC6. ANL prepared their solvent assuming 95\% purity to compensate for this. Samples of both the pristine solvent used in the July ANL multistage test, and solvent taken from the stripping stages of the contactor ("post-contactor" solvent), were sent to ORNL, where the extraction, scrubbing, and stripping performance was evaluated in the usual manner. A sample of pristine ORNL $\mathrm{Cs} 3 \mathrm{C} / 120 \mathrm{~L}-2$ solvent was also run as a control. The results, shown in Figure 7.1, reveal that the 
two pristine solvents perform identically on stripping, and nearly identically on extraction and scrubbing, but that the stripped solvent from the contactor was still giving elevated Cs distribution ratios on stripping (in the same range as was observed in the multistage test). The extraction and scrubbing $D_{\mathrm{Cs}}$ s for the stripped solvent from the contactor were also somewhat lower than those observed for the pristine solvents.

In a separate experiment, a sample of post-contactor solvent was contacted twice successively with strip solution containing Cs-137 tracer. In these "forward stripping tests", the $D_{\mathrm{Cs}}$ s obtained were 0.26 for the first strip and 0.21 for the second strip, again in the range observed in the multistage test (see Table 7.5). Thus, there was definitely something in this solvent which was giving rise to higher stripping $D_{\mathrm{Cs}}$ values. The questions to be answered were: What in the solvent is the culprit? and Where did it come from?

Proton and Phosphorus-31 NMR Analysis of Pristine and Post-Contactor Solvents. In an attempt to answer the first question, samples of the solvents were analyzed by both proton and phosphorus NMR. It was known that solvents containing organophosphorus compounds such as TBP and CMPO had previously been used in the centrifugal contactors, and it was suspected that perhaps there lingered some residue from these solvents which might have become dissolved in the Cs3B/120L solvent during some part of the multistage test, and which could in some way be negatively impacting the stripping efficiency. Residues of other organic materials (such as 1octanol, and crown ethers) may also have lingered in the contactor. The post-contactor solvent sample was slightly radioactive, and so was washed three times with stripping solution $(\mathrm{O} / \mathrm{A}=$ 0.5 ) to lower the Cs-137 activity to background levels before analyzing by NMR. Proton NMR analysis did not reveal anything unusual about the post-contactor solvent in relation to the pristine solvents, but then again the "impurity", if present, could have resonances that are buried under the resonances of the dominant solvent components (Isopar ${ }^{\circledR} \mathrm{L}, \mathrm{Cs} 3$ modifier, and BoBCalixC6). Phosphorus-31 NMR was more revealing. The pristine ANL solvent was clean (no signal observed), but the post-contactor solvent did contain a single peak in the P-31 spectrum at -0.314 ppm, which was identified to be TBP at a concentration of $0.015 \mathrm{M}$ (by integration against a known quantity of a separate phosphorus-containing material added to the NMR sample). The identity of TBP was confirmed both by independently determining the chemical shift of TBP in a pristine solvent sample (same as in the post-contactor solvent sample), and also by adding a known quantity of TBP to the post-contactor solvent sample. In the latter, if the impurity was not TBP, there should have been two peaks (albeit separated by perhaps only a few ppm). Instead, there was a single peak that integrated as the sum of the original TBP (concentration) plus the added amount. The likely breakdown product of TBP, dibutyl phosphate, has a different chemical shift (1.29 $\mathrm{ppm})$ than that of TBP $(0.04 \mathrm{ppm})$ under the same sample conditions (20 $\mu \mathrm{L}$ neat organophosphorus compound plus $730 \mu \mathrm{L}$ deutero-chloroform). 


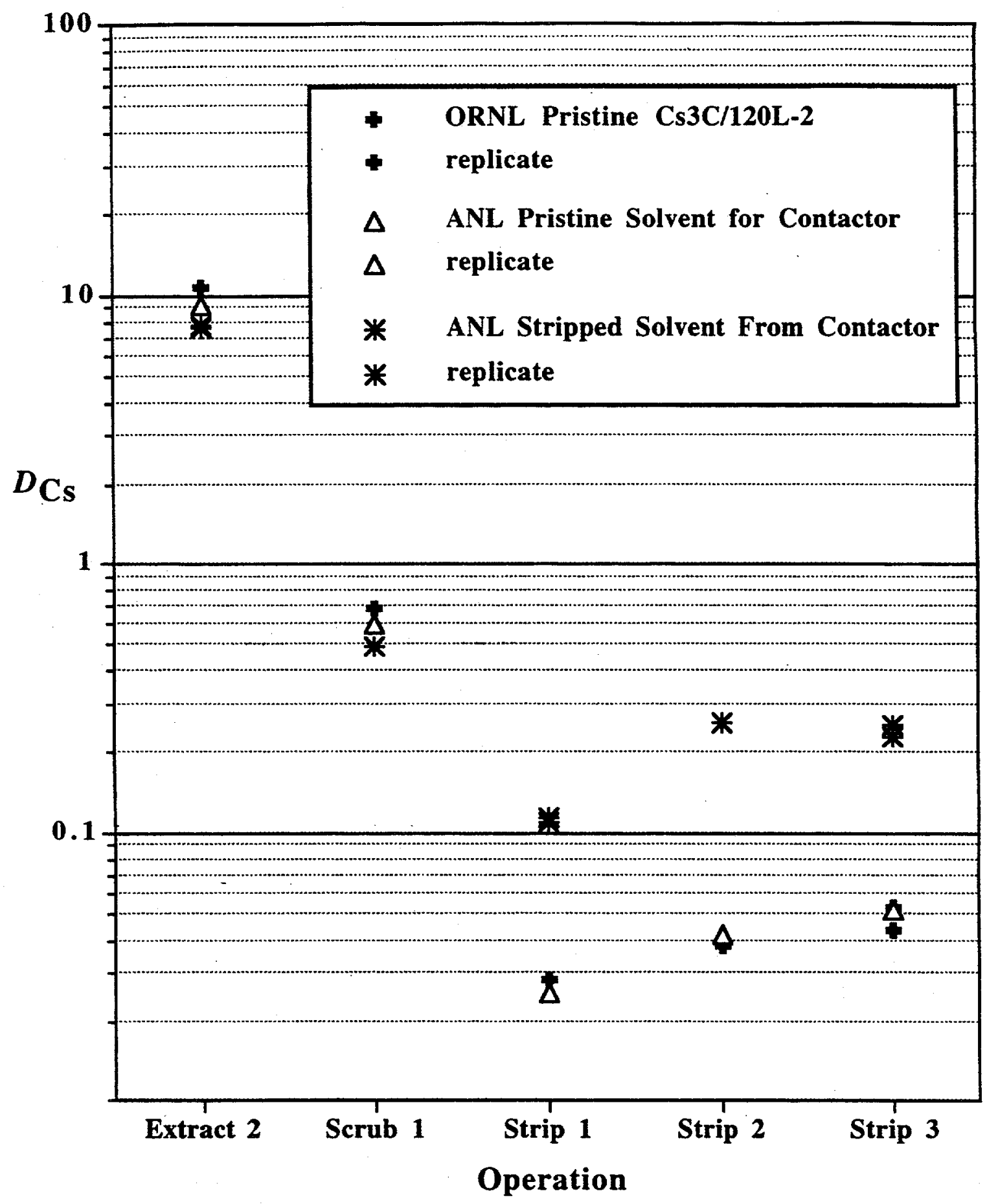

Figure 7.1. Comparison of solvents from ANL Multistage Test (both pristine and "post-contactor") with ORNL pristine solvent: post-contactor solvent is different. 
Effect of Suspected Impurities (TBP. dibutyl phosphate) on Stripping Performance. It is unlikely that dibutyl phosphate $\left((\mathrm{BuO})_{2} \mathrm{P}(\mathrm{O})-\mathrm{OH}\right)$ would be present in this solvent sample anyway, as it should have been washed out during the extraction contact with the simulant (Figure 7.1), and so should not have been present during the stripping stage of the contactor test to alter the stripping behavior. Nevertheless, since TBP was found in the solvent, and since dibutyl phosphate is a hydrolysis product of TBP, both of these potential impurities were examined to ascertain what effect, if any, they may have on the stripping behavior.

TBP was added to pristine Cs3C/120L-2 solvent at concentrations of 1,10 , and $100 \mathrm{mM}$. Samples of these solvents, along with pristine $\mathrm{Cs} 3 \mathrm{C} / 120 \mathrm{~L}-2$ as a control, were equilibrated twice with $0.5 \mathrm{mM}$ nitric acid with $\mathrm{O} / \mathrm{A}=0.33$. The solvents were then contacted at $\mathrm{O} / \mathrm{A}=1.0$ with standard strip solution ( $0.1 \mathrm{mM}$ cesium nitrate in $0.5 \mathrm{mM}$ nitric acid) that contained cesium-137 nitrate tracer. The $D_{\mathrm{Cs}} \mathrm{s}$ obtained respectively for TBP at concentrations of $0.0,1.0,10$, and 100 $\mathrm{mM}$ in the solvent were $0.020,0.021,0.018$, and 0.016 . Thus, the presence of TBP does not increase the $D_{\mathrm{Cs}}$ on stripping, but in fact lowers the $D_{\mathrm{Cs}}$ at the higher concentrations. This observation is in accord with other results obtained at ORNL, which indicate that TBP acts antagonistically with the modifier towards the extraction of cesium, and lowers the cesium extractability [2]. In fact, the cause of the lower extraction $D_{\mathrm{Cs}}$ for the post-contactor solvent $\left(D_{\mathrm{Cs}}\right.$ $=7.7$, see Figure 7.1) could be due to the presence of TBP at $15 \mathrm{mM}$ in that solvent.

Dibutyl phosphate was added to pristine Cs3C/120L-2 at a concentration of $0.1 \mathrm{mM}$, and the solvent contacted twice successively with strip solution containing Cs-137 nitrate tracer. The results (Table 7.5) show negligible effect on the $D_{\mathrm{Cs}}$ relative to pristine solvent alone.

Efforts to Restore Stripping Efficiency: Use of Tetraheptyl Ammonium Nitrate, and Solvent Washing. It was postulated that perhaps the addition of a lipophilic cation such as tetraheptyl ammonium nitrate to the ANL post-contactor solvent might cancel out the effect of an anionic impurity, if it was an anionic impurity that was responsible for the elevated cesium distribution ratios on stripping. It was also of interest to determine whether washing the solvent many times with base might wash out an impurity and restore the solvent. An experiment was performed in which the ANL post-contactor solvent was washed five times successively with 0.5 $\mathrm{M} \mathrm{NaOH}$ with $\mathrm{O} / \mathrm{A}=0.2$, followed by one contact with equal volume scrub solution. This washed solvent, plus a sample of the solvent which had been washed only with strip solution to reduce the activity (the solvent analyzed by NMR above), and a sample of ANL post-contactor solvent which had been spiked with tetraheptyl ammonium nitrate to a concentration of $0.1 \mathrm{mM}$, were all contacted (no pre-equilibration) with strip solution containing Cs-137 nitrate tracer twice successively. The results are also shown in Table 7.5. Extended washing of the solvent appears to result in lower cesium distribution ratios, though the distribution ratios are still higher than what one would obtain with pristine solvent. However, adding the tetraheptyl ammonium nitrate did in 
fact improve the stripping, (note section 3.4.4), with suggestion that there might in fact be an anionic "impurity" present in the solvent.

Table 7.5. Cesium distribution ratios for two stripping contacts from ANL "postcontactor solvent" subjected to various treatments, and from pristine controls.

\begin{tabular}{|l|c|c|}
\hline Solvent Treatment & $\begin{array}{c}\text { Strip 1 } \\
( \pm \mathbf{5 \%})\end{array}$ & $\begin{array}{c}\text { Strip 2 } \\
( \pm \mathbf{5 \%}\end{array}$ \\
\hline Pristine Cs3C/120L-2 (Control) & 0.019 & 0.022 \\
\hline ANL Post-contactor solvent as received & 0.265 & 0.210 \\
\hline Pristine Cs3C/120L-2 plus dibutyl phosphate (0.1 mM) & 0.049 & 0.026 \\
\hline $\begin{array}{l}\text { ANL Post-contactor solvent washed 3X O/A = 0.5 w/ } \\
\text { strip solution (sample analyzed by NMR) }\end{array}$ & 0.121 & 0.112 \\
\hline $\begin{array}{l}\text { ANL Post-contactor solvent washed 5X O/A = 0.2 w/ } \\
\text { 0.5 M NaOH, then once w/ O/A = 1 of 50 mM nitric acid }\end{array}$ & 0.078 & 0.074 \\
\hline $\begin{array}{l}\text { ANL Post-contactor solvent as received plus tetraheptyl } \\
\text { ammonium nitrate (0.1 mM) }\end{array}$ & 0.020 & 0.019 \\
\hline
\end{tabular}

\subsubsection{Effect of Simulant Preparation on Stripping Performance.}

It was still unclear where the "impurity" was coming from, so an additional set of experiments was conducted which examined the extraction, scrubbing, and stripping behavior using simulants prepared both at ANL and ORNL. A sample of simulant SRS\#2 received from ANL ("ANL SRS\#2") was evaluated alongside ORNL SRS\#2-2, and two versions of SRS\#4. Discussions with colleagues at ANL revealed that the methods for preparing the simulants at the two labs differed in the order of addition of the chemicals, and the labware used (glass beakers vs. Teflon ${ }^{\circledR}$ FEP bottles, see experimental section above). SRS\#4 simulants were prepared following a revised recipe from SRS in Teflon ${ }^{\circledR}$ FEP bottles at ORNL by two methods. One batch was prepared using the ORNL order of addition. A second batch was prepared employing the ANL order of addition, to determine whether something about the order of addition could give rise to the differences observed in stripping.

Table 7.6 shows the cesium distribution results obtained on two extractions, one scrubbing, and three stripping contacts using the four simulants. While no difference was observed between the three simulants prepared at ORNL, the stripping distribution values obtained 
with the ANL simulant were higher, and matched those previously obtained at ANL. A fourth strip was performed on the solvent used with this simulant, where the solvent following the third strip was doped with trioctyl amine so that the concentration was $0.1 \mathrm{mM}$. Under the mildly acidic conditions of the strip, the trioctyl amine would be protonated, and would function in the same manner as the tetraheptyl ammonium nitrate (see Table 7.5 above, and section 3.4.4). The distribution ratio for the fourth strip was observed to decrease below even the first strip. suggesting that there may be some anionic impurity in the solvent that came from the ANL simulant.

Table 7.6. Cesium distribution ratios for Cs3D/120L-2 solvent with various ORNL simulants, and Cs3C/120L-2 with ANL SRS\#2 simulant.

\begin{tabular}{|c|c|c|c|c|}
\hline $\begin{array}{l}\text { Contact } \\
\text { Stage }\end{array}$ & $\begin{array}{c}\text { ORNL SRS\#2-2 } \\
D_{\mathrm{CS}}( \pm 5 \%)\end{array}$ & $\begin{array}{c}\text { ORNL SRS\#40 } \\
D_{\mathrm{Cs}}( \pm 5 \%)\end{array}$ & $\begin{array}{c}\text { ORNL SRS\#4A } \\
D_{\mathrm{Cs}}( \pm 5 \%)\end{array}$ & $\begin{array}{l}\text { ANL SRS\#2 } \\
D_{\text {Cs }}( \pm 5 \%)\end{array}$ \\
\hline Extraction 1 & $11.11 ; 11.17$ & $11.04 ; 11.16$ & $11.31 ; 11.07$ & $11.85 ; 11.76$ \\
\hline Extraction 2 & $10.04 ; 10.05$ & $10.55 ; 10.68$ & $10.89 ; 10.82$ & $10.54 ; 10.62$ \\
\hline Scrub 1 & $0.674 ; 0.656$ & $0.727 ; 0.724$ & $0.713 ; 0.722$ & $0.792 ; 0.783$ \\
\hline Strip 1 & $0.031 ; 0.029$ & $0.034 ; 0.032$ & $0.035 ; 0.034$ & $0.118 ; 0.120$ \\
\hline Strip 2* & $0.047 ; 0.052$ & $0.068 ; 0.058$ & $0.057 ; 0.055$ & $0.305 ; \quad 0.300$ \\
\hline Strip 3* & $0.069 ; 0.079$ & $0.078 ; 0.069$ & $0.070 ; 0.065$ & $0.270 ; \quad 0.250$ \\
\hline Strip 4*\# & Not performed & Not performed & Not performed & 0.024 \\
\hline
\end{tabular}

* Additional cesium-137 nitrate tracer added to the strip solution.

\# Solvent from third strip was spiked with trioctyl amine (TOA) at $0.1 \mathrm{mM}$.

Extraction, scrubbing, and stripping experiments conducted with ANL SRS\#4 simulant gave elevated cesium distribution ratios on stripping similar to those obtained with ANL SRS\#2. It was noted that the value of $D_{\mathrm{Cs}}$ on stripping seemed to be dependent on the number of times the solvent was contacted with fresh ANL simulant. The $D_{\mathrm{Cs}}$ values were slightly lower when only one extraction contact was performed rather than two (see table 7.7).

It was hypothesized that employing an alkaline scrub prior to the $50 \mathrm{mM}$ nitric acid scrub might help wash out the mystery impurity introduced by the simulant, since some improvement in the stripping $D_{\mathrm{Cs}}$ was observed following extended solvent washing with $0.5 \mathrm{M} \mathrm{NaOH}$ (Table 
7.5). It was unclear at this stage whether the impurity was organic, or some type of inorganic (e.g., aluminosilicate) species capable of forming a complex with cesium. (A naturally occurring mineral form of cesium is pollucite, a cesium aluminosilicate having the formula. $\mathrm{Cs}_{2} \mathrm{O} \cdot \mathrm{Al}_{2} \mathrm{O}_{3} \cdot 4 \mathrm{SiO}_{2}$, [3]). If an aluminosilicate was responsible, it was thought that perhaps strong (e.g., $2 \mathrm{M}$ ) NaOH might destroy it and any complexes it (may have) formed with cesium.

The results (Table 7.7) show that the stripping $D_{\mathrm{Cs}}$ values are lower when the solvent is subjected to one extraction contact using ANL SRS\#2 simulant than with two extraction contacts. In fact, the stripping $D_{\mathrm{Cs}}$ values for the single extraction contact experiment are nearly half those obtained in the two extraction contact experiment. This suggests that there is something which transfers from the simulant to the solvent, and that additional contacts "load" the solvent with whatever species is responsible for the higher stripping $D_{\mathrm{Cs}}$ values. Comparing the $D_{\mathrm{Cs}}$ values obtained from the two ANL SRS\#2 contact, $2 \mathrm{M} \mathrm{NaOH}$ scrub (third column Table 7.7) with the data without the $2 \mathrm{M} \mathrm{NaOH}$ scrub (Table 7.6 last column) shows that the $\mathrm{NaOH}$ scrub slightly improves the stripping efficiency, giving slightly lower $D_{\mathrm{Cs}}$ values. The last two columns of Table 7.7 also show the effect of the $\mathrm{NaOH}$ scrub, with the $D_{\mathrm{Cs}}$ values on stripping being about $35 \%$ lower on average for the solvent that had been scrubbed with $2 \mathrm{M} \mathrm{NaOH}$.

It was of interest to know whether there was a finite amount of material that was transferred to the solvent from the simulant, or whether the material in question was regenerated in the simulant (i.e., whether the material is an inorganic that is in equilibrium with other components, and whether removing some of the material results in a re-establishment of equilibrium). The question was, if ANL simulant already contacted with solvent (raffinate) is recontacted with fresh solvent, is the stripping behavior of the solvent the same as it would be for solvent contacted with "pristine" simulant? The results show that in fact the stripping $D_{\mathrm{Cs}}$ values for solvent contacted with ANL SRS\#2 raffinate were, curiously, about $35 \%$ lower on average than solvent contacted with fresh ANL SRS\#2 simulant. Thus it appears that there is a "finite" amount of material in the simulant that can be transferred to the solvent.

In an attempt to more specifically determine whether silicon-containing species could contribute to elevated cesium distribution values on stripping, another variant of SRS\#4 simulant was prepared at ORNL, following the ANL order of addition, with the only difference being that the simulant was prepared in a glass beaker (as are the simulants at ANL). The preparation of this simulant, designated "ORNL SRS\#4A-G" is described above in the experimental section. It was noted that the simulant retained a slight haze for several days, unlike the simulants prepared in Teflon ${ }^{\circledR}$, which became clear immediately. Three samples of this simulant were prepared for testing, as described in the experimental section (spiked with tracer after 3 hours, spiked with tracer after two days, and spiked with tracer after two days after first filtering). The stripping behavior in all cases was the same, and was consistent with the stripping data obtained for the 
other simulants prepared at ORNL. Thus, the differences in behavior between the ANL and ORNL simulants is apparently not due to silicates introduced by dissolution of the beaker glass walls by base.

Table 7.7. Cesium distribution ratios for Cs3D/120L-2 solvent with various ANL simulants: effect of one vs. two extraction contacts, and scrubbing with $2 \mathrm{M}$ NaOH.

\begin{tabular}{|c|c|c|c|c|}
\hline $\begin{array}{c}\text { Contact } \\
\text { Stage }\end{array}$ & $\begin{array}{c}\text { ANL SRS\#2 } \\
D_{C s}( \pm 5 \%)\end{array}$ & $\begin{array}{l}\text { ANL SRS\#2 } \\
D_{\mathrm{Cs}}( \pm 5 \%)\end{array}$ & $\begin{array}{l}\text { ANL SRS\#4 } \\
D_{\mathrm{Cs}}( \pm 5 \%)\end{array}$ & $\begin{array}{l}\text { ANL SRS\#4 } \\
D_{\mathrm{Cs}}( \pm 5 \%)\end{array}$ \\
\hline Extraction 1 & 11.28 & 11.30 & 11.80 & 11.79 \\
\hline Extraction 2 & $* * * *$ & 10.41 & $* * * *$ & $* * * *$ \\
\hline $\begin{array}{c}2 \mathrm{M} \mathrm{NaOH} \\
\text { Scrub } \\
\end{array}$ & 34.76 & 30.19 & $* * * *$ & 38.94 \\
\hline $\begin{array}{c}50 \mathrm{mM} \\
\text { Nitric Acid } \\
\text { Scrub }\end{array}$ & 0.686 & 0.690 & 0.789 & 0.740 \\
\hline Strip 1 & 0.065 & 0.092 & 0.090 & 0.057 \\
\hline Strip $2^{*}$ & 0.132 & 0.267 & 0.119 & 0.076 \\
\hline Strip 3* & 0.119 & 0.243 & 0.101 & 0.070 \\
\hline
\end{tabular}

* Additional cesium-137 nitrate tracer added to the strip solution.

\subsubsection{Effect of Trialkylamines and Temperature on Stripping Performance (ANL and ORNL Experiments).}

Since trialkyl ammonium species seemed to remedy the stripping behavior obtained when ANL simulants are used, experiments were performed at both ORNL and ANL to see if trialkyl amines placed into the solvent at the beginning of the flowsheet contact would give lower stripping $D_{\mathrm{Cs}}$ values. Experiments conducted at ORNL using ORNL simulants and solvent Cs3D/120L-2 containing trioctyl amine (TOA) at $0.1 \mathrm{mM}$ lead to the interesting findings that a) the presence of the TOA was not detrimental to extraction efficiency, and b) the stripping efficiency with the TOA was better than without (see Table 7.8). The TOA might be capable of scavenging any offending 
species, which might give rise to higher stripping $D_{C s}$ values. Thus, addition of TOA to the solvent appears to improve the performance of the process generally.

Experiments performed by colleagues at ANL using tri-isooctyl amine (TiOA) in the solvent at concentrations of 1.0 and $0.1 \mathrm{mM}$ with ANL SRS\#4 simulant [4] also showed a marked drop in the stripping $D_{\mathrm{Cs}}$ values (see table 7.9). Thus, regardless of the differences between the simulants, the additional of trialkyl amines to the solvent would likely improve the process flowsheet.

Table 7.8. Cesium distribution ratios for Cs3D/120L-2 solvent with and without trioctyl amine (TOA) at $0.1 \mathrm{mM}$ with ORNL \#4 simulants at $25{ }^{\circ} \mathrm{C}$ (ORNL results).

\begin{tabular}{|c|c|c|c|c|}
\hline $\begin{array}{l}\text { Contact } \\
\text { Stage }\end{array}$ & $\begin{array}{l}\text { ORNL } \\
\text { SRS\#40 } \\
D_{\mathrm{Cs}}( \pm 5 \%)\end{array}$ & $\begin{array}{l}\text { ORNL SRS\#40 } \\
+ \text { TOA } \\
\quad D_{C s}( \pm 5 \%) \\
\end{array}$ & $\begin{array}{l}\text { ORNL } \\
\text { SRS\#4A } \\
\quad D_{C s}( \pm 5 \%)\end{array}$ & $\begin{array}{l}\text { ORNL SRS\#4A } \\
+ \text { TOA } \\
\quad D_{C s}( \pm 5 \%)\end{array}$ \\
\hline Extraction 1 & $11.04 ; 11.16$ & 11.17 & $11.31 ; 11.07$ & 11.07 \\
\hline Extraction 2 & $10.55 ; 10.68$ & 10.87 & $10.89 ; 10.82$ & 10.90 \\
\hline Scrub 1 & $0.727 ; 0.724$ & 0.721 & $0.713 ; 0.722$ & 0.696 \\
\hline Strip 1 & $0.034 ; 0.032$ & 0.019 & $0.035 ; 0.034$ & 0.019 \\
\hline Strip 2* & $0.068 ; 0.058$ & 0.014 & $0.057 ; 0.055$ & 0.014 \\
\hline Strip 3* & $0.078 ; 0.069$ & 0.023 & $0.070 ; 0.065$ & 0.014 \\
\hline
\end{tabular}

* Additional cesium-137 nitrate tracer added to the strip solution.

Experiments conducted at ANL also looked at the effect of temperature on the flowsheet. Specifically, batch-contacting experiments were performed by colleagues at ANL using ANL SRS\#4 simulant where the extraction and scrubbing contacts were conducted at $9{ }^{\circ} \mathrm{C}$, and the stripping contacts were performed at $52{ }^{\circ} \mathrm{C}$ [4]. The results gave a $D_{\mathrm{Cs}}$ on extraction of 26.4 , on scrubbing of 4.30 , and $D_{\mathrm{Cs}}$ values of $0.021,0.015$, and 0.011 for the first, second, and third stripping contacts, respectively. While it is unlikely that a temperature of $52{ }^{\circ} \mathrm{C}$ would be used in the process, the solvent is stable to dilute acid solutions at high temperature (see Chapter 6), and the solvent would likely be more stable to the alkaline simulant at lower temperatures. Thus. 
temperature control can in principle be used to improve the process flowsheet. provided temperature control can be performed using the actual contacting equipment at SRS.

Table 7.9. Cesium distribution ratios for $\mathrm{Cs} 3 \mathrm{C} / 120 \mathrm{~L}-2$ solvent with tri-isooctyl amine (TiOA) at $1.0 \mathrm{mM}$ and $0.1 \mathrm{mM}$ with ANL \#4 simulant at $25{ }^{\circ} \mathrm{C}$ (ANL results).

\begin{tabular}{|c|c|c|}
\hline $\begin{array}{c}\text { Contact } \\
\text { Stage }\end{array}$ & $\begin{array}{c}\text { ANL SRS\#4 + TiOA @ 1.0 mM } \\
D_{\text {Cs }}( \pm 5 \%)\end{array}$ & $\begin{array}{c}\text { ANL SRS\#4 + TiOA @ 0.1 mM } \\
D_{\text {Cs }} \pm \text { 5\%) }\end{array}$ \\
\hline Extraction 2 & 10.200 & 9.900 \\
\hline Scrub 1 & 0.560 & 0.570 \\
\hline Strip 1 & $\mathbf{0 . 0 3 2}$ & $\mathbf{0 . 0 3 7}$ \\
\hline Strip 2 & $\mathbf{0 . 0 2 6}$ & $\mathbf{0 . 0 3 6}$ \\
\hline Strip 3 & $\mathbf{0 . 0 2 2}$ & $\mathbf{0 . 0 4 1}$ \\
\hline
\end{tabular}

\subsubsection{Investigating What Might be Different Between ANL and ORNL Simulants using ICP}

It was still a mystery as to a) what was different about the ANL and ORNL simulants, b) whether there was an inorganic or organic impurity in the ANL simulants, c) whether there was the same material in the ORNL simulants but at lower concentrations, or d) whether the ORNL simulants actually contained something to begin with that improved stripping. To address some of these issues, samples of ANL and ORNL water (used in the preparation of simulants, scrubbing, and stripping solutions), ANL and ORNL stripping solutions, ANL simulants, and solvents contacted with both ANL and ORNL simulants, were analyzed by ICP or ICP/MS.

ICP Analyses of ANL and ORNL water, stripping solution, and ANL SRS\#2 and ANL SRS\#4 Simulants. One question that arose during the investigations dealt with the issue of whether there was some inorganic material that was responsible for the different behavior (see section 7.3.2), and whether this material was present in the water used to prepare the simulants. Samples of the water that was used to prepare the simulants (and all the solutions) from both ANL (house-distilled water), and ORNL (Barnstead Nanopure water) were analyzed by ICP, along with samples of ANL and ORNL stripping solution prepared from this water. The only elements found 
in any of the water or stripping solution samples were trace amounts of calcium, magnesium and sodium; elements typically found in water. Samples of water from both ANL and ORNL showed small amounts of sodium. ORNL water contained sodium at $1.87 \times 10^{-5} \mathrm{M}$, whereas ANL water contained only trace amounts below analytical detection limits. ANL water also contained trace amounts of calcium $\left(5.8 \times 10^{-5} \mathrm{M}\right)$ and magnesium $\left(5.4 \times 10^{-7} \mathrm{M}\right)$; these elements were not observed in the ORNL water. Both strip solutions only showed trace amounts of calcium and magnesium. ORNL strip solution contained calcium at $4.74 \times 10^{-7} \mathrm{M}$ and magnesium at $1.605 \times$ $10^{-7} \mathrm{M}$. Detection limits for $\mathrm{Ca}, \mathrm{Mg}$, and $\mathrm{Na}$ are $7.5 \times 10^{-9} \mathrm{M}, 1 . \times 10^{-8} \mathrm{M}$, and $5.6 \times 10^{-7} \mathrm{M}$, respectively. Essentially nothing unusual was found, and what was found was at concentrations likely too low to cause the difference in stripping behavior. The fact that concentrations for $\mathrm{Ca}$ and $\mathrm{Mg}$ were higher in the water sample than in the strip solution prepared from the water indicates the uncertainty at these low metal ion concentrations.

Pristine simulants prepared at ANL were analyzed by ICP as described above in sections 5.2.3 and 7.2.3. In addition, scrubbing solutions from extractions using ORNL Cs3D/120L-2 solvent and ANL SRS\#2 and ANL SRS\#4 simulants were analyzed for metals by ICP. The metals $\mathrm{Si}, \mathrm{Mg}$, and Ca were found at low levels in pristine ANL SRS\#2 and ANL SRS\#4 simulants. The only metals determined in the scrubbing solutions were $\mathrm{Na}$ and $\mathrm{K}$. Aluminum was only observed (very weakly) in the hydroxide scrub of the solvent contacted with ANL SRS\#2 simulant.

ICP Analyses of Organic Phases from Contacts with Various Simulants The following solvent samples were submitted to the Radioactive Materials Analysis Lab at ORNL for analysis for metals by ICP and ICP/MS: 1) ANL CS18 pristine solvent contacted with ANL SRS\#2 simulant; 2) ANL CS18 pristine solvent contacted with ANL SRS\#4 simulant; 3) solvent from ANL 8-12-98 Dispersion Test (as received from ANL); 4) post-contactor solvent (solvent obtained from ANL centrifugal contactor test 7/22/98, which contained organic contaminants from the contactor); 5) ORNL CS3D/120L-2 pristine solvent contacted with ORNL SRS\#2-2 simulant; 6) ORNL CS3D/120L-2 pristine solvent contacted with ORNL SRS\#4O simulant; 7) ORNL CS3D/120L-2 pristine solvent contacted with ORNL SRS\#4A simulant; and finally 8) ORNL CS3D/120L-2 pristine solvent contacted with ANL SRS\#2 simulant. This last solvent underwent two extractions, and the effect of loading is evident by the analysis. Two controls were run: 1) ANL pristine CS18 and 2) ORNL pristine CS3D/120L-2.

Solvent samples were prepared according to the procedure discussed in 7.2.3. ICP results indicated that only metals that were expected to be extracted into the solvent were observed in the digested samples (see Table 7.10). Some deviations in the Si determination were observed, with a $\mathrm{Si}$ level in the controls of approximately $55 \mathrm{ppm}$. In general, more Si appears to be present in solvents contacted with ANL simulants than with ORNL prepared simulants, but this data should 
Table 7.10. ICP and ICPMS results from solvent analysis.

SAMPLES

\begin{tabular}{|c|c|c|c|c|c|c|c|c|c|c|}
\hline Element & $\begin{array}{l}\text { Control 1 } \\
\text { Pristino } \\
\text { ANL Cste } \\
\text { (ppm) }\end{array}$ & $\begin{array}{l}\text { Control 2 } \\
\text { Priatimo } \\
\text { Cs30/120L-2 } \\
\text { (ppm) } \\
\end{array}$ & $\begin{array}{c}\text { T } \\
\text { ANL Cs1: } \\
\text { with ANL sAsm } \\
\text { (pem) }\end{array}$ & $\begin{array}{c}2 \\
\text { ANL CS1S } \\
\text { with ANL SRSe4 } \\
\text { (ppm) }\end{array}$ & $\begin{array}{l}3 \\
\text { ANL o/12/08 } \\
\text { Oisperston Tost } \\
\text { (ppm) }\end{array}$ & $\begin{array}{c}1 \\
\text { Post-contector } \\
\text { solvont } \\
\text { (ppm) } \\
\end{array}$ & $\begin{array}{c}6 \\
\text { CS3D/12OL.2 } \\
\text { with ORNL SASM2.2 } \\
\text { (PPm) } \\
\end{array}$ & $\begin{array}{c}6 \\
\text { CS3D/120L-2 } \\
\text { whth ORNL SRSA4O } \\
\text { (ppm) }\end{array}$ & $\begin{array}{c}7 \\
\text { CS3D/12OL-2 } \\
\text { wth ORHL SRSMA } \\
(\mathrm{ppm}) \\
\end{array}$ & $\begin{array}{c}\text { C830/120L-2 } \\
\text { with ANL SAS*2 } \\
\text { (ppm) }\end{array}$ \\
\hline Al & $<0.07$ & $<0.07$ & 0.15 & $<0.07$ & 6.09 & 0.39 & 1.37 & 1.13 & $<0.07$ & 0.09 \\
\hline B & $<0.20$ & $<0.20$ & $<0.20$ & $<0.20$ & $<0.20$ & $<0.20$ & $<0.20$ & $<0.20$ & $<0.20$ & $<0.20$ \\
\hline $\mathrm{Ca}$ & 3.36 & $<1.3$ & 3.99 & $<1.3$ & $<1.3$ & $<1.3$ & $<1.3$ & $<1.3$ & $<1.3$ & $<1.3$ \\
\hline Cs-133 & $<0.17$ & $<0.17$ & 11.72 & 4.34 & 1.88 & 0.72 & 11.62 & 4.36 & 4.05 & 16.99 \\
\hline $\mathrm{Gr}$ & $<0.07$ & $<0.07$ & $<0.06$ & $<0.07$ & $<0.07$ & $<0.07$ & $<0.07$ & 0.51 & $<0.07$ & $<0.07$ \\
\hline ar & $<0.53$ & $<0.53$ & 0.62 & 0.79 & $<0.53$ & $<0.53$ & 0.94 & 0.66 & $<0.53$ & $<0.53$ \\
\hline $\mathrm{Fe}$ & $<0.53$ & 3.05 & 1.00 & $<0.53$ & $<0.53$ & 0.66 & $<0.53$ & $<0.53$ & $<0.53$ & $<0.67$ \\
\hline$K$ & $<25$ & $<24$ & 103.00 & 67.70 & $<24$ & $<24$ & 103.00 & 80.30 & 77.70 & 118.00 \\
\hline $\mathrm{Na}$ & $<8.3$ & $<8.2$ & 102.00 & 96.30 & $<8.1$ & $<8.2$ & 103.00 & 89.20 & 89.80 & 67.00 \\
\hline $\mathrm{Mg}$ & $<3.9$ & $<3.9$ & $<3.6$ & $<3.8$ & $<3.8$ & $<3.9$ & $<3.9$ & $<3.8$ & $<3.8$ & $<3.9$ \\
\hline $\mathrm{Si}$ & 55.30 & 57.80 & 159.00 & 142.00 & 77.00 & 53.70 & 117.00 & 92.50 & 83.60 & 52.70 \\
\hline
\end{tabular}

Noles: 1.. All other elements were below delection limits.

2. The Al and Cs-133 analyses were performed by ICP.MS.

3. Al background was high on the instrument but all reported results were 2-3X higher than the blank, but Al may still be biased high.

4. The Si date should be used with caution because no special effort was taken to avoid glassware contamination. 
be interpreted with caution as glassware contamination from the digestion can significantly add silica to the sample.

\subsection{CONCLUSIONS AND RECOMMENDATIONS}

The differences in stripping performance observed at ANL and ORNL were shown to be attributable to differences in the waste simulants prepared at the two different labs. The causative agent(s) in the ANL simulants responsible for the different stripping behavior as of this writing remain unidentified. However, an understanding of how the "impurity" behaves in a generic sense has been developed, and it was shown that the impurity in the simulant is an extractable species that is likely anionic. Adding trialkyl amines to the solvent, in addition to preventing BoBCalixC6 ion-pair dissociation by maintaining sufficient nitrate (see section 3.4.4), may be preventing negative impact from potentially (an)ionic impurities. Good stripping results were obtained with both trioctylamine (ORNL experiments) and tri-isooctyl amine (ANL experiments).

Another way to control the stripping behavior involves controlling the temperature. Cesium distribution ratios are sensitive to temperature, and stripping performance improves as the temperature is increased (as was seen in Chapter 3). Experiments performed by ANL colleagues showed that lowering the temperature during the extraction stages to $9^{\circ} \mathrm{C}$ raised the extraction $D_{\mathrm{Cs}}$ to 26.4 , whereas increasing the temperature during the stripping stages to $52{ }^{\circ} \mathrm{C}$ lowered the stripping $D_{\mathrm{Cs}}$ by an order of magnitude relative to $25^{\circ} \mathrm{C}$.

Relevance to Real Waste. It is too soon to tell how the differences encountered between the two simulants relates to tank-to-tank differences in real waste. However, two key findings should be useful in improving the process generally. One is the use of a trialkyl amine in the solvent, and the second is the judicious use of temperature controls.

\subsection{REFERENCES}

1. Bonnesen, P.V.; Moyer, B.A.; Presley, D.J.; Armstrong, V.S.; Haverlock, T.J.; Counce, R.M.; and Sachleben, R.A. Alkaline-Side Extraction of Technetium from Tank Waste Using Crown Ethers and Other Extractants; Report ORNL/TM-13241, Oak Ridge National Laboratory: Oak Ridge, TN, June, 1996.

2. Bonnesen, 'P.V., Oak Ridge National Laboratory, Oak Ridge, TN. Unpublished results, 1996-97. 
3. Klopfenstein, R.K.; Arnold, D.S. Journal of Metals, 1966, 1195-1197.

4. Connor, C.; Sedlet, J.; Vandegrift, G.F. Argonne National Laboratory, Argonne, IL. Communication to Oak Ridge National Laboratory, September 1998. 


\section{INTERNAL DISTRIBUTION}

1. C.W. Alexander

2-7. P.V. Bonnesen

8. G.M Brown

9. R.R. Brunson

10. J. C. Bryan

11. C.F. Coleman

12. J.L Collins

13. L.H. Delmau

14. T.J. Haverlock

15. R.D. Hunt

16. R.T. Jubin

17. J.M. Keller

18. T.M. Kent

19. D.D. Lee
20. C.P. McGinnis

21-46. B.A. Moyer

47. T.E. Myrick

48. R.A. Sachleben

49. B.B. Spencer

50. J.S. Watson

51. T.D. Welch

52-53. ORNL Laboratory Records

54. ORNL Laboraory Records, RC

55. ORNL Patent Section

56. Y-12 Technical Library Document Reference Center

57-58. Central Research Library

\section{EXTERNAL DISTRIBUTION}

59-64. Argonne National Laboratory, 9700 South Cass Ave., Argonne, IL 60439-4831.

C. Connor

M.L. Dietz

R.A. Leonard

K.L. Nash

J. Sedlet

G.F. Vandegrift

65-66. BNFL, Inc., 2940 George Washington Way, Richland, WA 99352

M.E. Johnson

S. Turner

67-68. Department of Energy, Savannah River Site, P.O. Box A, Aiken, SC 29802

P.S. Kirkland

P.C. Suggs

69-72. Idaho National Engineering and Environmental Laboratory, Idaho Falls, ID 83415

D.A. Knecht

B.J. Mincher

T.A. Todd

D.J. Wood

73-74. Lockheed Martin Hanford Corporation (LMHC), S7-85, P.O. Box 1500, Richland, WA 99352-1505.

J.N. Appel

J.O. Honeyman 
75-77. Numatec Hanford Corp., Richland, WA 99352
R.A. Kirkbride
D.L. Herting (P.O. Box 1300, T6-07)
D.L. Penwell

78-79. Office of Assistant Manager, Energy Research and Development, DOE-ORO, P.O. Box 2008, Oak Ridge, TN 37831-6269
J.L. Harness
J.G. Hart

80-81. Office of Scientific and Technical Information, P.O. Box 62, Oak Ridge, TN 37831

82-92. Pacific Northwest National Laboratory, P.O. Box 999, Richland, WA 99352
D.L. Blanchard
K.P. Brooks
T.M. Brouns
R.L. Gilchrist
B.P. Hay
L.K. Holton
W.L. Kuhn
D.E. Kurath
G.J. Lumetta
R.K. Quinn
B.M. Rapko

93-105. Westinghouse Savannah River Co., Aiken, SC 29802

J.T. Carter

H.H. Elder

S.D. Fink

M.E. Hodges

L.M. Papouchado

R.A. Peterson

S.F. Piccolo

M.R. Poirier

K.J. Rueter

P.L. Rutland

W.L. Tamosaitis

M.C. Thompson

T.L. White

106. H. Babad, 2540 Cordoba Court, Richland, WA 99352-1609

107. R.M. Chamberlin, Los Alamos National Laboratory, CST-11, MS J514 Los Alamos, NM 87545 
108. J.-F. Dozol, CEA Cadarache DESD/SEP/LPTE, 13108 St Paul lez Durance Cedex, France

109. J.T. Davis, Department of Chemistry and Biochemistry, University of Maryland at College Park, College Park, MD 20742

110. E.P. Horwitz, Eichrom Industries, 8205 S. Cass Ave., Suite 107, Darien, IL, 60561

111. S.R. Izatt, IBC Advanced Technologies, Inc., P.O. Box 98, 856 East Utah Valley Dr., American Fork, Utah 84003

112. J. Janata, School of Chemistry and Biochemistry, Georgia Tech, Atlanta, GA 303320400, U.S.A.

113. J.L. Kovach, NUCON, 7000 Huntley Rd., Columbus, OH 43229

114. J.D. Lamb, Department of Chemistry, 207 ESC, Brigham Young University, Provo, UT 84602

115. R. Ludwig, FU Berlin, Inst. f. Inorg. and Analyt. Chemistry, Fabeckstr. 34-36, 14195 Berlin, Germany

116. C. Madic, Commissariat a l'Energie Atomique, DCC, CEA-Saclay, 91191 Gif-s-Yvette, France

117. J. McGlynn, SAIC, 555 Quince Orchard Road, Suite 500, Gaithersburg, MD 20878

118. R.L. Miller, Los Alamos National Laboratory, CST-11, MS J514, Los Alamos, NM 87545

119. R.D. Rogers, Department of Chemistry, The University of Alabama Tuscaloosa, AL 35487

120. W. W. Schulz, 5314 Arbustos Ct., Albuquerque, NM 87111

121. J.L. Swanson, 1318 Cottonwood Dr., Richland, WA 99352

122. I. Tasker, Universe Technologies, 9 East second Street, Frederick, Maryland 21701 
123. L.L. Tavlarides, Syracuse University, Dept. of Chemical Engineering, 320 Hinds Hall, Syracuse, NY 13244-1190

124. V. Van Brunt, Dept. of Chemical Engineering, University of South Carolina, Swearingen Engineering Center, Columbia, SC 29208

125. J. Vicens, ECPM-ULP Strasbourg, 1, rue Blaise Pascal, F-67008, Strasbourg, FRANCE 


\section{Development of an Alkaline-Side Solvent Extraction Process for the Removal of Cesium from Tank Waste*}

Peter V. Bonnesen, Derek J. Presley, Tamara J. Haverlock, Richard A. Sachleben, Goutam Das, and Bruce A. Moyer

Chemical and Analytical Sciences Division

Oak Ridge National Laboratory

Bldg. 4500S, MS-6119, P.O. Box 2008

Oak Ridge, TN 37831-6119

Abstract of a presentation to be given at the Tenth Symposium on Separation Science and

Technology for Energy Applications, Gatlinburg, TN, October 20-24, 1997.

"The submitted manuscript has been authored by a contractor of the U.S. Government under contract No. DE-AC05-960R22464. Accordingly, the U.S. Gevermment retains a nonexclusive, royalty-free Govermment retains a nonlish or reproduce the published form of license to publish or reproduce the published form this contribution, or allow

*Research sponsored by the Efficient Separations and Processing Cross-Cutting. Program of the Office of Technology Development, Office of Environmental Restoration and Waste Management. U. S. Department of Energy, under Contract DE-AC05-96OR22464 with Oak Ridge National Laboratory, managed by Lockheed Martin Energy Research Corporation. 


\section{DEVELOPMENT OF AN ALKALINE-SIDE CS SX PROCESS APPLICABLE TO SAVANNAH RIVER HLW USING A CALIXARENE-CROWN EXTRACTANT. FY98 REPORT.}

Bruce A. Moyer, Peter V. Bonnesen, Laetitia H. Delmau,

Tamara J. Haverlock, and Richard A. Sachleben

Chemical and Analytical Sciences Division,

Oak Ridge National Laboratory,

P.O. Box 2008, Oak Ridge, TN 37831-6119

October 1, 1998

Prepared for the

Westinghouse Savannah River Corporation

Prepared by the

OAK RIDGE NATIONAI LABORATORY

Oak Ridge, Tennessee 37831-6119

managed by

LOCKHEED MARTIN ENERGY RESEARCH CORP

for the

U. S. DEPARTMENT OF ENERGY

under contract DE-AC05-960R22464

\footnotetext{
"The submitted manuscript has been authored by a contractor of the U.S. Govemment under contract No. DE-AC05-960R22464. Accordingly, the U.S. Government retains a nonexclusive, royalty-tree license to publish or reproduce the published form of this contribution, or allow others to do so. for U.S. Government purposes."
} 